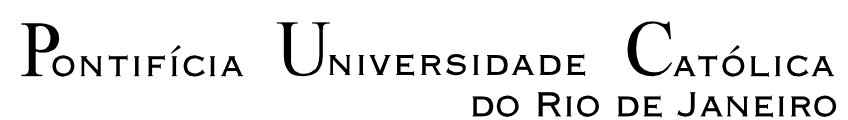

DO RIO DE JANEIRO

Emerson Pestana Martins

Caracterização do Canal de Radiopropagação em Banda Larga nas Faixas 2,5 e 3,5 GHz

Dissertação de Mestrado

Dissertação apresentada ao Programa de Pós-Graduação em Engenharia Elétrica da PUC-Rio como requisito parcial para obtenção do título de Mestre em Engenharia Elétrica.

Orientador: Prof. Luiz Alencar Reis da Silva Mello

Co-orientador: Carlos Vinicio Rodríguez Ron

Rio de Janeiro

Setembro de 2013 


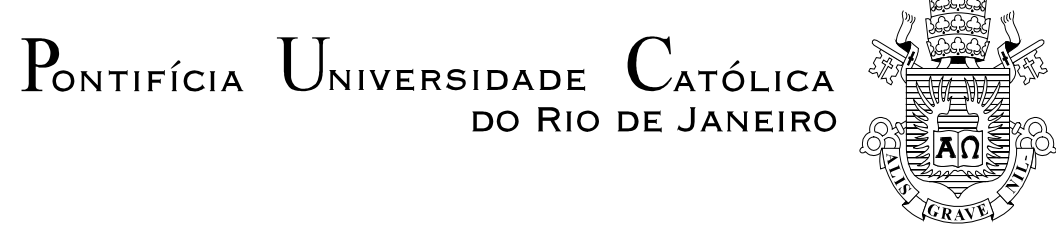

Emerson Pestana Martins

\section{Caracterização do Canal de Radiopropagação em Banda Larga nas Faixas 2,5 e 3,5 GHz}

Dissertação de Mestrado apresentada como requisito parcial para obtenção do grau de Mestre pelo Programa de PósGraduação em Engenharia Elétrica do Departamento de Engenharia Elétrica do Centro Técnico Científico da PUCRio. Aprovada pela Comissão Examinadora abaixo assinada.

Prof. Luiz Alencar Reis da Silva Mello

Orientador

Centro de Estudos em Telecomunicações - PUC-Rio

Prof. Carlos Vinicio Rodríguez Ron

Co-Orientador

Centro de Estudos em Telecomunicações - PUC-Rio

Prof. Glaucio Lima Siqueira

Centro de Estudos em Telecomunicações - PUC-Rio

Prof. Rodrigo Martins de Souza

UGF

Prof. José Eugenio Leal

Coordenador Setorial do Centro

Técnico Científico - PUC-Rio

Rio de Janeiro, 13 de setembro de 2013 
Todos os direitos reservados. É proibida a reprodução total ou parcial do trabalho sem autorização da universidade, do autor e do orientador.

\section{Emerson Pestana Martins}

Graduou-se em Engenharia Elétrica com Ênfase em Telecomunicações pela UniverCidade (Universidade da Cidade) em 2002. Concluiu Pós-Graduação Lato Sensu em Gerência de Redes de Computadores e Tecnologia Internet pelo NCE/UFRJ (Núcleo de Comutação Eletrônica/Universidade Federal do Estado do Rio de Janeiro). Atua Profissionalmente na área de Redes de Computadores desde 2002. Efetuou estudos de mestrado na área de Caracterização de Canal Radiopropagação no CETUC (Centro de Estudos de Telecomunicações da Pontifícia Universidade Católica do Rio de Janeiro (PUC-Rio)

Ficha Catalográfica

\section{Martins, Emerson Pestana}

Caracterização do canal de radiopropagação em banda larga nas faixas 2,5 e 3,5 GHz / Emerson Pestana Martins; orientador: Luiz Alencar Reis da Silva Mello; coorientador: Carlos Vinicio Rodríguez Ron - 2013.

$113 \mathrm{f.} ; 30 \mathrm{~cm}$

Dissertação (mestrado) - Pontifícia Universidade Católica do Rio de Janeiro, Departamento de Engenharia Elétrica, 2013.

Inclui bibliografia

1. Engenharia elétrica - Teses. 2. Radiopropagação. 3. Caracterização de canal. 4. Sistemas banda larga. I. Mello, Luiz Alencar Reis da Silva. II. Ron, Carlos Vinicio Rodríguez. III. Pontifícia Universidade Católica do Rio de Janeiro. Departamento de Engenharia Elétrica. III. Título. 
Dedico este trabalho aos meus pais Francisco e Amélia, a minha esposa Simone e aos meus filhos Philip, Nathália e Isabella. 


\section{Agradecimentos}

A Deus, por me dar força e confiança em todos os momentos da minha vida.

Ao meu orientador, Professor Luiz Alencar Reis da Silva Mello, pela excelente orientação, paciência, confiança e por sua consideração e amizade.

Ao meu coorientador Carlos Vinicio Rodriguez Ron, por ter me apoiado nos momentos de dúvida.

Ao colega, amigo e colaborador Leonardo Gonsioroski da Silva, pelo apoio durante as medições e implementação dos códigos em MATLAB.

A todos os colegas que participaram das campanhas de medições.

A todos os professores do grupo de sistemas de comunicação do CETUC, pela excelente receptividade e por contribuírem bastante para o meu crescimento profissional.

Ao meu chefe na OI, Márcio Rodrigo Borges por ter me apoiado durante o Mestrado.

A minha esposa Simone Ferreira Martins, pela motivação e paciência durante todo o curso.

Aos meus filhos Philip Ferreira Pestana Martins, Nathália Ferreira Pestana Martins e Isabella Ferreira Pestana Martins, por serem a minha maior inspiração e motivação na vida. 


\section{Resumo}

Pestana Martins, Emerson; Silva Mello, Luiz Alencar Reis da (Orientador); Ron, Carlos Vinicio Rodríguez (Co-orientador). Caracterização de Canal de Radiopropagação em Banda Larga nas faixas de 2.5 e 3.5 GHz. Rio de Janeiro, 2013. 113p. Dissertação de Mestrado - Departamento de Engenharia Elétrica, Pontifícia Universidade Católica do Rio de Janeiro.

Este trabalho tem como objetivo caracterizar o canal de radiopropagação móvel a partir de resultados das medições realizadas nas faixas de $2.5 \mathrm{GHz}$ e 3.5 GHz em ambiente urbano. Para alcançar tal objetivo, será utilizada a técnica de sondagem em frequência de multiportadoras, utilizando modulação OFDM e as técnicas de filtragem de perfil de retardos de potência CFAR e/ou CLEAN para identificar os multipercursos válidos. Após o processo de filtragem e processamento dos dados, será feita a comparação dos parâmetros recomendados pela recomendação ITU-R P.1411-6 validando os resultados encontrados e também gerando novos parâmetros nas faixas de $2.5 \mathrm{GHz}$ e $3.5 \mathrm{GHz}$, dentro das condições de especificações das medições realizadas.

\section{Palavras-chave}

Radiopropagação; caracterização de canal; sistemas banda larga. 


\section{Abstract}

Pestana Martins, Emerson; Silva Mello, Luiz Alencar Reis da (Advisor); Ron, Carlos Vinicio Rodríguez (Co-advisor). Wideband Channel Characterization at 2.5 and 3.5 GHz. Rio de Janeiro, 2013. 113p. MSc. Dissertation - Departamento de Engenharia Elétrica, Pontifícia Universidade Católica do Rio de Janeiro.

This work aims to characterize the mobile radio propagation channel according to the results of the measurements in the ranges of $2.5 \mathrm{GHz}$ and 3.5 $\mathrm{GHz}$ in an urban environment. To achieve this goal, we will use the frequency multicarrier sounding technique, using OFDM modulation and power delay profile (PDP) filtering techniques CFAR and CLEAN to identify valid multipath. After the filtering process, the comparison will be made of the parameters found with the ITU-R P.1411-6 validating the results and also generating new parameters in the ranges of $2.5 \mathrm{GHz}$ and $3.5 \mathrm{GHz}$, within the terms of specifications of measurements.

\section{Keywords}

Radiopropagation; channel characterization; wideband systems. 


\section{Sumário}

1 Introdução 14

1.1. Objetivos da Dissertação 15

2 O Canal de Radiopropagação Móvel 17

2.1. Principais Características 17

2.2. Caracterização em Banda Larga 18

2.3. Efeitos de Propagação 20

2.3.1. Variação da Atenuação Com a Distância $\quad 21$

2.3.2. Multipercurso 21

2.3.3. Desvanecimento de Pequena Escala $\quad 22$

2.3.4. Desvanecimento de Larga Escala 23

2.3.5. Perfil de Retardos de Potência (Power delay profile) 24

2.3.6. Banda de Coerência $\quad 27$

2.3.7. Efeito Doppler 28

3 Medições 30

3.1. Modulação OFDM 30

3.2. Técnicas de Medições

3.2.1. Técnica no Domínio do Tempo 35

3.2.2. Técnica no Domínio da Frequência $\quad 35$

3.2.2.1. Técnica de Multiportadoras 36

3.3. Técnica de Limpeza de Perfis de Retardos CFAR 36

3.4. Técnica de Limpeza de Perfil de Retardos CLEAN 38

4 Campanhas de Medições $\quad 40$

4.1. Medições em $2.5 \mathrm{GHz} \quad 40$

4.1.1. Set-up de Transmissão em $2.5 \mathrm{GHz}$

4.1.2. Set-up de Recepção em $2.5 \mathrm{GHz}$

4.1.3. Campanha de medições em $2.5 \mathrm{GHz}$

4.2. Medições em $3.5 \mathrm{GHz} \quad 49$

4.2.1. Set-up de Transmissão em $3.5 \mathrm{GHz}$

4.2.2. Set-up de Recepção em $3.5 \mathrm{GHz}$

4.2.3. Campanha de medida em $3.5 \mathrm{GHz} \quad 56$

4.3. Equipamentos utilizados nas campanhas de medição 60

4.3.1. Analisador de Espectro de Frequência 60

4.3.2. Gerador de Sinais MG 3700A 61

4.3.3. Amplificador de potência 62

4.3.4. Antena de Transmissão - PCTEL 17VP90NUF (2.5 GHz) 63

4.3.5. Antena de Transmissão - Hyperlink HG3515P-120 (3.5 GHz) 655

4.3.6. Antena de Recepção para $2.5 \mathrm{GHz} \quad 65$

4.3.7. Antena de Recepção para $3.5 \mathrm{GHz} \quad 65$

4.3.8. Cabos LMR-400 e LMR-600 - KMP (3.5 GHz) 66

4.3.9. Amplificador de Baixo Ruído (LNA - 2.5 GHz) 67

4.3.10. Amplificador de Baixo Ruído (LNA - 3.5 GHz) 67

4.3.11. Global System Position - GPS (2.5 GHz) 68

4.3.12. Global System Position - GPS (3.5 GHz) 68 
5 Análise dos Resultados

5.1. Análise com a técnica CFAR 72

5.2. Análise com a técnica CLEAN 81

5.3. Comparação com a Recomendação ITU-R P.1411-6 88

5.3.1. Recomendação ITU-R P.1411-6 88

6 Conclusões $\quad 92$

7 Sugestões para trabalhos futuros 94

8 Referências Bibliográficas 95

Anexo A: Códigos em MATLAB 97

Anexo B: Especificação de Equipamentos 108 


\section{Lista de figuras}

$\begin{array}{lr}\text { Figura 2.1: Modelo de Canal Variante no Tempo } & 18\end{array}$

Figura 2.2: Relações entre Funções de Caracterização de Canal 20

Figura 2.3: Comportamento de sinal em ambiente urbano 21

Figura 2.4: Fenômeno de Multipercurso 22

Figura 2.5: Exemplo típico de perfil de retardos $\quad 24$

Figura 2.6: Exemplo de perfil de retardos (mostrando os parâmetros) 26

Figura 3.1: Ortogonalidade no Domínio da Frequência (OFDM) 31

Figura 3.2: Ortogonalidade no Domínio do Tempo (OFDM) 32

Figura 3.3: Definição de Parâmetros do sinal OFDM [11] 34

Figura 3.1: Definição do Limiar de Ruído. 37

Figura 3.2: Sinal de Calibração - medida de referência (CLEAN). 39

Figura 4.1: Diagrama do set-up de transmissão $\quad 41$

Figura 4.2: Sinal OFDM de $20 \mathrm{MHz}$ de Largura de Banda 42

Figura 4.3: Varredura de Espectro 43

Figura 4.4: Visão frontal da antena de transmissão 44

Figura 4.5: Visão $45^{\circ}$ a direita da antena de transmissão 44

Figura 4.6: Visão $45^{\circ}$ a esquerda da antena de transmissão 45

Figura 4.7: Resposta Impulsiva do sinal de Calibração $(2.5 \mathrm{GHz})$

Figura 4.8: Set-up de recepção $\quad 47$

Figura 4.9: Rota das Medições - 09/10/2012 48

Figura 4.10: Dados Válidos da Rota do dia 09/10/2012 48

Figura 4.11: Diagrama do set-up de transmissão 49

Figura 4.12: OFDM - FFT $20 \mathrm{MHz}$

Figura 4.13: OFDM - $20 \mathrm{MHz} \quad 51$

Figura 4.14: Azimute 90 graus NM 52

Figura 4.15: Azimute 150 graus NM 52

Figura 4.16: Azimute 30 graus NM 53

Figura 4.17: Instalação de equipamentos 53

Figura 4.18: Ambiente de medições para calibração 54 
Figura 4.19: Sinal para calibração $20 \mathrm{MHz}$

Figura 4.20: Resposta de equipamentos para $20 \mathrm{MHz}$

Figura 4.21: Consulta SITAR - Sistemas ponto-a-ponto e ponto-área 57

Figura 4.22: Rota realizada para varredura de espectro 58

Figura 4.23: Varredura de espectro 58

Figura 4.24: Ocupação de espectro 59

Figura 4.25: Rota realizada para Medições 60

Figura 4.26: Analisador de Espectro Rodge \& Schwartz 61

Figura 4.27: Gerador de Sinais MG 3700A 61

Figura 4.28: Amplificador de Potência Milmega AS0204-7B 7W 62

Figura 4.29: Curva de Linearidade do Amplificador Milmega (2.5 GHz) 63

Figura 4.20: Curva de Linearidade do Amplificador Milmega (3.5 GHz)[3] 63

Figura 4.31: Antena de Transmissão PCTEL 64

Figura 4.32: Diagramas Polares de Irradiação da Antena de Transmissão 64

Figura 4.33: Antena omni direcional, modelo MGRM-WLF 65

Figura 4.34: Antena omni direcional, modelo HG3505RD-RSP 66

Figura 4.35: Características Elétricas do Cabo LMR-400 66

Figura 4.36: LNA WENTEQ Microwave Corp. - ABL0800-12-3315 67

Figura 4.37: GPS da marca GARMIN modelo GPSMAP 62

Figura 4.38: GPS da marca GARMIN modelo GPSMAP 60 CS 69

Figura 4.39: Analisador Vetorial de Sinais MS2781B 69

Figura 4.40: Símbolos OFDM Capturados - Sinal de 20 MHz (2.5 GHz) 70

Figura 5.1: Resposta Impulsiva do Canal $(2.5 \mathrm{GHz})$

Figura 5.2: Resposta Impulsiva do Canal CFAR (2.5 GHz) - amostra 18973

Figura 5.3: Multipercursos válidos pela técnica CFAR (2.5 GHz) - amostra 18974

Figura 5.4: Resposta Impulsiva do Canal (3.5 GHz) 74

Figura 5.5: Resposta Impulsiva do Canal CFAR (3.5 GHz) - amostra $72 \quad 75$

Figura 5.6: Multipercursos válidos pela técnica CFAR (3.5 GHz) - amostra 7275

Figura 5.7: Retardo Médio vs Distância (2.5 GHz) 78

Figura 5.8: RMS Delay Spread vs Distância (2.5 GHz) 78

Figura 5.9: Retardo Médio vs Distância (3.5 GHz) 79

Figura 5.10: RMS Delay Spread vs Distância (3.5 GHz) 79

Figura 5.11: Potência Recebida vs Retardo - dBm (2.5 GHz) 80 
Figura 5.12: Potência Recebida vs Retardo - dBm (3.5 GHz) 80

Figura 5.13: Resposta Impulsiva do Canal - CLEAN (2.5 GHz) - amostra 18982

Figura 5.14: Possíveis Multipercursos válidos - CLEAN (2.5 GHz) 82

Figura 5.15: Multipercursos válidos - CLEAN (2.5 GHz) - amostra 189

Figura 5.16: Caracterização Temporal do Canal - CLEAN (2.5 GHz) 84

Figura 5.17: Resposta Impulsiva do Canal - CLEAN (3.5 GHz) - amostra 7284

Figura 5.18: Possíveis Multipercursos válidos - CLEAN (3.5 GHz) 85

Figura 5.19: Multipercursos válidos - CLEAN (3.5 GHz) - amostra 72

Figura 5.20: Caracterização Temporal do Canal - CLEAN (3.5 GHz) 86

Figura 5.21: Determinação do número de picos ITU-R P.1411-6 [20] 90 


\section{Lista de tabelas}

Tabela 4.1: Parâmetros utilizados na geração do sinal OFDM 41

Tabela 4.2: Parâmetros utilizados na geração do sinal OFDM 50

Tabela 5.1: Resposta da Caracterização para $2.5 \mathrm{GHz} \quad 76$

Tabela 5.2: Resposta da Caracterização para 3.5 GHz 76

Tabela 5.3: Resposta da Caracterização para $2.5 \mathrm{GHz} \quad 86$

Tabela 5.4: Caracterização Temporal para $3.5 \mathrm{GHz} \quad 87$

Tabela 5.5: Resposta da Caracterização para 3.5 GHz 87

Tabela 5.6: Valores Típicos de Coeficientes RMS 88

Tabela 5.7: Valores encontrados de Coeficientes RMS CFAR 89

Tabela 5.8: Valores Típicos de Espalhamento de Atraso RMS [20] 89

Tabela 5.9: Valores encontrados de Espalhamento de atraso RMS 89

Tabela 5.10: Número máximo de Componentes de sinal ITU-R P.1411-6 [20] 91

Tabela 5.11: Número máximo de Componentes de sinal encontrados 91 


\section{1}

\section{Introdução}

Com a evolução das tecnologias multimídia, a grande tendência de convergência de serviços e a necessidade de acesso de forma abrangente, surgiu a necessidade de utilização de serviços de voz, vídeo e dados independentemente do tipo de mídia, infraestrutura de redes ou localização, de forma eficiente e com qualidade de serviço.

O grande desafio é desenvolver redes convergentes que tenham a capacidade de transportar todos os tipos de serviços mencionados anteriormente com qualidade, capacidade de usuários e taxas que atendam as demandas atuais e futuras, a curto e médio prazo.

Além disso, é necessário oferecer aos usuários múltiplos serviços com diferentes classes de qualidade de serviço (QoS), compatibilidade e interoperabilidade com os padrões existentes, arquitetura aberta (isto é, não proprietária de um determinado fabricante) e suporte a tráfego assimétrico.

Atualmente as duas tecnologias de acesso à rede de dados através de sistemas celulares de quarta geração são o WiMAX (Worldwide Interoperability for Microwave Access) e o LTE (Long Term Evolution). As faixas de frequência licenciadas no Brasil para atender essas redes são $2.5 \mathrm{GHz}$ e $3.5 \mathrm{GHz}$.

Para permitir o adequado projeto das redes é necessária a caracterização do canal de radiopropagação dentro da faixa de frequência utilizada, ou seja, é necessário saber como o canal se comporta em relação à propagação do sinal faixa larga já que as características do canal mudam dependendo do ambiente onde está realizando-se a propagação. O principal fator que limita a capacidade e desempenho das redes móveis é o desvanecimento por multipercursos. Assim é necessário realizar um estudo aprofundado de cada característica que pode afetar o desempenho do canal radiopropagação móvel. Em um ambiente urbano existem edificações além de diversos espalhadores movendo-se aleatoriamente na área de cobertura. O espalhamento gerado provoca o efeito de multipercurso, onde o sinal enviado ao difratar ou refletir nos espalhadores, gera réplicas do sinal original que chegarão ao receptor com diferentes retardos, amplitudes e fases, causando a 
dispersão do sinal no tempo que se caracteriza através do espalhamento de retardo. As réplicas do sinal ao chegarem no receptor, podem gerar efeito construtivo ou destrutivo no sinal resultante e sendo assim provocar o desvanecimento rápido. Outro efeito característico de sistemas móveis, onde o receptor muda de posição em relação ao transmissor, é o desvio Doppler. No caso de uma análise para multipercurso, tem-se não um desvio, mas sim espalhamento Doppler, já que os sinais chegam ao receptor de várias direções.

Para que seja possível a otimização do canal radiopropagação, é necessário executar medições de propagação em banda larga e com isso obter, para a faixa de frequência analisada, a resposta do canal ao impulso. Essas medições descrevem completamente o canal e dessa forma possibilitam obter informações importantes no processo de construção de seletores de frequência, equalizadores adaptativos e escolha de posição ótima de antenas, visando reduzir os efeitos negativos do multipercurso.

Dessa forma, é necessário ao desenvolvimento de sistemas de comunicações sem fio, a correta caracterização do canal radiopropagação, contribuindo com o planejamento adequado, melhor uso dos recursos e redução dos custos de implementação.

A correta caracterização do canal radiopropagação ainda está em estudo para vários ambientes e faixas de frequência. Sendo assim, a pesquisa nessa área é necessária ao conhecimento dos parâmetros adequados na implementação dos sistemas de comunicações móveis.

\section{1}

\section{Objetivos da Dissertação}

Esse trabalho tem como objetivos, utilizando a técnica de sondagem de multiportadoras:

1) Caracterizar o canal radiopropagação na faixa de $2.5 \mathrm{GHz}$ e $3.5 \mathrm{GHz}$ em ambiente urbano através do perfil de retardo, utilizando como parâmetros o retardo médio e o valor r.m.s. do retardo;

2) Utilizar a melhor técnica de limpeza de perfil de retardo de potência entre a CFAR e CLEAN para identificar os multipercursos válidos; 
3) Após escolher a melhor técnica de limpeza de perfil de retardo de potência, comparar os parâmetros encontrados nos multipercursos considerados válidos com a recomendação ITU-R P.1411-6, caracterizando assim o canal de rádio propagação móvel.

Os dados que serão utilizados nesse trabalho para a faixa de frequência de 3.5 GHz foram obtidos a partir de campanhas de medições realizadas durante a Tese de Doutorado do Carlos Vinicio Rodríguez Ron (coorientador nesse trabalho). Os dados utilizados para a faixa de frequência de $2.5 \mathrm{GHz}$ foram coletados especificamente para esse trabalho. Serão utilizados programas em MATLAB para possibilitar a análise dos dados e geração dos resultados. 


\section{2}

\section{O Canal de Radiopropagação Móvel}

Neste capítulo, serão abordadas as principais características do canal radiopropagação e os efeitos de propagação.

\section{1}

\section{Principais Características}

O meio de propagação entre transmissor e receptor pode variar, desde uma ligação com visada direta, até uma severamente obstruída por prédios, relevo e a vegetação. Essa variação do meio de propagação altera significativamente a característica de transferência do sinal através do canal radiopropagação móvel.

A propagação, independentemente do tipo de ambiente, depende dos diferentes obstáculos (espalhadores) existentes no percurso entre o transmissor e o receptor. Estes obstáculos geram diversos efeitos como a refração, reflexão e difração do sinal transmitido. O desvanecimento (fading) seletivo é provocado pela propagação por multipercurso. A qualidade do sinal é afetada diretamente por esse fenômeno, que provoca sua degradação. Esta degradação determina limitações da taxa de transmissão de dados. Quanto maior a degradação do sinal maior a taxa de erro na recepção.

Para que seja realizada a otimização do sistema rádio, tanto quanto às taxas de transmissão suportadas como quanto ao uso de diversidade e equalizadores, é necessária a caracterização do canal radiopropagação móvel mais correta possível. A caracterização do canal pode ser dividida principalmente em: caracterização em banda estreita e caracterização em banda larga.

Para a sondagem em banda estreita deve ser feita a análise das variações espacial e temporal do sinal, através da identificação da variação rápida e lenta do sinal, com base nas respectivas distribuições estatísticas. Para a sondagem de banda larga os parâmetros a serem analisados são o espalhamento de retardo, tempo de coerência, espalhamento Doppler e banda de coerência. 
A banda de coerência quantifica a largura de banda na qual as componentes espectrais do sinal transmitido são afetadas de forma semelhante. Nos casos em que a largura de banda do sinal é menor que a banda de coerência, o canal é considerado canal de banda estreita. Por outro lado, nos casos em que a largura de banda do sinal é maior que a banda de coerência é considerado canal de banda larga [1].

\section{2}

\section{Caracterização em Banda Larga}

Na caracterização em banda larga o canal de rádio propagação móvel é considerado como um sistema linear. Este trabalho trata dos canais lineares com mobilidade, ou seja, canais lineares variantes no tempo.

A modelagem do canal rádio propagação móvel pode ser realizada por um filtro linear com resposta impulsiva que varia no tempo. Inicialmente considera-se o canal deterministicamente variante no tempo. Dessa forma pode-se dizer que a resposta impulsiva do canal, $h(t, \tau)$, é função de duas variáveis: o tempo de excitação $\tau$ (o tempo de retardo após uma excitação) e o tempo $t$ (tempo físico do canal) [2].

A figura 2.1 ilustra o modelo de canal como um filtro linear deterministicamente variante no tempo, que possui entrada dada pela equação (2.1), onde $\mathrm{z}(\mathrm{t})$ é a envoltória complexa do sinal e $\mathrm{f}_{\mathrm{c}}$ a frequência de portadora [2].

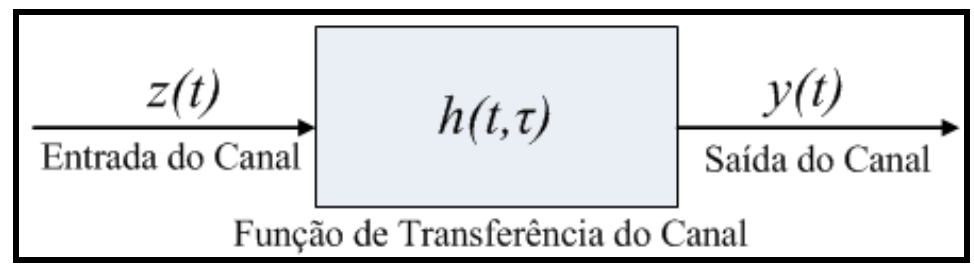

Figura 2.1: Modelo de Canal Variante no Tempo

$$
x(t)=\operatorname{Re}\left[z(t) e^{j 2 \pi f_{c} t}\right]
$$

Sabendo que a resposta impulsiva é variante no tempo, a envoltória complexa da resposta impulsiva do filtro equivalente ao canal é dada por $\mathrm{h}(\mathrm{t}, \tau)$. Assim, a envoltória complexa da saída do filtro y(t) é relacionada a envoltória complexa da entrada $z(t)$, através da convolução[2, 3]: 


$$
y(t)=\int_{-\infty}^{+\infty} z(t-\tau) \cdot h(t, \tau) d \tau
$$

A equação 2.2 fornece a representação física do canal como uma contribuição contínua de espalhadores estacionários, onde cada espalhador elementar acrescenta uma parcela $h(t, \tau) d \tau$ e fornece retardos na faixa $(\tau, \tau+d \tau)$.

Segundo Bello [4], os canais lineares variantes no tempo podem ser caracterizados numa forma simétrica com variáveis tanto no domínio do tempo como no domínio da frequência.

No domínio da frequência, o canal é caracterizado pela função H(f, v), que é a função dual da resposta impulsiva do canal variante no tempo h(t, $\tau)$ [3].

$$
Y(f)=\int_{-\infty}^{+\infty} Z(f-v) H(f-v, v) d v
$$

Ainda segundo Bello [4], caracterização do canal é possível por meio da função de transferência variante no tempo T(f, t). Esta mesma função é a transformada de Fourier da função de resposta ao impulso $h(t, \tau)$, e ao mesmo tempo da transformada inversa de Fourier da função de desvio Doppler H(f, v):

$$
T(f, t)=\int_{-\infty}^{+\infty} h(t, \tau) e^{-j 2 \pi f \tau} d \tau=\int_{-\infty}^{+\infty} H(f, v) e^{j 2 \pi v t} d v(2.4)
$$

As funções de resposta ao impulso e desvio Doppler, representam a resposta do canal tanto no domínio do retardo como no do desvio Doppler. A função que expressa de forma única estas duas características é a função denominada função de retardo Doppler $S(\tau, v)$, que é dada pela seguinte expressão [3, 4]:

$$
S(\tau, v)=\int_{-\infty}^{+\infty} h(t, \tau) e^{-j 2 \pi v t} d t
$$

Desta forma é possível relacionar as funções propostas por Bello conforme ilustrado na figura 2.2. 


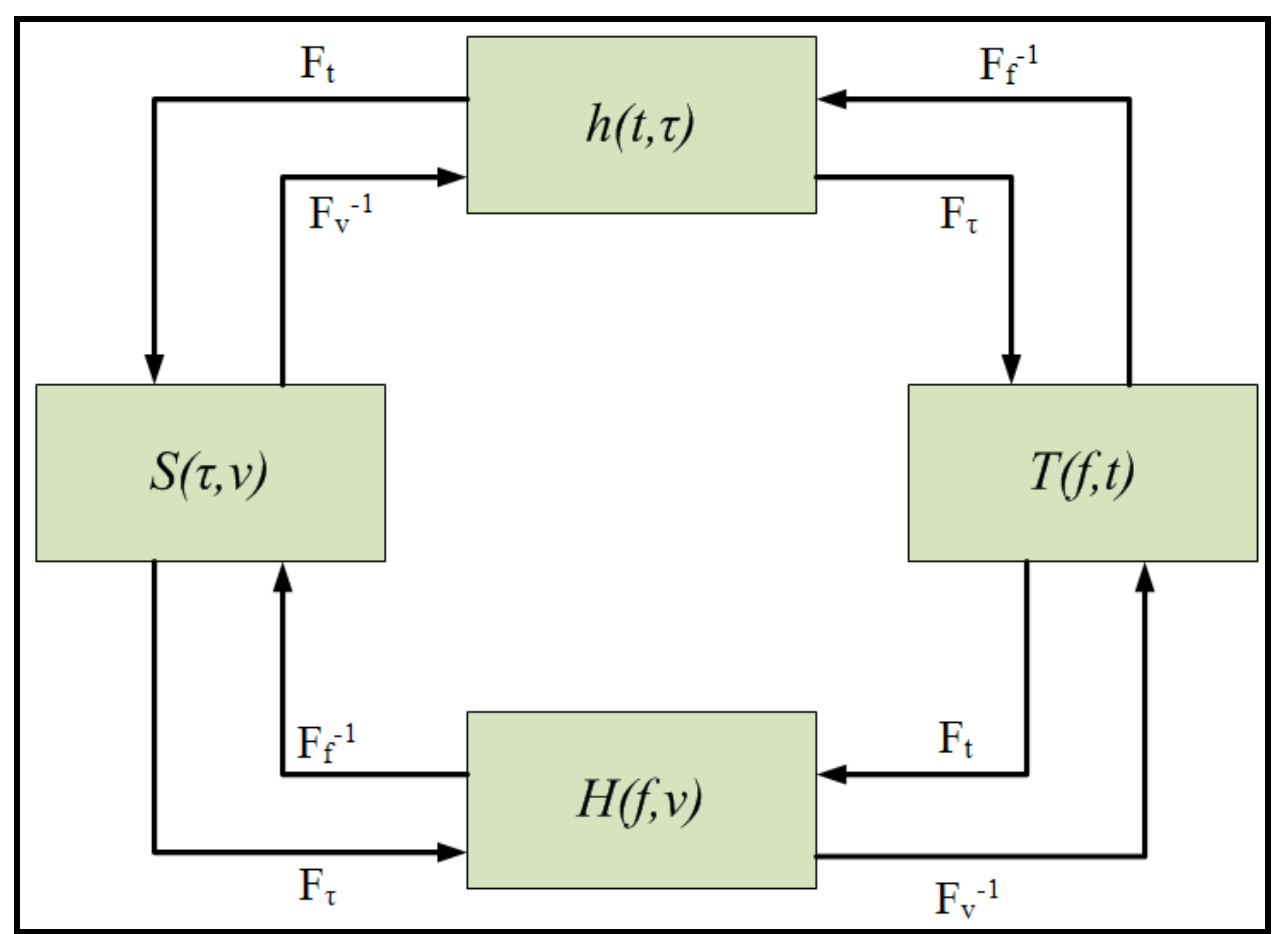

Figura 2.2: Relações entre Funções de Caracterização de Canal

As funções de sistema descritas anteriormente tratam o canal banda larga de forma determinística. Um ambiente urbano real possui um nível de complexidade que requer um tratamento estatístico, onde as funções se comportam como processos estocásticos. Neste caso, a caracterização completa do canal requer a obtenção das funções densidade de probabilidade conjunta das variáveis envolvidas [3].

\section{3}

\section{Efeitos de Propagação}

A Figura 2.3 ilustra um sinal com desvanecimento de pequena escala, desvanecimento de longa escala e a perda de percurso [1]. 


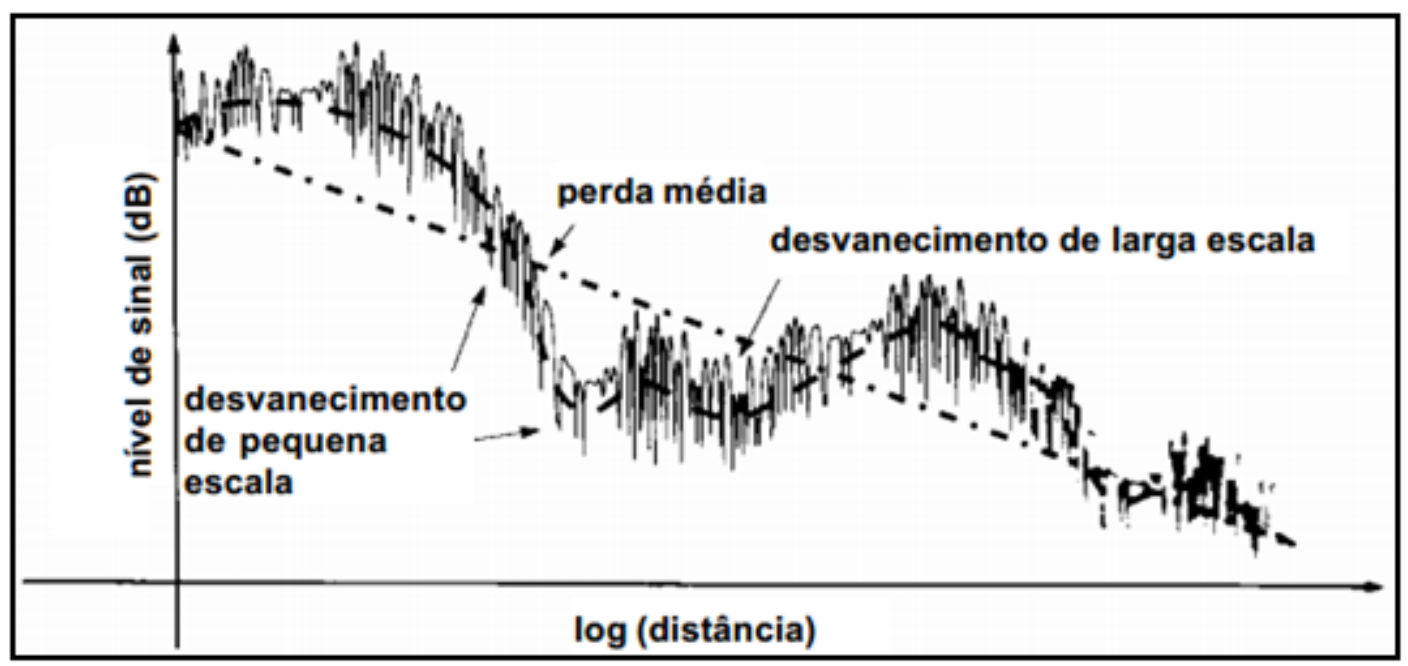

Figura 2.3: Comportamento de sinal em ambiente urbano

Na figura acima é possível perceber dois comportamentos distintos. As flutuações rápidas do sinal são denominadas desvanecimento em pequena escala, associadas ao multipercurso. O desvanecimento de larga escala trata-se de variação mais suave e lenta, associada ao sombreamento causado por obstáculos. Além destes dois comportamentos do sinal há ainda a queda do nível de potência do sinal com a distância (perda média), segundo uma lei de potência em que o expoente da atenuação com a distância varia conforme o ambiente.

\subsection{1}

\section{Variação da Atenuação Com a Distância}

Em ambiente radiopropagação móvel, o nível do sinal recebido no receptor diminui conforme a distância a partir do transmissor. Vários modelos de propagação indicam que a potência do sinal recebido decresce de forma logarítmica com o aumento da distância. Esse comportamento (perda média) é ilustrado na figura 2.3 .

\subsection{2}

\section{Multipercurso}

A faixa de frequências utilizadas pelos sistemas móveis celulares, o ambiente de propagação e a mobilidade fazem com que o sinal resultante no 
receptor seja resultado da composição das componentes do sinal que percorrem diversos e distintos percursos desde o transmissor até o receptor. O sinal é transmitido ao receptor através de efeitos de propagação como reflexão, difração, espalhamento, além de visada direta.

$\mathrm{Na}$ grande maioria dos casos em que as comunicações ocorrem em regiões urbanas, o sinal pode sofre reflexões ou difrações geradas, principalmente, por edificações, conforme mostrado na figura 2.4. O móvel recebe sinais resultantes dos vários mecanismos de propagação gerados pelo ambiente. Devido à mobilidade, a cada instante e em cada local o terminal do usuário recebe uma combinação diferente de sinais. Os diversos sinais refletidos e refratados no ambiente são os principais geradores do desvanecimento seletivo por multipercurso.

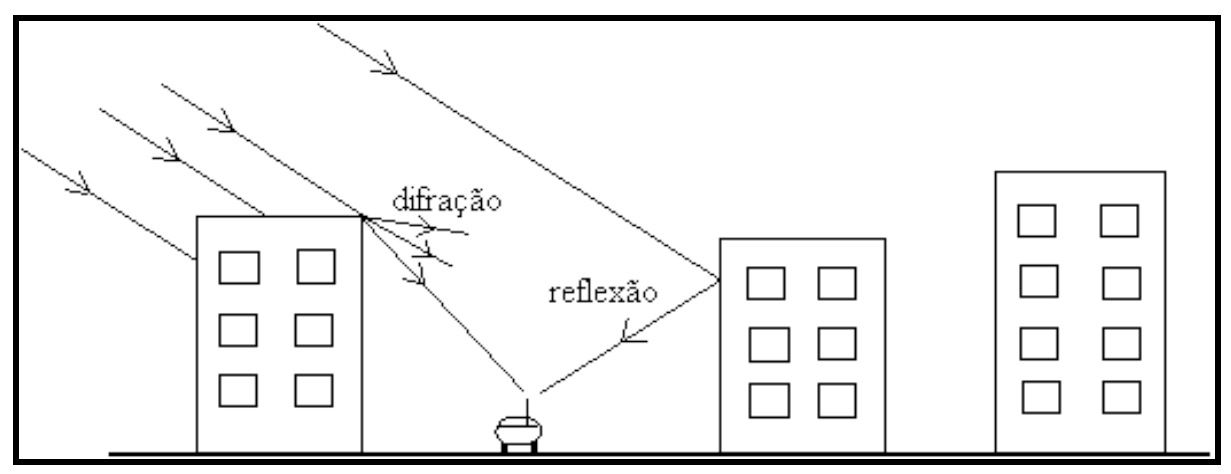

Figura 2.4: Fenômeno de Multipercurso

Os campos associados aos diversos percursos somam-se fasorialmente gerando um campo resultante oscilante. Como já mencionado anteriormente, as variações rápidas no nível do sinal que chega ao receptor, geradas pelo efeito do multipercurso são conhecidas como desvanecimento de pequena escala. Desvanecimentos rápidos e profundos podem ocorrer com espaçamentos de meio comprimento de onda.

\subsection{3}

\section{Desvanecimento de Pequena Escala}

O comportamento aleatório das componentes do sinal pode gerar efeito construtivo ou destrutivo dependendo da diferença de fase entre elas e dos valores 
de amplitude ao chegar ao receptor. O desvanecimento em pequena escala é percebido a curtas distâncias ou pequenos intervalos de tempo.

Uma função de densidade de probabilidade que descreve a amplitude do sinal para o desvanecimento em pequena escala, quando as componentes chegam ao receptor somente através de multipercurso, ou seja, quando não há nenhuma componente cuja amplitude seja significativamente maior que as demais (raio direto), é a função de Rayleigh [5], dada por:

$$
P_{r}(r)=\frac{r}{\sigma^{2}} \exp \left(\frac{-r^{2}}{2 \sigma^{2}}\right)
$$

Nos casos em que além das componentes de multipercurso, chega ao receptor também um raio direto a distribuição de Rayleigh não mais descreve adequadamente o envelope do sinal recebido. Nesse caso, a função que pode ser utilizada para descrever o envelope adequadamente é distribuição Rice [6]. Na distribuição Rice há uma componente dominante (raio direto), e a sua função densidade de probabilidade, que descreve a amplitude do sinal, é dada por:

onde:

$$
P_{r}(r)=\frac{r}{\sigma^{2}} \exp \left(-\frac{r^{2}+r_{s}^{2}}{2 \sigma^{2}}\right) I_{0}\left(\frac{r r_{s}}{\sigma^{2}}\right)
$$

$\mathrm{I}_{0}()=$. Função de Bessel modificada de primeira espécie.

$\mathrm{r}_{\mathrm{s}}=$ Parâmetro relativo à amplitude da componente dominante.

$\sigma=$ Relativo ao desvio padrão das componentes do sinal.

\subsection{4}

\section{Desvanecimento de Larga Escala}

O desvanecimento em larga escala está relacionado principalmente a obstruções naturais do relevo e a construções, como casas e prédios. Devido ao efeito de sombreamento causado por essas obstruções, o desvanecimento de larga escala é conhecido também como sombreamento. Quando o móvel sofre o efeito de sombreamento, ou seja, fica atrás de uma obstrução, recebe um sinal com potência bastante reduzida. O sinal recebido alcança o receptor principalmente através de difração e espalhamento e a amplitude do sinal recebido segue uma 
função de distribuição de probabilidade log-normal [6], que corresponde a uma distribuição Gaussiana ou normal para o nível de sinal em dB:

$$
P_{l}(L)=\frac{1}{\sigma L \sqrt{2 \pi}} e^{-\left[\frac{(\ln L-\mu)^{2}}{2 \sigma^{2}}\right]}
$$

onde $\mu$ é o valor médio da distribuição e $\sigma$ seu desvio padrão.

\subsection{5}

\section{Perfil de Retardos de Potência (Power delay profile)}

Conforme já mencionado anteriormente, quando o canal sofre multipercurso o sinal recebido é composto por diversos componentes do sinal original. Como cada componente do sinal percorre caminhos distintos desde o transmissor até o receptor os tempos de chegada de cada componente serão distintos. Essas diferenças entre os tempos de chegada de cada componente são chamadas de retardos. Perfil de retardos de potência (power delay profile), é caracterizado pelo gráfico da figura 2.5 que mostra cada componente significativa de multipercurso com sua respectiva potência e instante de tempo de chegada.

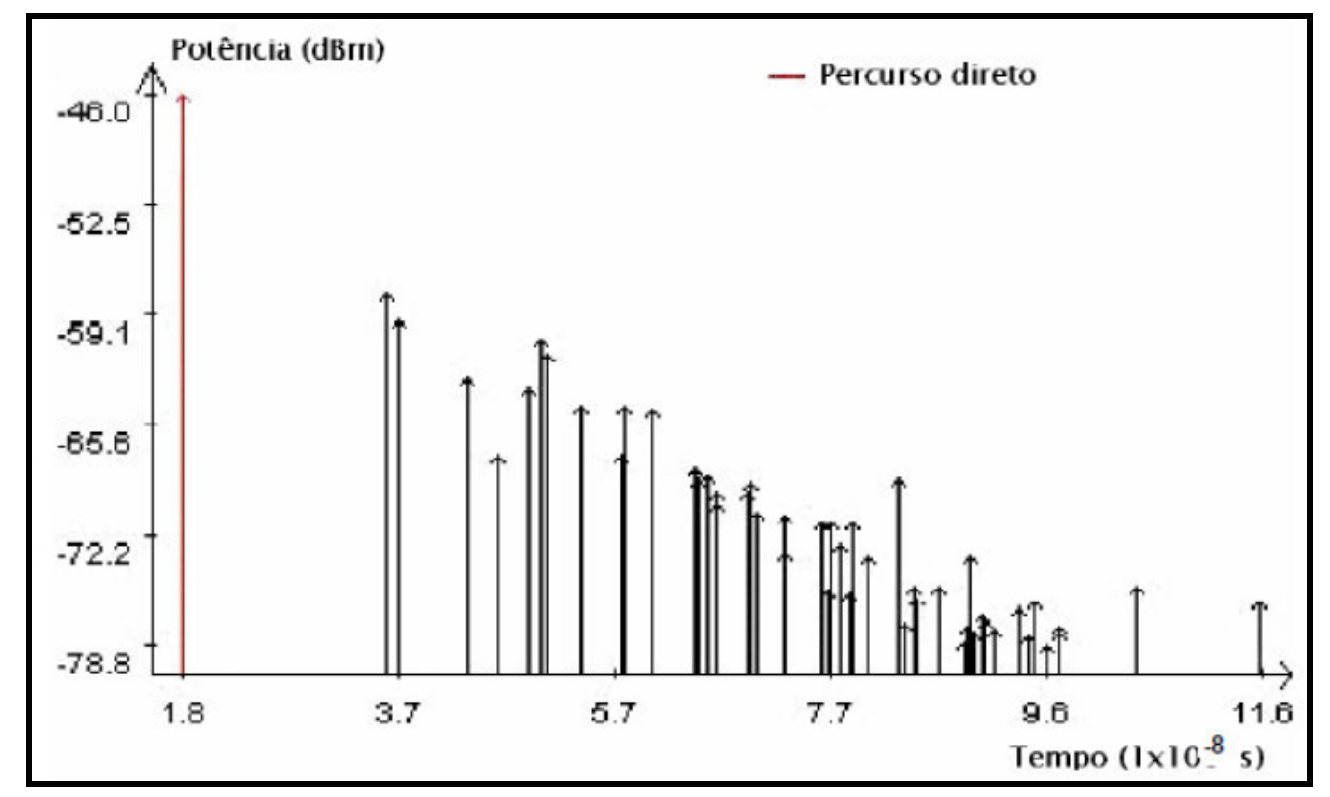

Figura 2.5: Exemplo típico de perfil de retardos

Alguns parâmetros importantes para a caracterização do canal relacionada à dispersão temporal podem ser analisados a partir do perfil de retardos de potência 
como, por exemplo: retardo excedido médio (mean excess delay), espalhamento temporal RMS (RMS delay spread), espalhamento temporal excedido (excess delay spread). Uma breve descrição desses parâmetros [7]:

a) Retardo excedido médio (mean excess delay): é o parâmetro que determina o atraso médio de chegada das componentes em relação à primeira componente que chega ao receptor. É definido matematicamente como:

$$
\bar{\tau}=\frac{\sum_{k} P\left(\tau_{k}\right) \tau_{k}}{\sum_{k} P\left(\tau_{k}\right)}
$$

onde $\tau_{\mathrm{k}}$ é o retardo de propagação da k-ésima onda, ou seja, é a diferença de tempo de chegada no receptor em relação ao primeiro sinal $\left(\tau_{0}=0\right)$ e $\mathrm{P}\left(\tau_{\mathrm{k}}\right)$ é a respectiva potência da componente $\mathrm{k}$ com chegada em atraso no receptor de $\tau_{\mathrm{k}}$.

b) Espalhamento temporal RMS (RMS delay spread): é a medida do espalhamento temporal do perfil de retardos em torno do retardo excedido médio. Para ambiente outdoor, os valores típicos são da ordem de microssegundos e para ambiente indoor, na ordem de nanosegundos. O cálculo do espalhamento temporal RMS é dado pela fórmula:

$$
\sigma_{\tau}=\sqrt{\overline{\tau^{2}}-(\bar{\tau})^{2}}
$$

sendo

$$
\overline{\tau^{2}}=\frac{\sum_{k} P\left(\tau_{k}\right) \tau_{k}^{2}}{\sum_{k} P\left(\tau_{k}\right)}
$$

onde:

$\mathrm{P}\left(\tau_{\mathrm{k}}\right)=$ potência da componente $\mathrm{k}$ de multipercurso.

$\tau_{\mathrm{k}}=$ atraso de propagação da k-ésima onda em relação à incidência do primeiro sinal.

$\tau=$ retardo excedido médio.

Então:

$$
\sigma_{t}=\sigma_{r m s}=\sqrt{\frac{\sum_{k}\left(\tau_{k}-\bar{\tau}\right)^{2} P\left(\tau_{k}\right)}{\sum_{k} P\left(\tau_{k}\right)}}
$$

c) Espalhamento temporal excedido (excess delay spread): indica o retardo máximo em relação à primeira componente recebida, onde a energia decai $\mathrm{X}$

$$
\tau_{\max }(X)=\tau_{X}-\tau_{0}
$$


dB (valor estipulado) abaixo do maior nível recebido. É definido matematicamente como:

onde:

$\tau_{0}=$ tempo de chegada do primeiro sinal.

$\tau_{\mathrm{x}}=$ tempo de chegada do último sinal com nível de potência ainda acima do limite $\mathrm{X} \mathrm{dB}$ e abaixo do sinal de maior amplitude.

O espalhamento temporal excedido define a extensão temporal em que as componentes de múltiplos caminhos estão acima de determinado patamar. O valor de $\tau_{\mathrm{x}}$ às vezes é chamado de difusão por atraso em excesso de um perfil de atraso de potência, mas em todos os casos deve ser especificado um patamar que relaciona o piso de ruído de caminho múltiplo ao componente máximo recebido do caminho múltiplo [7]. Na prática, os valores para estes parâmetros de dispersão temporal dependem da escolha do limiar de piso de ruído usado para processar o nível de potência recebida $\mathrm{P}\left(\tau_{\mathrm{k}}\right)$. É necessário tomar cuidado ao escolher o patamar adotado que não deve ser muito baixo evitando assim que o ruído seja processado como componente de multipercurso [7].

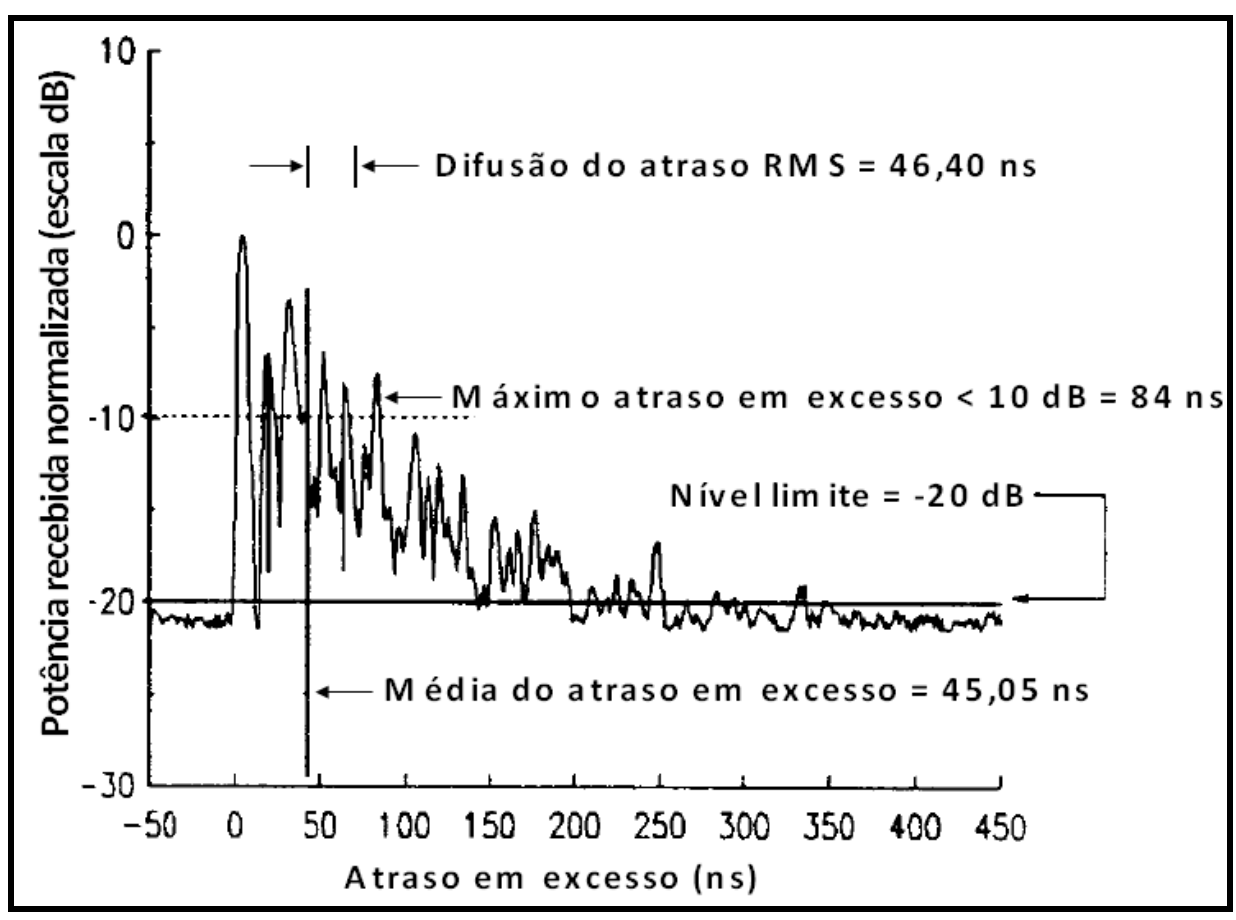

Figura 2.6: Exemplo de perfil de retardos (mostrando os parâmetros) 
A figura 2.6 mostra o cálculo do máximo atraso em excesso para componentes de caminho múltiplo dentro de 10 dB do máximo.

\subsection{6}

\section{Banda de Coerência}

Enquanto o perfil de retardos é um fenômeno natural causado pelos caminhos de propagação refletido e dispersado no canal de radiopropagação, a banda de coerência, $B_{c}$, é uma relação definida, derivada do espalhamento de atraso rms. A banda de coerência é uma medida estatística da faixa de frequências sobre as quais o canal pode ser considerado "uniforme” (ou seja, um canal que passa todos os componentes espectrais com ganho aproximadamente igual e fase linear). Resumindo, a banda de coerência é uma faixa de frequência sobre a qual dois componentes de frequência têm um forte potencial para correlação de amplitude. Duas senóides com separação de frequência maior que $B_{c}$ são afetadas de formas muito diferentes pelo canal. Se a banda de coerência for definida como a largura de banda sobre a qual a função de correlação de frequência é acima de 0,9, então a banda de coerência é aproximadamente [7]:

$$
B_{c}=\frac{1}{50 \sigma_{\tau}}
$$

Onde, $\sigma_{\tau}$ é o parâmetro espalhamento de retardos (delay spread).

Se a definição for relaxada, de modo que a função de correlação de frequência seja acima de 0,5, então a banda de coerência é aproximadamente [7]:

$$
B_{c}=\frac{1}{5 \sigma_{\tau}}
$$

É importante ressaltar que uma relação exata entre banda de coerência e o espalhamento de atraso rms é uma função das respostas ao impulso do canal específico e sinais aplicados. As equações 2.14 e 2.15 são apenas estimativas aproximadas. Em geral, técnicas de análise espectral e simulações são exigidas para determinar o impacto exato que o caminho múltiplo variável no tempo tem sobre um sinal transmitido em particular. 
Canais com largura de banda menor que a banda de coerência são considerados canais banda estreita, enquanto que canais com largura de banda maior que a banda de coerência devem ser tratados como canais banda larga [1].

Um conceito importante que é relacionado à banda de coerência é a atenuação seletiva em frequência. Para a atenuação seletiva em frequência, o espectro do sinal transmitido tem uma largura de banda maior que a banda de coerência $B_{c}$ do canal. No domínio da frequência, o canal se torna seletivo em frequência, onde o ganho é diferente para diferentes componentes de frequência. A atenuação seletiva em frequência é causada por atrasos de caminho múltiplo que se aproximam ou excedem o período de símbolo do símbolo transmitido. Os canais de atenuação seletiva de frequência também são conhecidos como canais de banda larga, pois a largura de banda do sinal é maior que a largura de banda da resposta ao impulso do canal [7]. Nesse caso, em sistemas digitais, a taxa máxima de dados que podem ser transmitidos no canal é limitada devido ao grande impacto causado pela seletividade em frequência.

\subsection{7}

\section{Efeito Doppler}

Em um ambiente real de transmissão e recepção para sistemas móveis, o receptor estabelece um movimento relativo ao transmissor, que possui velocidade variante no tempo. Esse movimento gera um desvio de frequência que é maior na medida em que aumenta a velocidade de deslocamento do receptor em relação à direção de propagação da onda de rádio. Esse desvio de frequência gera uma percepção errada da frequência do sinal que foi originalmente transmitido. Este efeito é conhecido como Efeito Doppler ou Desvio Doppler. Pode-se deduzir o valor do desvio Doppler em função da velocidade de movimento através de uma abordagem relativística [7] ou por geometria [8]. Em ambas as abordagens os resultados levam à expressão:

onde:

$$
f_{d}=\frac{1}{2 \pi} \cdot \frac{\Delta \phi}{\Delta t}=\frac{v}{\lambda} \cdot \cos \theta
$$

$f_{d}$ é o desvio Doppler

$v$ é a velocidade do móvel 
$\theta$ é o ângulo entre a direção do movimento e a direção de propagação da onda eletromagnética.

Em uma análise prática da característica de um canal radiopropagação móvel, é possível constatar que cada um dos sinais dos multipercursos sofrerão diferentes desvios Doppler, devido ao sinal ser recebido de várias direções e as estruturas possuírem características variadas de acordo com a posição do terminal móvel. Esses diferentes desvios Doppler formam o que se pode chamar de espectro Doppler [7]. 


\section{3}

\section{Medições}

Neste capítulo serão abordadas as principais técnicas de medições aplicáveis a testes realizados em ambiente outdoor. Nesse trabalho a técnica aplicada é a de multiportadoras OFDM, que é a alternativa para medições no domínio da frequência que, em geral, são aplicáveis apenas para ambiente indoor. Dessa forma, essa técnica será explicada em mais detalhes que as demais. Além das técnicas de medições serão abordadas também as técnicas de limpeza de perfil de retardos CFAR e CLEAN, as quais serão utilizadas para selecionar os multipercursos válidos que serão, posteriormente, analisados de acordo com a recomendação ITU-R P.1411-6.

\section{1}

\section{Modulação OFDM}

Em um ambiente de propagação onde existem muitas ondas refletidas, ou seja, multipercursos, é comum que ocorra desvanecimento seletivo do sinal transmitido, além de outros efeitos. A modulação OFDM (Orthogonal frequencydivision multiplexing) consiste na transmissão paralela de dados em diversas subportadoras com modulação QAM ou PSK, onde a taxa de transmissão de dados em cada subportadora é uma fração da taxa global.

Na transmissão paralela os dados são enviados em sequências simultâneas, onde, em um determinado momento, ocorre a transmissão de um conjunto de símbolos. Quando é utilizada a modulação multiportadora com N subportadoras, o sinal de entrada é dividido, com uma taxa $\mathrm{R}$ bps e ocupando uma faixa de $\mathrm{W} \mathrm{Hz}$, em $\mathrm{N}$ subcanais, cada um com uma taxa $\mathrm{R} / \mathrm{N}$ bps e ocupando uma faixa de W/N Hz. Cada subcanal é modulado com um símbolo diferente da sequência de entrada, durante um intervalo de símbolo, e então os $\mathrm{N}$ subcanais são multiplexados na frequência [9]. 
A redução na taxa de transmissão de cada subportadora, implicando no aumento da duração dos símbolos transmitidos, acarreta na diminuição da sensibilidade à seletividade em frequência causada por efeitos de multipercurso.

Nos sistemas OFDM, é selecionado um espaçamento em frequência entre as subportadoras de forma que cada uma delas tenha seu máximo em pontos de cruzamento de zero do espectro das demais, evitando assim que uma subportadora interfira na outra como indicado na figura 3.1 a seguir:

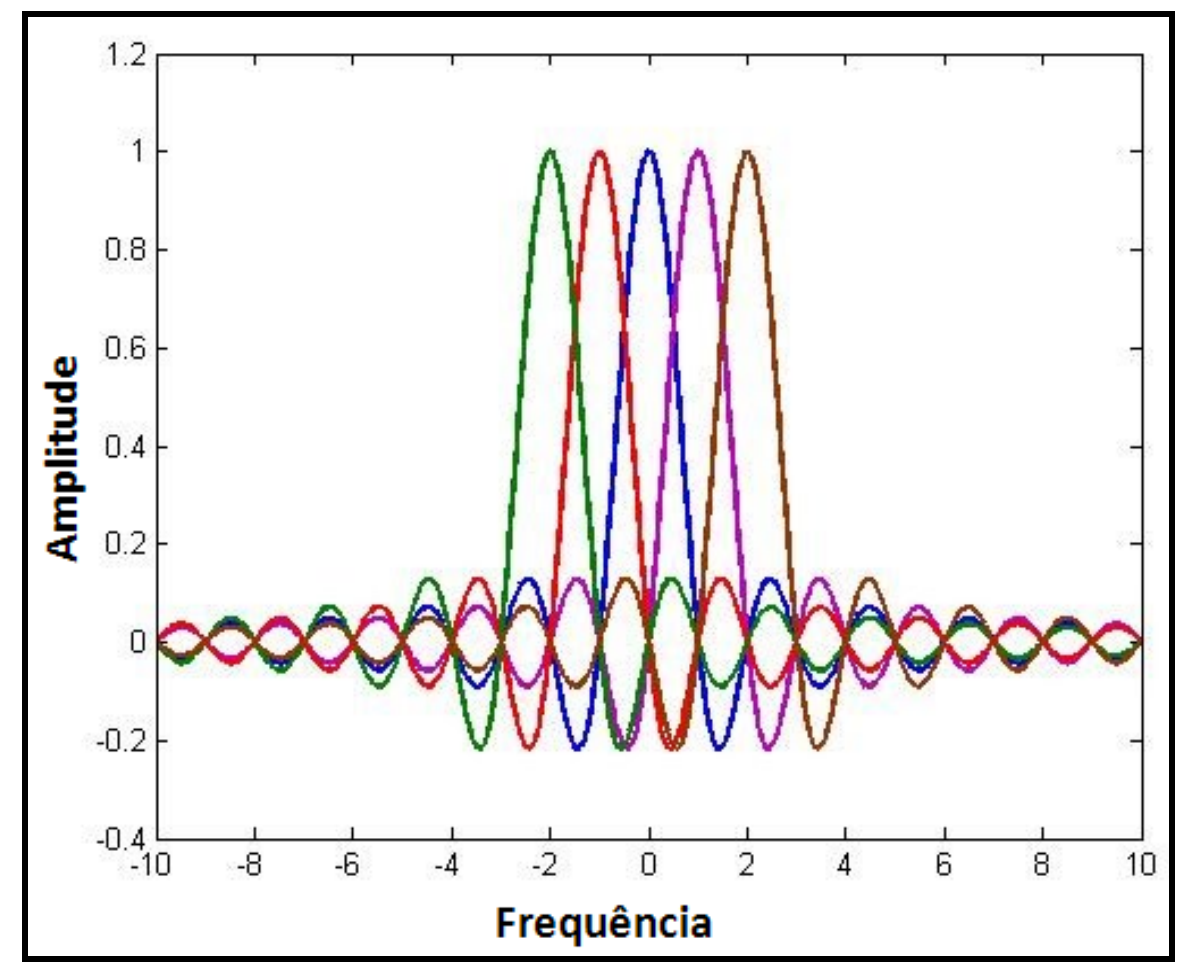

Figura 3.1: Ortogonalidade no Domínio da Frequência (OFDM)

Apesar de existir superposição espectral de subportadoras moduladas, a informação transportada por cada uma delas pode ser isolada das demais através de um correlator (ou filtro casado) adequado. Admitindo sincronização de relógio, a saída deste correlator corresponde à projeção do sinal OFDM recebido sobre a subportadora a ele associada. Devido ao espaçamento de frequência empregado, é proporcionada a ortogonalidade entre as subportadoras. Para que ocorra ortogonalidade na recepção entre os subcanais, é necessário que as subportadoras estejam centradas nas respectivas frequências dos subcanais OFDM [10]. 
Em relação ao domínio do tempo, a característica de ortogonalidade entre subportadoras implica que duas subportadoras quaisquer diferem exatamente por um número inteiro de ciclos durante um intervalo de símbolo OFDM. Essa condição é mostrada na figura 3.2 a seguir:

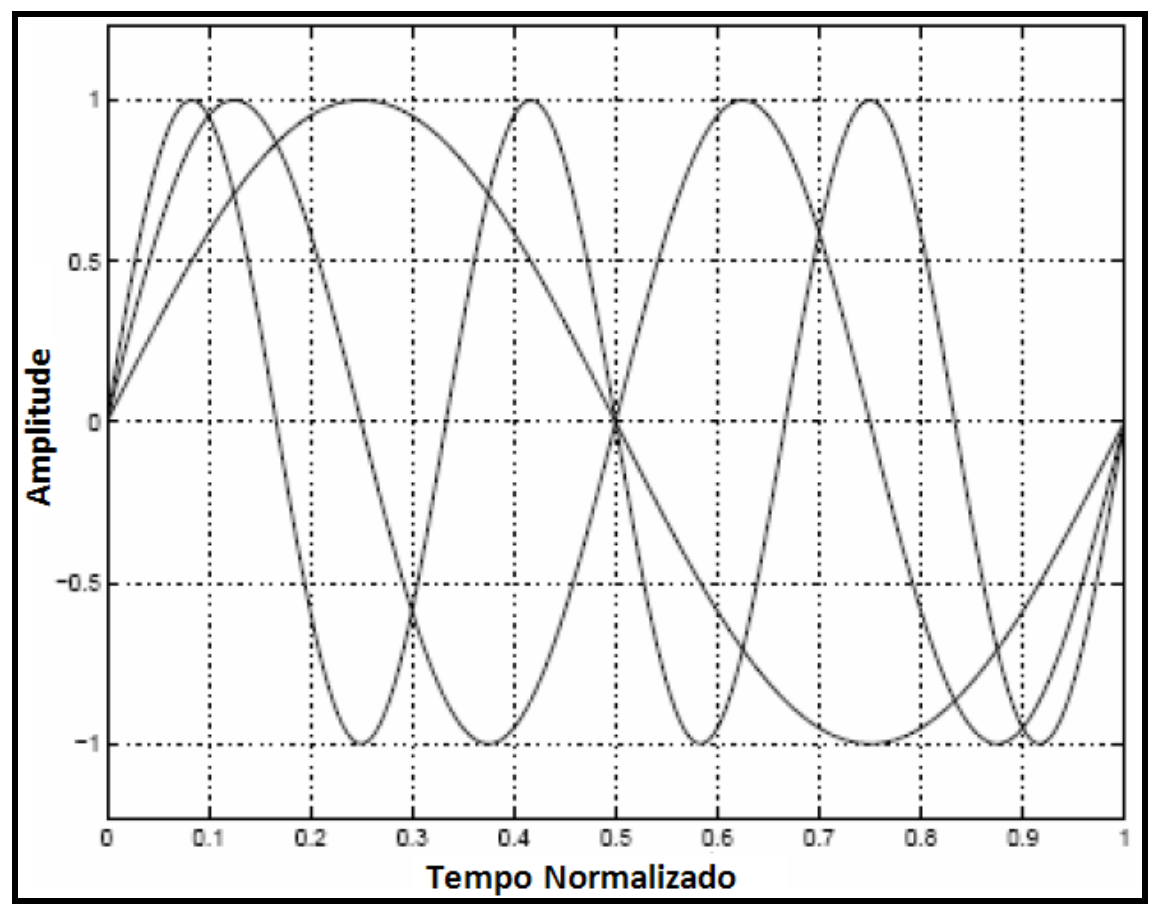

Figura 3.2: Ortogonalidade no Domínio do Tempo (OFDM)

A utilização de canais de faixa mais estreita ao invés de um único canal de largura de faixa maior proporciona uma grande melhoria no que diz respeito à seletividade em frequência. Um provável desvanecimento seletivo em frequência apresentado por um canal de portadora única, pode ser revertido no desvanecimento plano ou quase plano apresentada pelas frações deste canal, quando a modulação OFDM é utilizada [10].

Uma das principais vantagens de se utilizar a modulação OFDM é a forma como ela lida com o espalhamento de retardo RMS do canal, tipo de degradação comum em canais de propagação com multipercurso. A conversão série-paralelo dos dados de entrada tem como consequência o aumento da duração de cada símbolo transmitido por um fator $\mathrm{N}$, o que faz também com que a relação entre o espalhamento de retardo RMS e a duração de cada símbolo seja reduzida pelo mesmo fator. 
Para propiciar a eliminação da interferência entre símbolos, um intervalo de guarda é introduzido a cada símbolo OFDM. Esse intervalo é dimensionado de modo que as componentes multipercurso de um símbolo OFDM não tenham como interferir na recepção do símbolo OFDM subsequente.

Considerando-se que os respectivos valores de retardo sejam menores do que o intervalo de guarda pode-se garantir que réplicas retardadas do símbolo OFDM terão sempre um valor inteiro de ciclos dentro do intervalo de cálculo da FFT (Fast Fourier Transform). Como resultado, os sinais multipercurso com retardo menor que o intervalo de guarda não causarão ICI (Inter-Carrier Interference).

Tanto nas medições realizadas neste trabalho na faixa de $2.5 \mathrm{GHz}$ quanto nas medições realizadas em 3.5 GHz por Carlos Ron [3], foi gerado e transmitido um sinal OFDM com largura de banda de $20 \mathrm{MHz}$, com objetivo de: registrar e analisar o perfil de retardos de potência do canal banda larga móvel urbano, analisar os multipercursos válidos e, posteriormente, realizar a comparação com a recomendação ITU-R P.1411-6. Para que o sinal OFDM transmitido seja gerado de forma correta, é necessário o entendimento da formação dos símbolos OFDM. Para suprir esse entendimento, serão listados a seguir os parâmetros que formam o símbolo OFDM [11]:

- Largura Nominal do Canal $\left(\mathrm{BW}_{\mathrm{N}}\right.$ em $\left.\mathrm{Hz}\right)$ - Representa a largura inteira do canal já incluída os efeitos de filtro e de banda de guarda;

- Largura de Banda Usada $\left(\mathrm{BW}_{\mathrm{U}}\right.$ em $\left.\mathrm{Hz}\right)$ - É a faixa de frequências que representa efetivamente no domínio da frequência o sinal OFDM transmitido. A Largura de banda usada é dada por $\mathrm{BW}_{\mathrm{U}}=\mathrm{N}_{\text {Usadas }} \mathrm{x} \Delta \mathrm{f}$;

- Frequência de Amostragem $\left(F_{s}\right.$ em $\left.\mathrm{Hz}\right)$ - É a frequência utilizada pelo conversor Digital/Analógico do Gerador de Sinais;

- Fator de Amostragem (n) - É dado pela razão entre a frequência de amostragem e a largura de banda do sinal transmitido, é normalmente maior que uma unidade;

- Tamanho da FFT $\left(\mathrm{N}_{\mathrm{FFT}}\right)$ - Especifica o número de amostras do sinal OFDM todo, incluindo as subportadoras usadas e as de guarda; 
- Espaçamento entre subportadoras $(\Delta \mathrm{f}$ em $\mathrm{Hz})$ - É a razão entre a frequência de amostragem e o tamanho da FFT;

- Tempo de símbolo útil $\left(\mathrm{T}_{\mathrm{b}}\right.$ em $\left.\mathrm{s}\right)$ - É o tempo de duração de informação livre de interferência entre símbolos, é também chamado de intervalo de ortogonalidade. $\mathrm{T}_{\mathrm{b}}=1 / \Delta \mathrm{f}$;

- Relação de Período de Guarda (G) e Tempo de Prefixo Cíclico ( $\mathrm{T}_{\mathrm{g}}$ em s) - É uma fração do símbolo útil que é adicionado ao sinal OFDM com o objetivo de coletar a informação do multipercurso. O tempo absoluto de duração do período de guarda é chamado prefixo cíclico (CP);

- Tempo do Símbolo OFDM (Ts em s) - duração completa do símbolo OFDM. $\mathrm{T}_{\mathrm{s}}=\mathrm{T}_{\mathrm{b}}+\mathrm{T}_{\mathrm{g}}$.

A figura 3.3 ilustra esses parâmetros no domínio da frequência e no domínio do tempo:

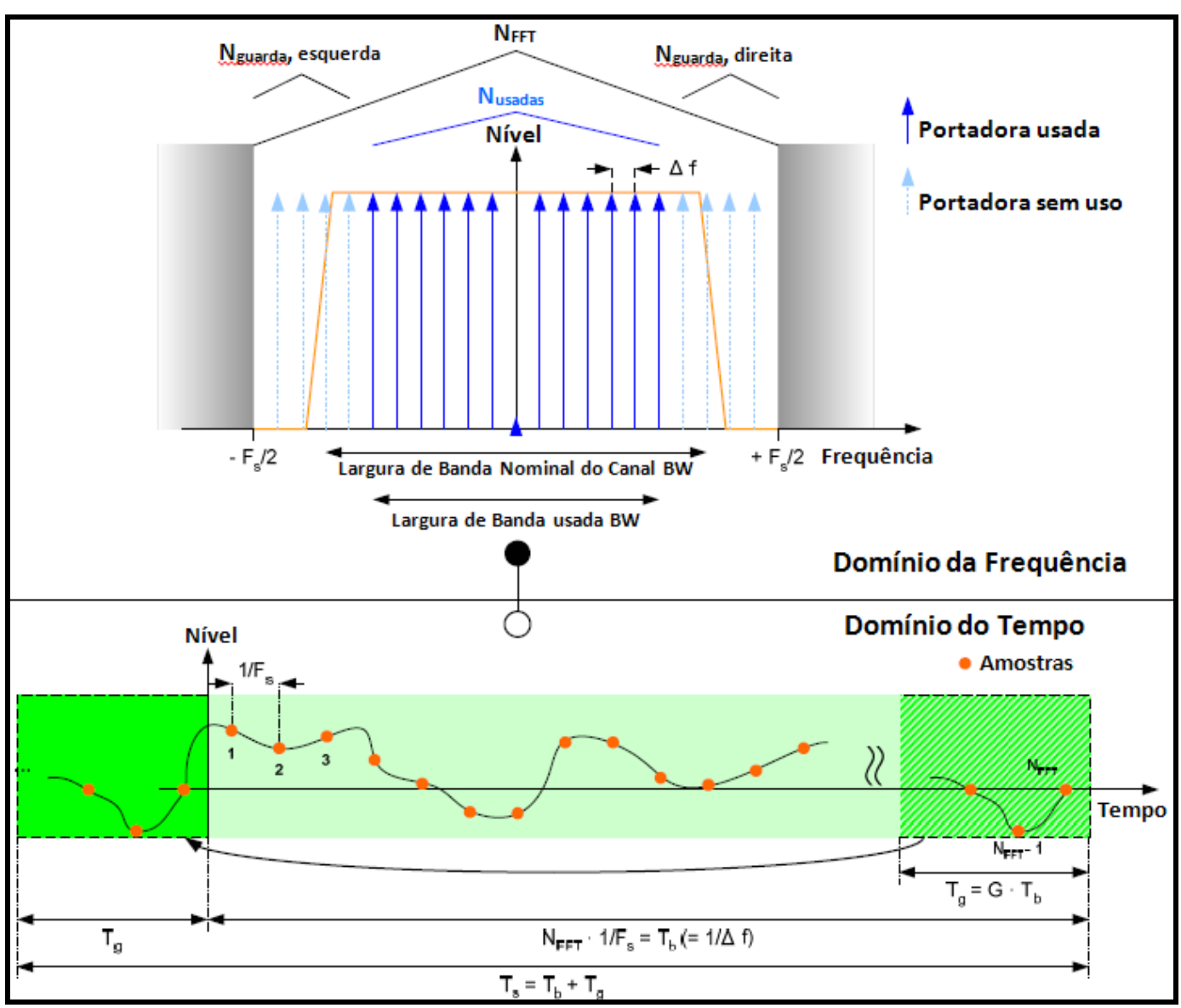

Figura 3.3: Definição de Parâmetros do sinal OFDM [11] 


\section{2}

\section{Técnicas de Medições}

Atualmente as técnicas utilizadas em testes de campo para ambiente outdoor de forma a caracterizar os canais variantes no tempo se dividem nas seguintes categorias: Técnicas no Domínio do Tempo (Pulse Compression) e Técnicas no Domínio da Frequência [3, 12].

\section{2 .1}

\section{Técnica no Domínio do Tempo}

O ruído branco, através de suas propriedades, permite realizar operações de autocorrelação entre o sinal transmitido e o sinal recebido. Desta forma esta técnica consiste em inserir ruído branco no canal a ser medido e, através da operação de autocorrelação, identificá-lo durante a recepção obtendo-se assim a resposta ao impulso do canal [3].

Para fins de se obter resultados semelhantes com o uso de sinais determinísticos, pode-se utilizar sequências binárias pseudo-aleatórias (PN) ao invés do ruído branco. Uma sequência pseudo-aleatória possui uma função de autocorrelação periódica, que apresenta uma sucessão de pulsos nos pontos de deslocamento zero (máxima correlação). A resolução mínima de retardo será a largura do pico de autocorrelação, que corresponde ao dobro do período de chip da sequência pseudo-aleatória [1].

O método mais utilizado de implementação dessa técnica é conhecido como CMF (Convolution Matched Filter) devido ao uso de um filtro casado no receptor. Outra opção de implementação desta técnica de medição, que não faz uso do filtro casado no receptor, é descrita em [1, 13].

\section{2 .2}

\section{Técnica no Domínio da Frequência}

Uma das formas de se aplicar essa técnica é através da realização de várias medições da transmissão de uma onda CW (Continuous Wave), ou seja, com amplitude e frequência constantes. Para cada uma das medidas seria gerada uma 
onda CW diferente. Um dos maiores problemas dessa técnica é caracterizar o comportamento seletivo em frequência do canal uma vez que as medições não são realizadas simultaneamente.

Outras técnicas no domínio da frequência foram utilizadas em [2, 14]. Estas técnicas fazem uso de sincronização entre a estação base e a estação móvel, sendo mais aplicadas em ambientes do tipo indoor. Para ambiente outdoor a alternativa é o uso da técnica de multiportadoras.

\subsubsection{1}

\section{Técnica de Multiportadoras}

Para suprir a limitação já mencionada da técnica no domínio da frequência, a técnica de multiportadoras utiliza a modulação OFDM que permite a transmissão simultânea no canal inteiro de várias subportadoras em frequências diferentes em todo o canal, sem que uma subportadora interfira nas vizinhas devido à sua ortogonalidade. A técnica de modulação OFDM foi explicada na seção 3.1. Uma explicação mais detalhada da técnica de multiportadoras pode ser encontrada em [3]. Os parâmetros utilizados para a geração do sinal OFDM utilizado nesse trabalho estão nos items 4.1.2 e 4.2.2.

Os perfis de retardo medidos diretamente pela técnica de multiportadoras são contaminados pelo ruído eletromagnético ambiente. Mesmo considerando que a faixa de frequências para a medição foi escolhida com base numa varredura de espectro de modo a minimizar o ruído presente, é necessário utilizar técnicas de limpeza dos perfis de retardo medidos de forma a distinguir as reais componentes de multipercurso das componentes de ruído.

\section{3}

\section{Técnica de Limpeza de Perfis de Retardos CFAR}

A técnica CFAR (Constant False Alarme Rate) foi utilizada originalmente para aplicações em radar e permite que seja feita a estimativa dos sinais de multipercurso ou ecos verdadeiros presentes no receptor, com base na avaliação do ruído presente. 
Este método permite a captura de sinais que chegam ao receptor e, com base na avaliação do ruído presente, estima os sinais de multipercurso ou ecos verdadeiros capturados no receptor. Deve-se tomar cuidado no cálculo do limiar de deteç̧ão, pois se for selecionado um limiar muito baixo poderá acarretar na seleção de todos os sinais presentes no receptor, inclusive ruído, como sendo multipercurso $[15,16,17]$.

A técnica consiste em avaliar o ruído presente através da determinação da mediana do perfil de retardos de potências e de seu desvio padrão para estabelecer os níveis de variação do ruído. O limiar de ruído será a diferença entre o pico máximo e a mediana somada ao desvio padrão, conforme ilustrado na Figura 3.1 a seguir [3].

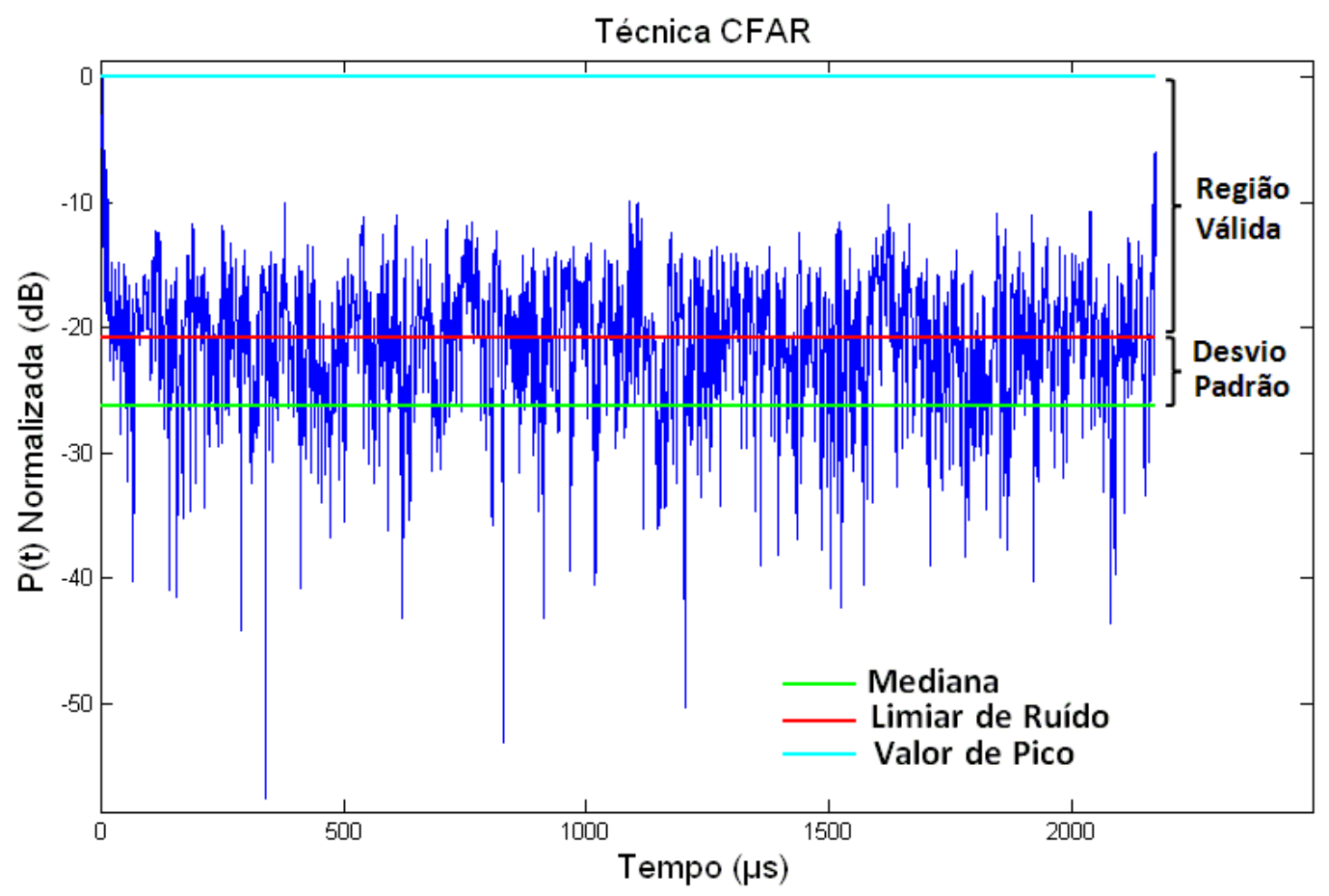

Figura 3.1: Definição do Limiar de Ruído.

Além do limiar de ruído, o método é aplicado com a seguinte sequência de avaliação de multipercurso [3]:

a) Se um determinado retardo medido excede o limiar de ruído, verificar se o limiar também é excedido para os dois retardos medidos, anterior e posterior, do perfil de retardos avaliado;

b) Para que o retardo seja considerado uma medida válida, ao menos um dos vizinhos deve satisfazer à condição anterior. 
Esta é uma das técnicas que serão utilizadas para obter a curva de perfil de retardos para análise.

\section{4}

\section{Técnica de Limpeza de Perfil de Retardos CLEAN}

Durante o processo de transmissão e recepção utilizando as técnicas de sondagem, os dados medidos estão sujeitos a erros gerados pelos equipamentos envolvidos. Dessa forma, é necessário verificar se a potência recebida em cada valor de retardo trata-se realmente de uma componente de multipercurso válido, ou seja, oriunda de um espalhador e não um espúrio indesejado [2].

A utilização da técnica de sondagem no domínio da frequência nos leva à obtenção de uma resposta impulsiva, que contém os efeitos do canal e dos equipamentos de medida.

A técnica CLEAN tem como objetivo retirar os efeitos dos equipamentos que fazem parte do sistema de medida a partir da comparação entre uma medida de referência realizada em ambiente controlado e a resposta impulsiva $h(t, \tau)$, que contém os efeitos dos equipamentos e do canal.

A medida de referência deve ser feita em visibilidade (LOS) e ambiente aberto com o mínimo possível de espalhadores. Dessa forma a resposta impulsiva conterá somente os efeitos dos equipamentos, praticamente sem multipercursos [2].

O chamado sinal mais forte é obtido pela correlação da PDP (Power Delay Profiles) recebida com a PDP de referência (sem multipercurso), a fim de identificar o maior pico de correlação. A amostra que gerou o pico mais alto é subtraída da PDP recebida resultando num sinal limpo que irá mais uma vez ser correlacionada com o sinal de referência. Este procedimento é repetido até que o nível do sinal de "CLEAN" atinge o limite de ruído. É considerado válido qualquer multipercurso que supere $80 \%$ de correlação.

No caso das medições em $2.5 \mathrm{GHz}$, por exemplo, a obtenção do sinal de referência foi realizada através de uma transmissão gerada no estacionamento da PUC durante um domingo, em que praticamente não existiam pedestres e carros. Sendo assim pode-se considerar que as obstruções estavam muito distantes 
quando comparadas com a distância das antenas transmissora e receptora. Nessas condições a transmissão pode ser considerada LOS, sem multipercusos.

A Figura 3.2 a seguir ilustra o sinal de calibração utilizado como referência:

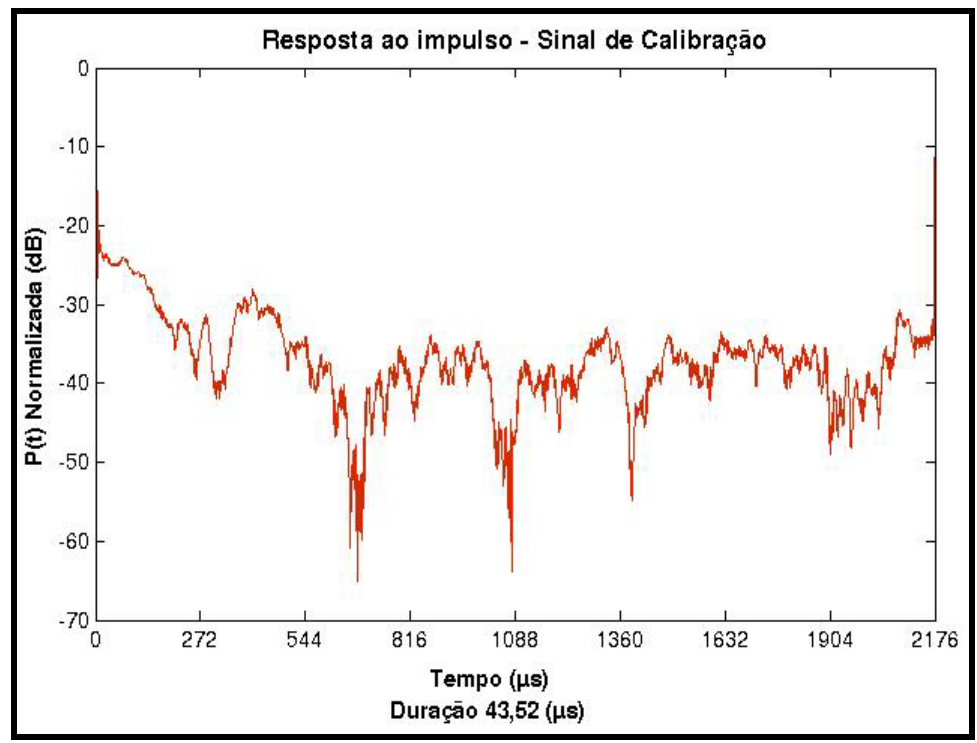

Figura 3.2: Sinal de Calibração - medida de referência (CLEAN).

O algoritmo da técnica CLEAN é explicado em mais detalhes em [2]. 


\section{Campanhas de Medições}

Esse trabalho tem o objetivo de caracterizar o canal de radiopropagação para as faixas de frequência de $2.5 \mathrm{GHz}$ e $3.5 \mathrm{GHz}$, obtendo dados estatísticos dos multipercursos válidos com base em medições. Esses dados são confrontados com a recomendação ITU-R P.1411-6 para validação e também para que novos parâmetros sejam recomendados em função das características apresentadas nas medições constantes nesse trabalho.

Neste capítulo é descrito como foram montados os set-ups de medições com relação à transmissão e recepção de acordo com a técnica de sondagem de multiportadoras, as áreas de coberturas utilizadas. Também são descritos os procedimentos e equipamentos utilizados de modo a obter os dados experimentais que caracterizam o canal de radiopropagação móvel.

\section{1}

Medições em $2.5 \mathrm{GHz}$

\subsection{1}

\section{Set-up de Transmissão em $2.5 \mathrm{GHz}$}

Foi montado o set-up de transmissão de acordo com a técnica das multiportadoras discutida no item 3.1.2.1. O set-up consiste na transmissão de um sinal OFDM, gerado através do software MATLAB. Esse sinal foi posteriormente convertido, através do software IQ Producer da Anritsu para o formato utilizado pelo gerador de sinais MG 3700A. Além do gerador de sinais, foram utilizados também no processo de transmissão do sinal um amplificador de potência e uma antena setorial, além dos cabos e conectores que foram utilizados nas interligações dos equipamentos. O set-up de transmissão é ilustrado na Figura 4.1. 


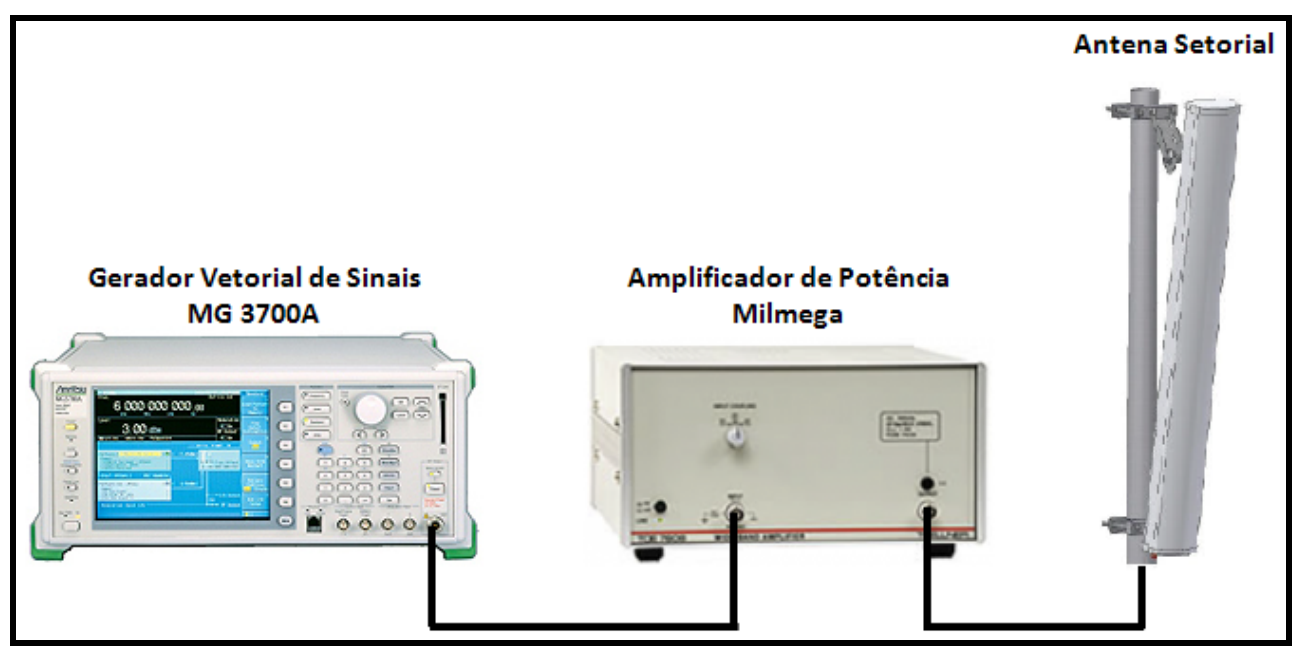

Figura 4.1: Diagrama do set-up de transmissão

Seguem abaixo os equipamentos utilizados na etapa de transmissão:

- Gerador Vetorial de Sinais - Anritsu MG3700A;

- Amplificador de RF - Milmega AS0204-7B;

- Antena setorial - PCTEL 17VP90NUF.

Com o intuito de caracterizar o canal banda larga, o sinal OFDM foi gerado com uma largura de banda de $20 \mathrm{MHz}$, servindo como referência para os sistemas de comunicações móveis de 4G como WiMAX e LTE, já que é a largura máxima de canal dos mesmos.

O sinal foi gerado através de código MATLAB desenvolvido por Carlos Ron [3], tratado e convertido para o formato .wvi, de forma a estar adequado ao gerador de sinais MG3700A da Anritsu. Estão descriminados na tabela 4.1 os parâmetros utilizados na geração do sinal OFDM, conforme capítulo 3.

Tabela 4.1: Parâmetros utilizados na geração do sinal OFDM

\begin{tabular}{|c|c|c|}
\hline Parâmetro & Valor & Unidade de Medida \\
\hline Largura do Canal [BW] & 20 & $\mathrm{MHz}$ \\
\hline Tamanho da FFT [NFFT] & 1024 & amostras \\
\hline Fator de Amostragem & 2 & adimensional \\
\hline Frequência de Amostragem [Fs] & 50 & $\mathrm{MHz}$ \\
\hline Prefixo Cíclico [CP] & $1 / 16$ & amostras \\
\hline
\end{tabular}

O software IQ Producer da Anritsu foi utilizado no tratamento e conversão do sinal. Foi necessário inserir um intervalo gap entre cada símbolo OFDM de 
modo a ser possível a identificação do sinal OFDM no processo de pósprocessamento [3].

Com a análise da varredura realizada foi concluído que a melhor frequência central de transmissão, de modo a não interferir e nem sofrer interferência durante as medições, seria de $2.487 \mathrm{GHz}$, pois era a frequência central mais próxima de $2.5 \mathrm{GHz}$ que melhor acomodava um sinal com largura de faixa de $20 \mathrm{MHz}$, conforme ilustrado na Figura 4.2, minimizando assim o efeito de interferência em outros sistemas e produzindo a melhor relação sinal-interferência (S/I). A Figura 4.3 ilustra o resultado da varredura do espectro.

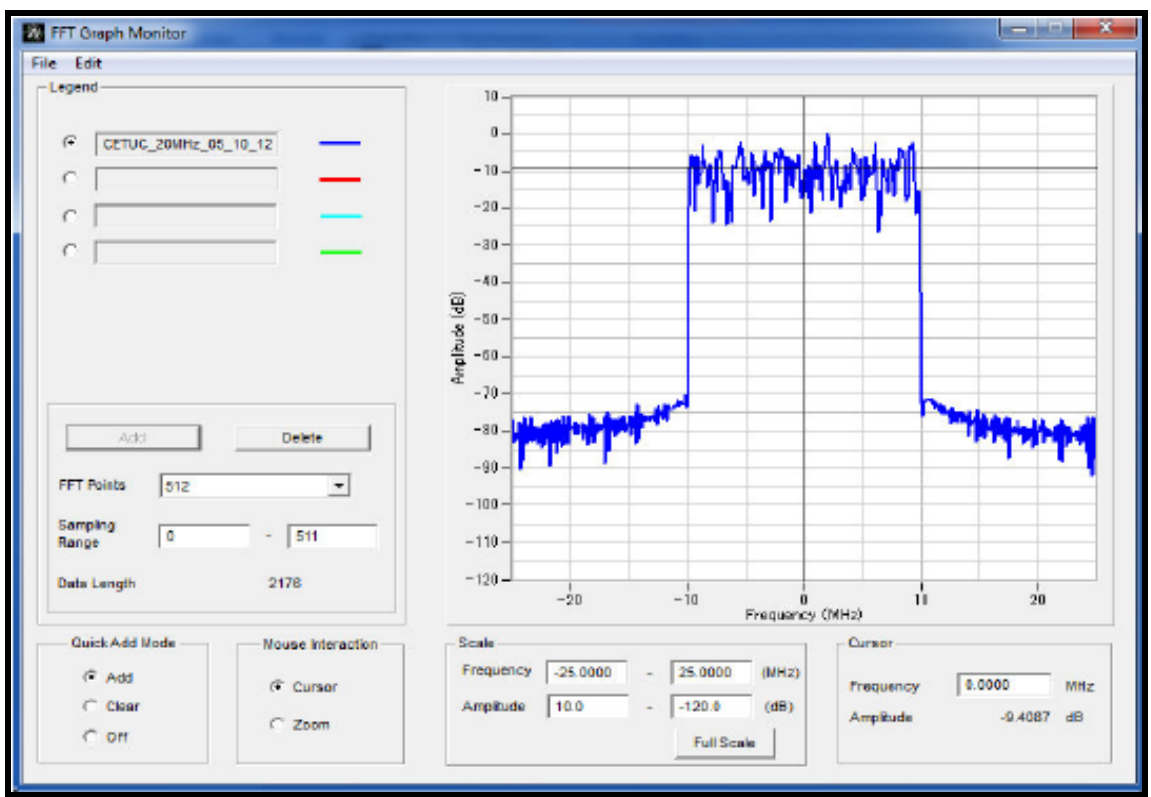

Figura 4.2: Sinal OFDM de $20 \mathrm{MHz}$ de Largura de Banda 


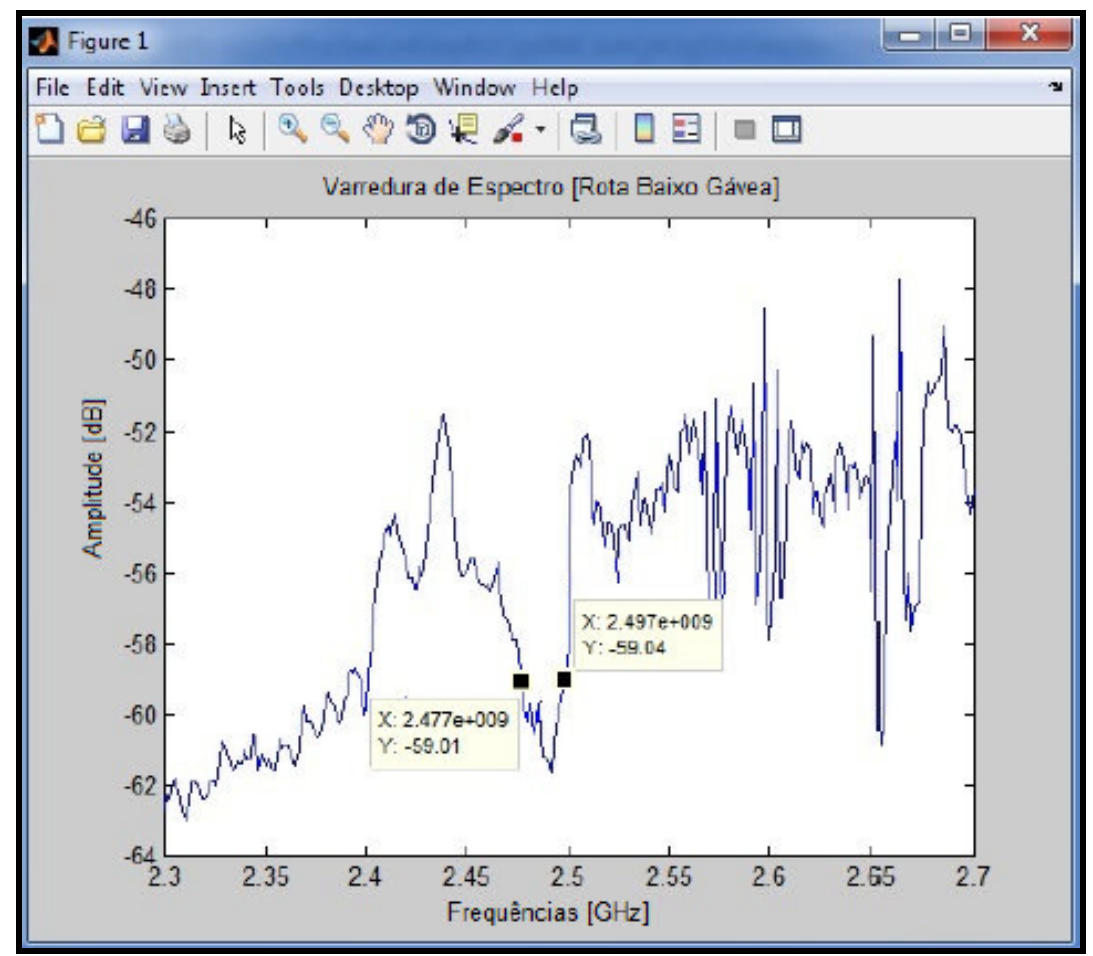

Figura 4.3: Varredura de Espectro

A antena transmissora foi posicionada a uma altura de 30 metros em relação ao nível médio do mar, no terraço do prédio da ala Kennedy da Pontifícia Universidade Católica do Rio de Janeiro. As coordenadas geográficas da posição

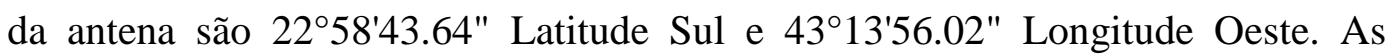
visões frontal e periférica de irradiação da antena, considerando o ângulo de abertura de $90^{\circ}$ da mesma, estão mostradas nas figuras de Figura 4.4 à Figura 4.6. O posicionamento da antena foi feito de modo a possibilitar a cobertura da área compreendida entre os bairros do Leblon, na altura das Ruas Bartolomeu Mitre e Delfim Moreira e Gávea, na altura da Rua Marquês de São Vicente, estendendo também à região da lagoa Rodrigo de Freitas, na altura das Avenidas Borges de Medeiros e Epitácio Pessoa que contornam a Lagoa. 


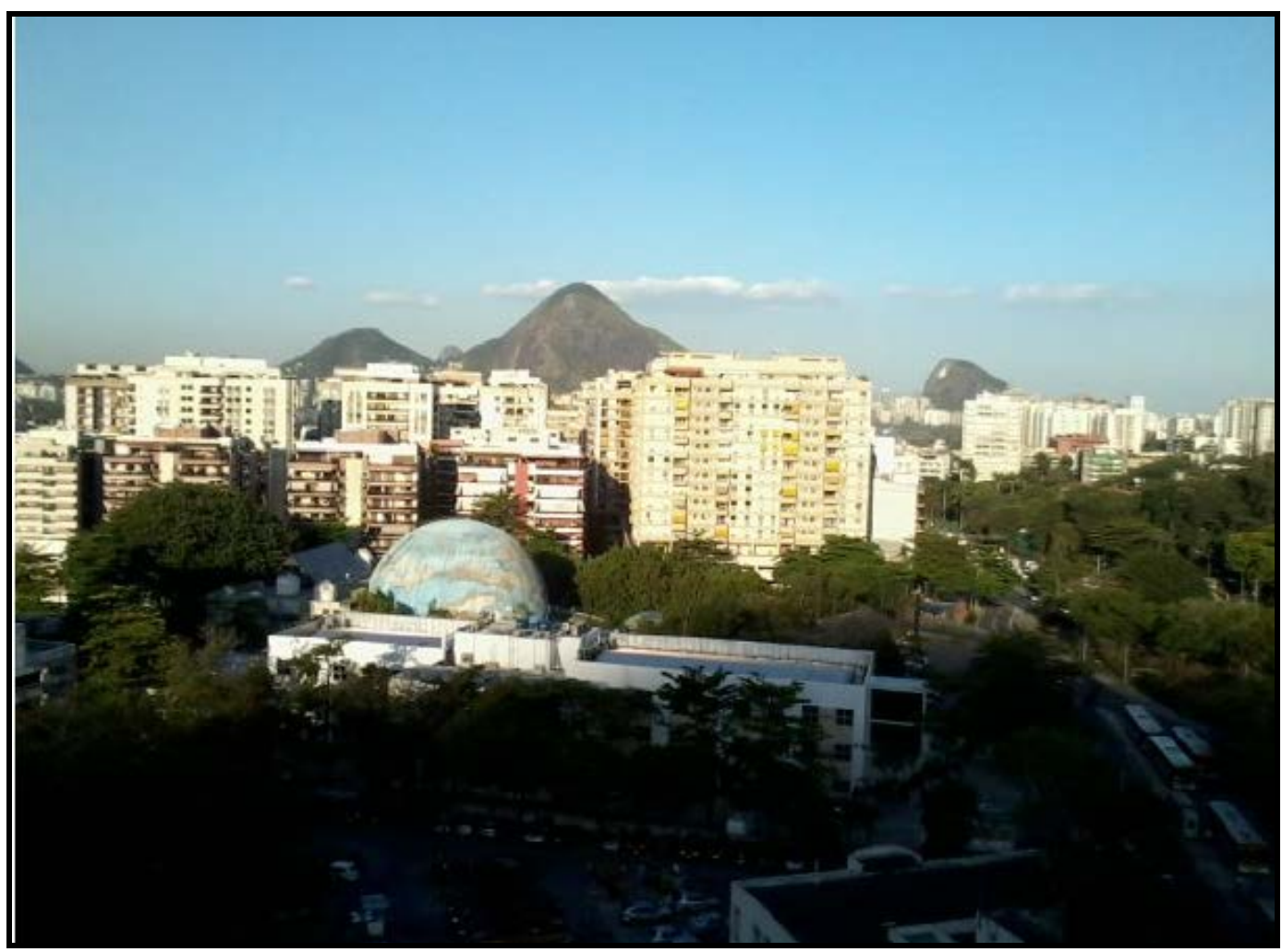

Figura 4.4: Visão frontal da antena de transmissão

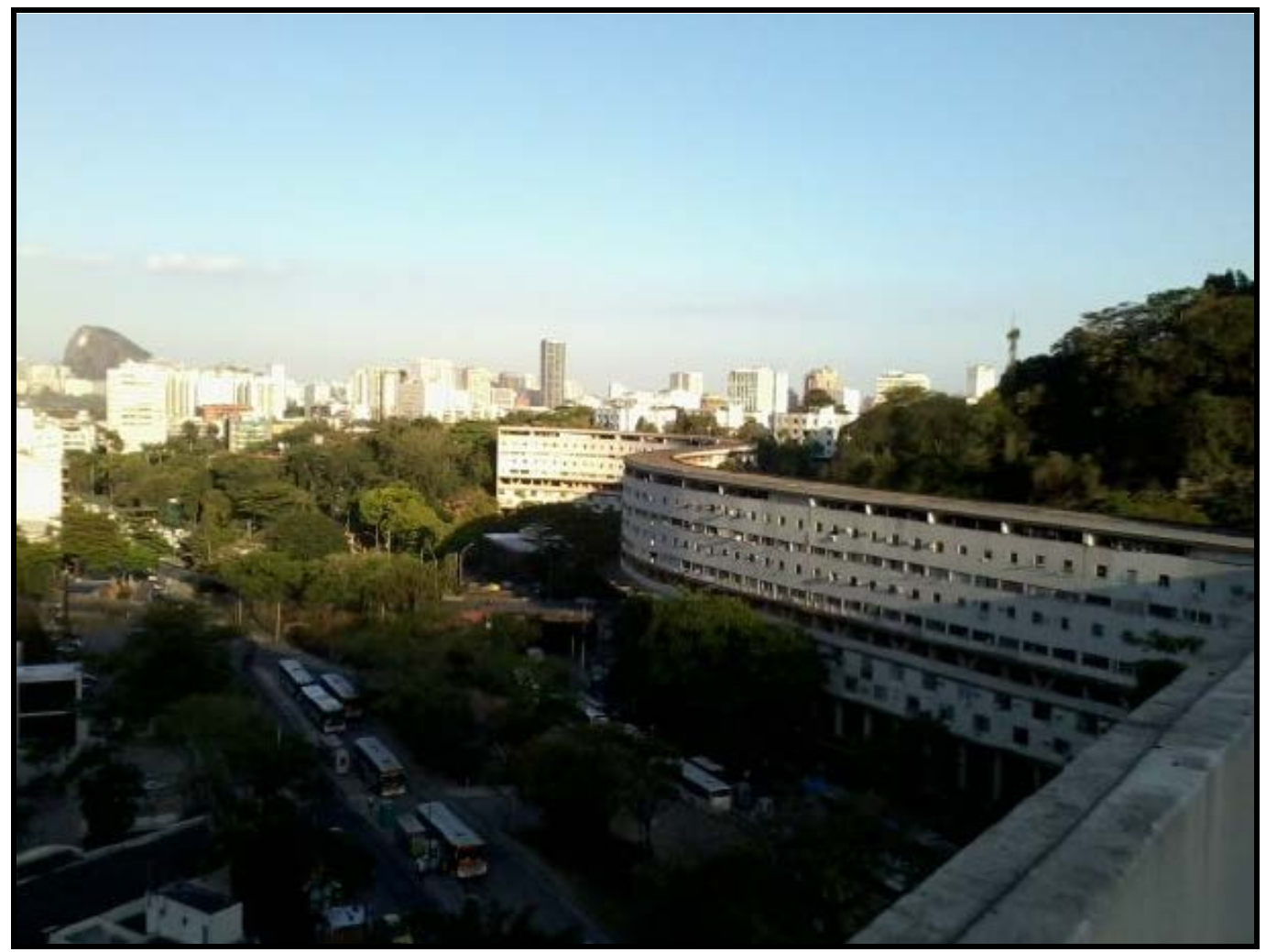

Figura 4.5: Visão $45^{\circ}$ a direita da antena de transmissão 


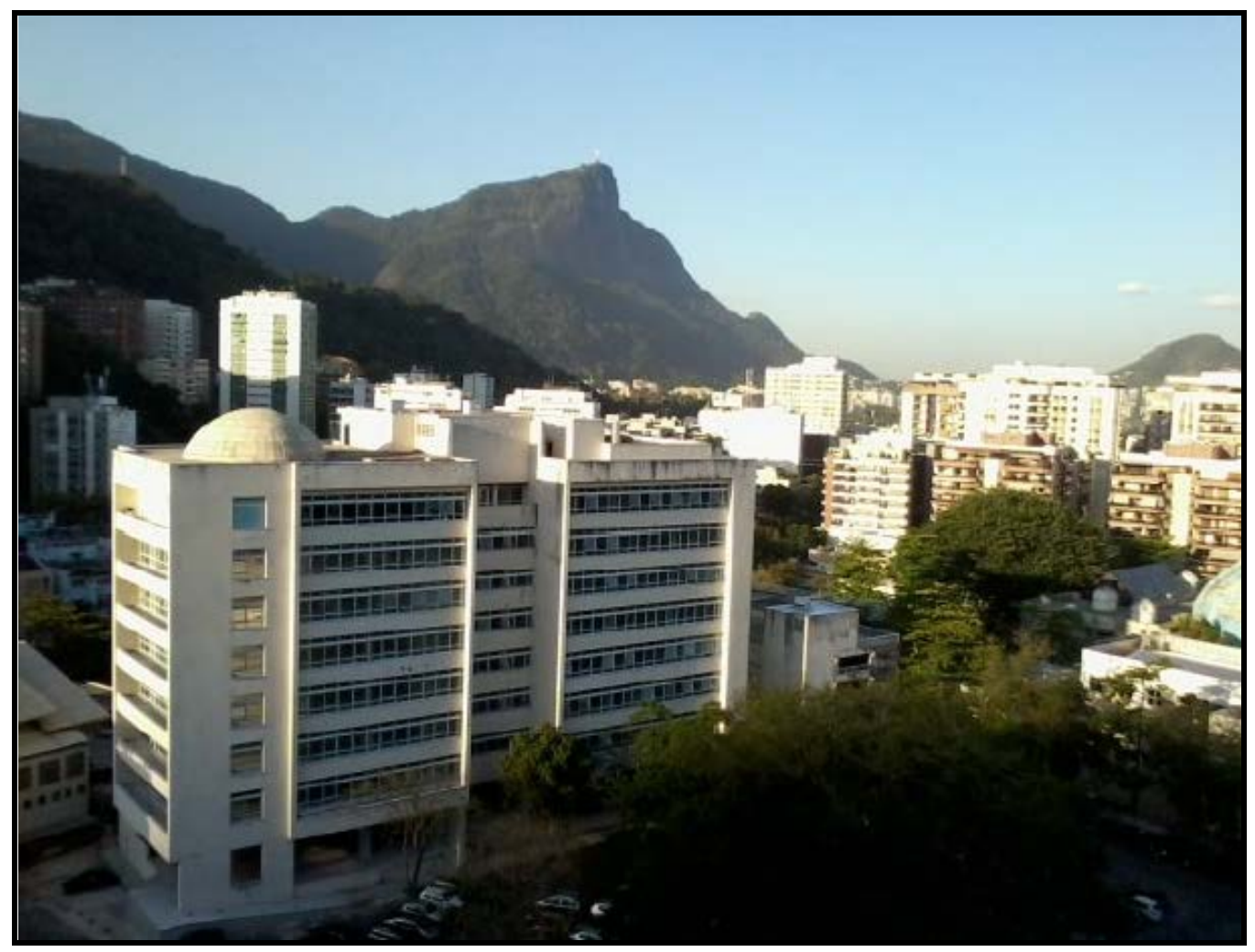

Figura 4.6: Visão $45^{\circ}$ a esquerda da antena de transmissão

De acordo com [3], de forma a se obter uma resposta de referência a partir dos equipamentos utilizados nas medições, foi gerado um sinal de calibração que servirá para compensar os efeitos nas medições dos equipamentos utilizados durante o pós-processamento. Este sinal de calibração será utilizado pela técnica CLEAN de limpeza de perfil de retardos. O sinal foi gerado no estacionamento da PUC durante um dia de domingo, minimizando possíveis efeitos adicionais por espalhadores como carros e pessoas se movimentando no ambiente. As obstruções existentes estavam distantes se comparadas com a distância das antenas transmissora e receptora. Dessa forma foi possível capturar o sinal de calibração praticamente sem multipercurso possível.

A Figura 4.7 mostra a resposta ao impulso do sinal de calibração processada em MATLAB. 


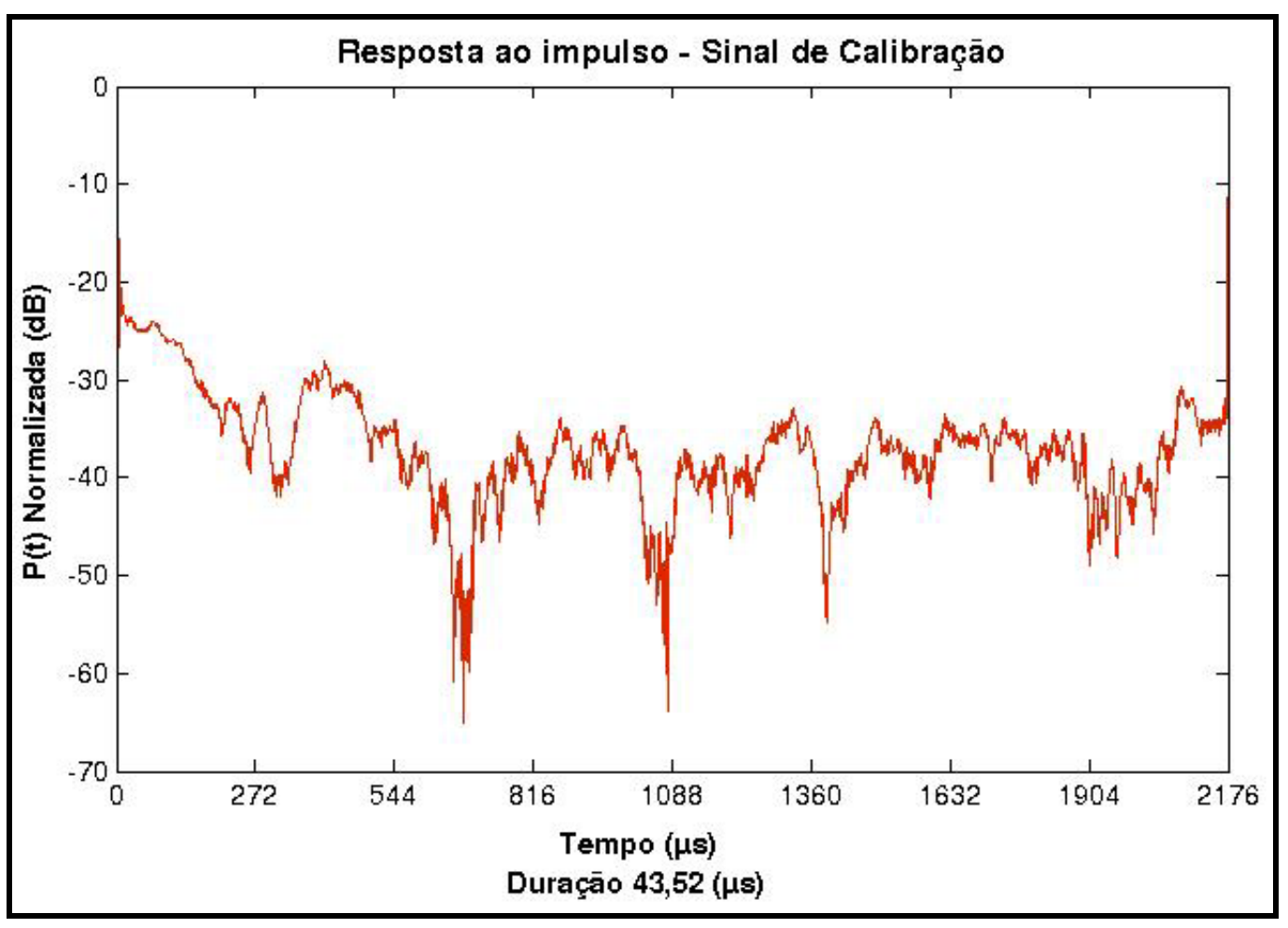

Figura 4.7: Resposta Impulsiva do sinal de Calibração $(2.5 \mathrm{GHz})$

\subsection{2}

\section{Set-up de Recepção em $2.5 \mathrm{GHz}$}

O sinal que foi gerado e transmitido no processo de transmissão deve ser capturado e tratado no processo de recepção. Foi utilizada uma unidade móvel contendo todos os equipamentos do set-up de recepção. Essa unidade móvel percorreu uma rota pré-determinada. Segue abaixo a lista de equipamentos utilizados no set-up de recepção:

- Antena Omnidirecional para recepção - Modelo RM-WLF-1C-BLK-12

- Amplificador de Baixo Ruído - ABL0800-12-3315

- Analisador Vetorial de Sinais MS2781B - Signature

- Fonte Regulada DC

- Cabos e Conectores

- GPS Garmim GPSMAP 62

Segue abaixo a Figura 4.8 que ilustra o set-up de recepção: 


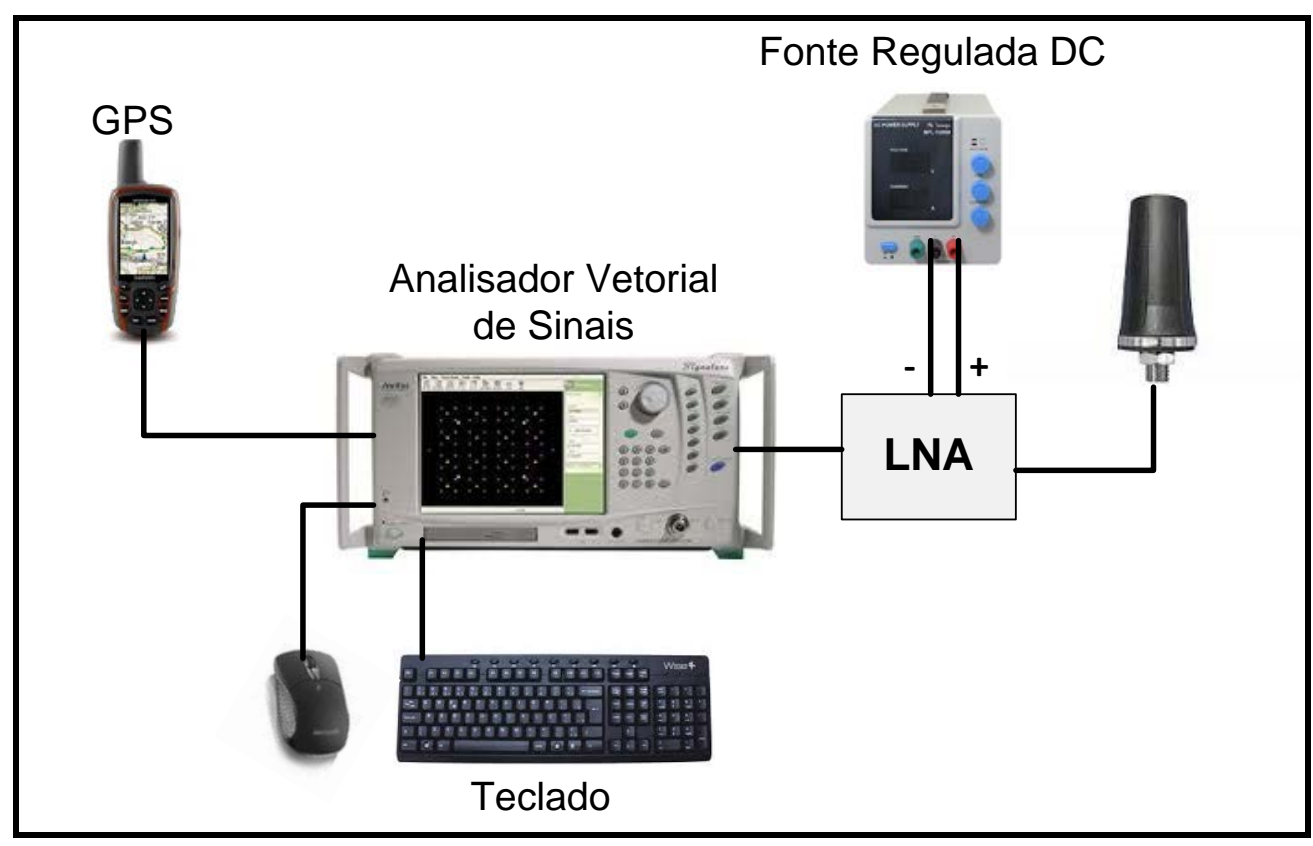

Figura 4.8: Set-up de recepção

\subsection{3}

\section{Campanha de medições em $2.5 \mathrm{GHz}$}

A campanha de medições foi realizada em outubro de 2012. A rota realizada pela unidade móvel foi a região do bairro da Gávea, conforme pode ser visto na Figura 4.9. A região em estudo pode ser considerada urbana e densa devido à quantidade de edificações com 15 andares em média, o que corresponde a uma altura dos prédios de aproximadamente $45 \mathrm{~m}$.

O percurso foi realizado com uma velocidade média de $30 \mathrm{~km} / \mathrm{h}$ podendo ser considerada constante já que no horário em que as medições foram realizadas o fluxo de veículos era reduzido.

O percurso teve início no estacionamento da PUC-Rio, seguiu no sentido lagoa Rodrigo de Freitas pela Av. Padre Leonel França e Rua Mario Ribeiro, fez o contorno pela Rua Adalberto Ferreira e Rua Tumbira, passando pelo Largo da Memória e seguindo em direção ao Jardim Botânico. Subiu a Rua Marquês de São Vicente e percorreu as quadras da região da Gávea conhecida como Baixo Gávea e em seguida retornou ao estacionamento da PUC-Rio, passando ao lado do prédio do Planetário. A Figura 4.9 mostra a rota e área de cobertura da medição. 


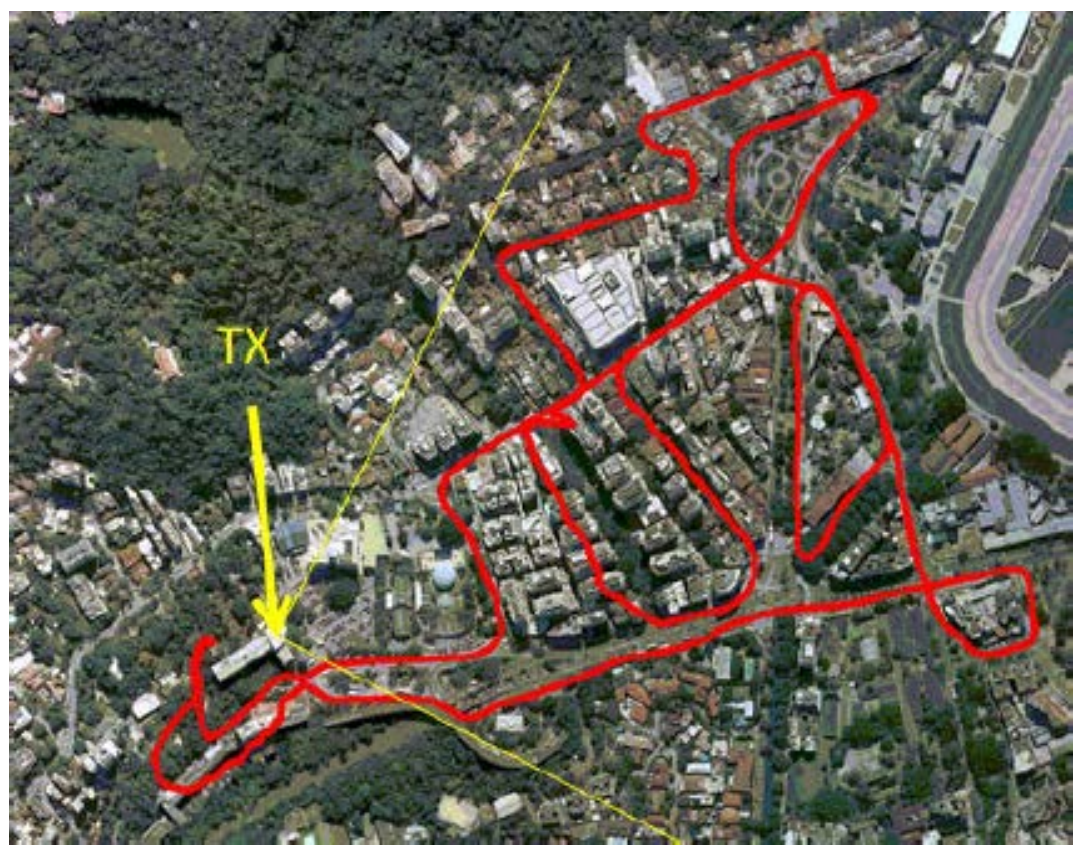

Figura 4.9: Rota das Medições - 09/10/2012

Para realizar as medições na rota da Figura 4.9 acima foi necessária a realização de duas gravações dos dados, com duração total de aproximadamente 40 minutos. A Figura 4.10 mostra, em vermelho, os pontos de medições que foram considerados válidos através da correlação do prefixo cíclico constante no sinal OFDM gerado e o sinal recebido.

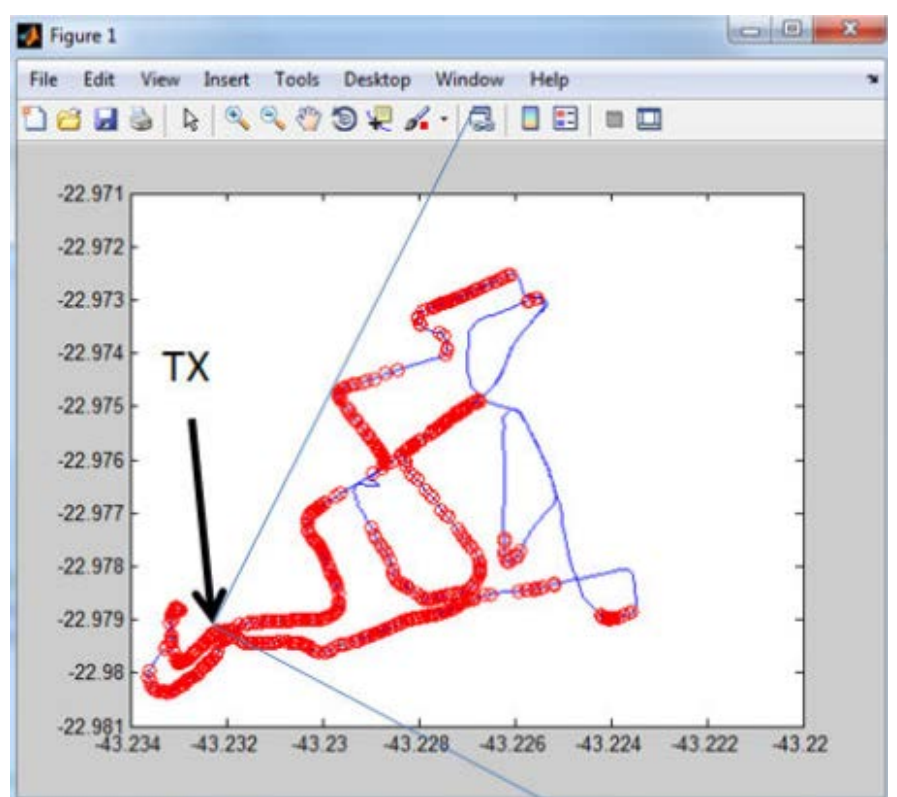

Figura 4.10: Dados Válidos da Rota do dia 09/10/2012

Em cada ponto de medida considerada como válida, ou seja, onde o sinal recebido é identificado como sendo o sinal que foi transmitido, é calculada computacionalmente a Transformada Inversa de Fourier da resposta em 
frequência do canal através da razão entre o sinal recebido e o transmitido, resultando na resposta impulsiva do canal a cada instante. As respostas impulsivas obtidas durante as medições são analisadas para que sejam determinados os parâmetros de dispersão temporal do canal causados pelo efeito de multipercurso gerado durante a propagação.

Após a limpeza dos perfis de retardo através das técnicas de limpeza, discutidas nos itens 3.3 e 3.4, os multipercursos considerados válidos serão analisados e comparados estatisticamente com a recomendação ITU-R P.1411-6.

\section{2}

\section{Medições em 3.5 GHz}

\subsection{1}

\section{Set-up de Transmissão em $3.5 \mathrm{GHz}$}

A técnica de medição das multiportadoras utilizada na campanha de medições contempla a transmissão de sinal com modulação OFDM na faixa de 3.5 GHz, seguem abaixo os equipamentos utilizados na etapa de transmissão:

- Gerador Vetorial de Sinais - Anritsu MG3700A;

- Amplificador de RF - Milmega AS0204-7;

- Antena painel - Hyperlink HG3515P-120;

- Cabos LMR-400 e LMR-600 - KMP.

A Figura 4.11 que ilustra o set-up de transmissão:

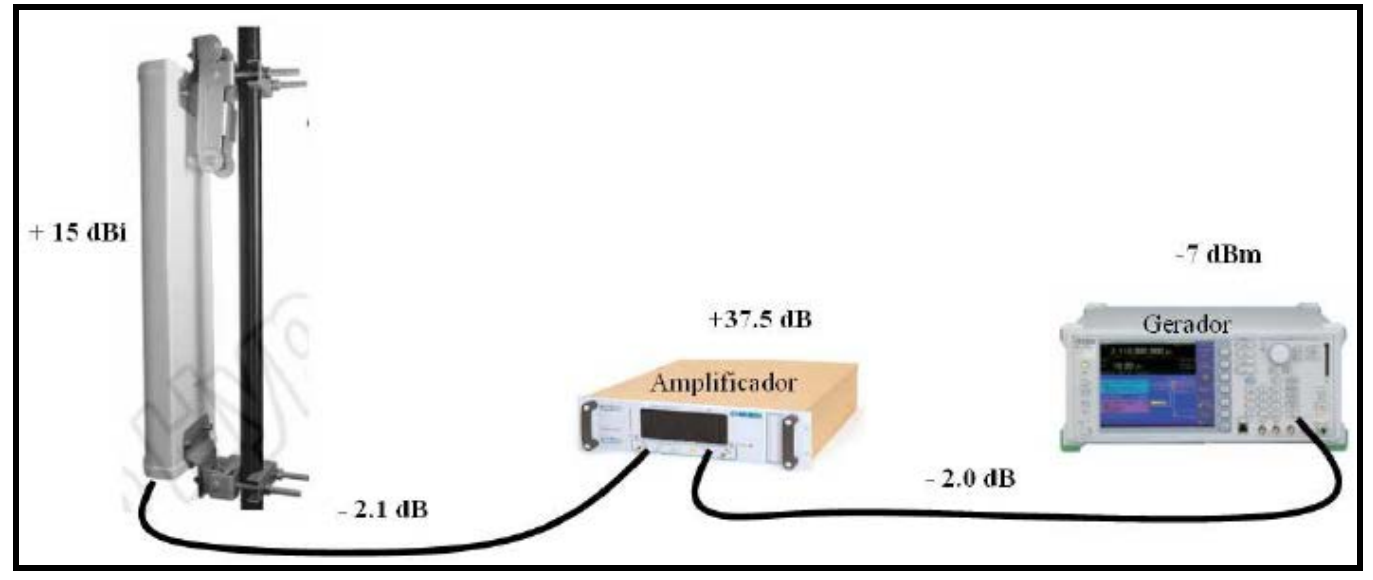

Figura 4.11: Diagrama do set-up de transmissão 
Para as medições na faixa de $3.5 \mathrm{GHz}$, a frequência central foi escolhida como resultado de uma varredura do espectro compreendido entre 3.4 e $3.6 \mathrm{GHz}$, realizada como primeira etapa da campanha de medições [3].

De forma a obter um sinal OFDM a ser utilizado na campanha de medições, foi adotado o seguinte procedimento:

- Obtenção dos vetores de fase (I) e quadratura (Q) do sinal OFDM com o software MATLAB;

- Conversão dos vetores de fase (I) e quadratura (Q) com a ferramenta IQ producer para o formato do gerador de sinais MG3700A;

- Envio de dados para o gerador de sinais.

Os parâmetros relevantes do sinal OFDM são a frequência de amostragem, o fator de amostragem, o número de pontos da Transformada de Fourier implementada com o algoritmo da FFT e o prefixo cíclico. Na tabela 4.2 é apresentado um resumo dos parâmetros dos sinais OFDM utilizados nas campanhas de medições [3]:

Tabela 4.2: Parâmetros utilizados na geração do sinal OFDM

\begin{tabular}{|c|c|c|}
\hline Parâmetro & Valor & Unidade de Medida \\
\hline Largura do Canal [BW] & 20 & $\mathrm{MHz}$ \\
\hline Tamanho da FFT [NFFT] & 1024 & amostras \\
\hline Fator de Amostragem & 2 & adimensional \\
\hline Resolução de Multipercurso & 15 & $\mathrm{~m}$ \\
\hline Prefixo Cíclico [CP] & $1 / 16$ & amostras \\
\hline
\end{tabular}

Os sinais OFDM foram gerados com a ferramenta MATLAB [18]. O sinal OFDM obtido para transmissão, no domínio da frequência, é indicado na Figura 4.12: 


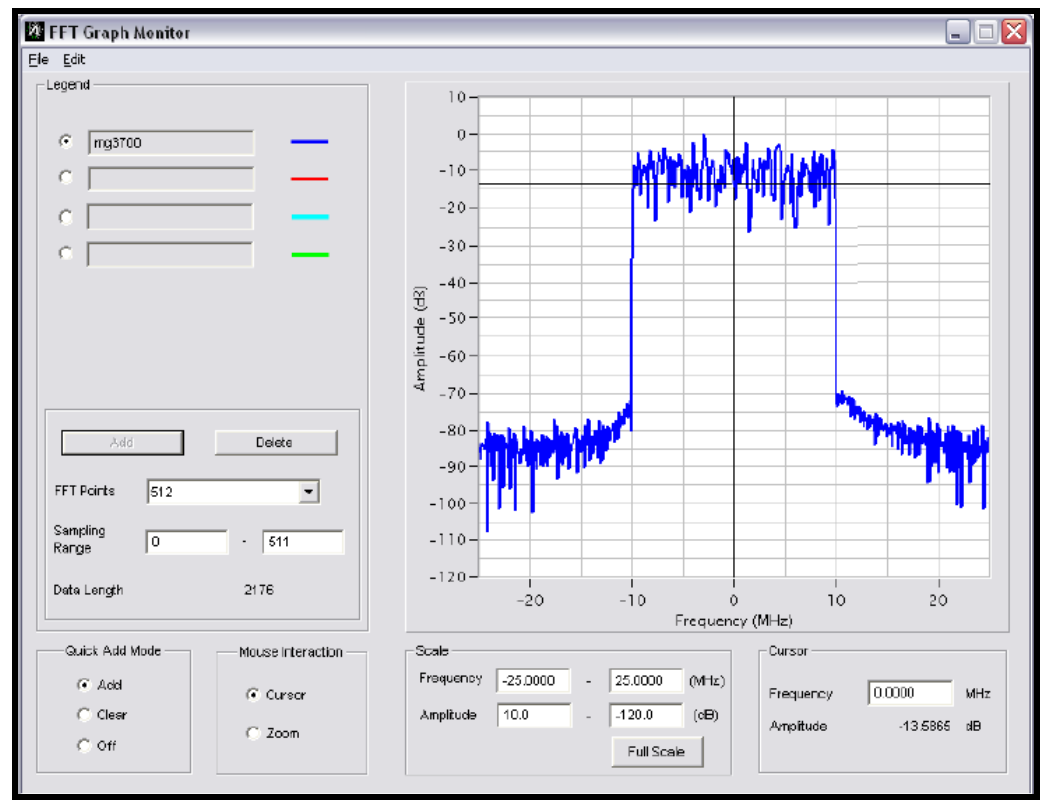

Figura 4.12: OFDM - FFT $20 \mathrm{MHz}$

O software IQ Producer da Anritsu foi utilizado no tratamento e conversão do sinal. Foi necessário inserir um intervalo gap entre cada símbolo OFDM de modo a ser possível a identificação do sinal OFDM no processo de pósprocessamento [3].

No domínio do tempo, o sinal OFDM transmitido é indicado na Figura 4.13:

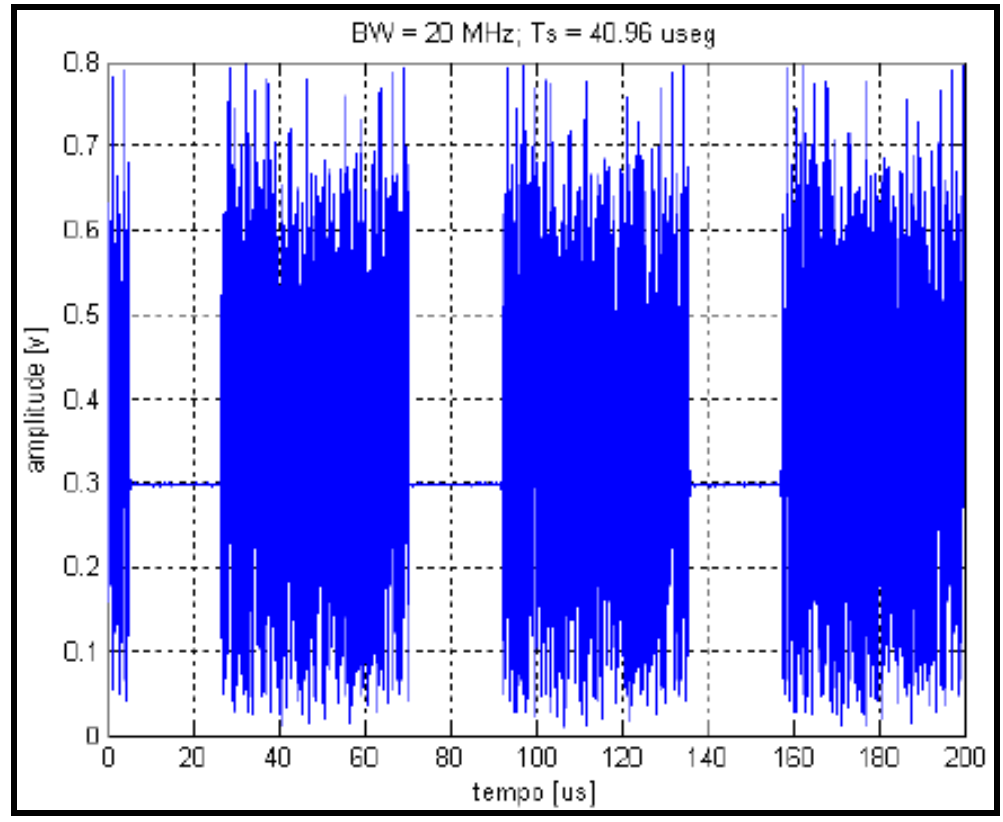

Figura 4.13: OFDM - $20 \mathrm{MHz}$ 
A instalação da antena de transmissão foi realizada na altura de 42 metros e com azimute de 90 graus em relação ao Norte Verdadeiro. Esta configuração pode ser observada nas fotos das Figuras 4.14 a 4.16 :

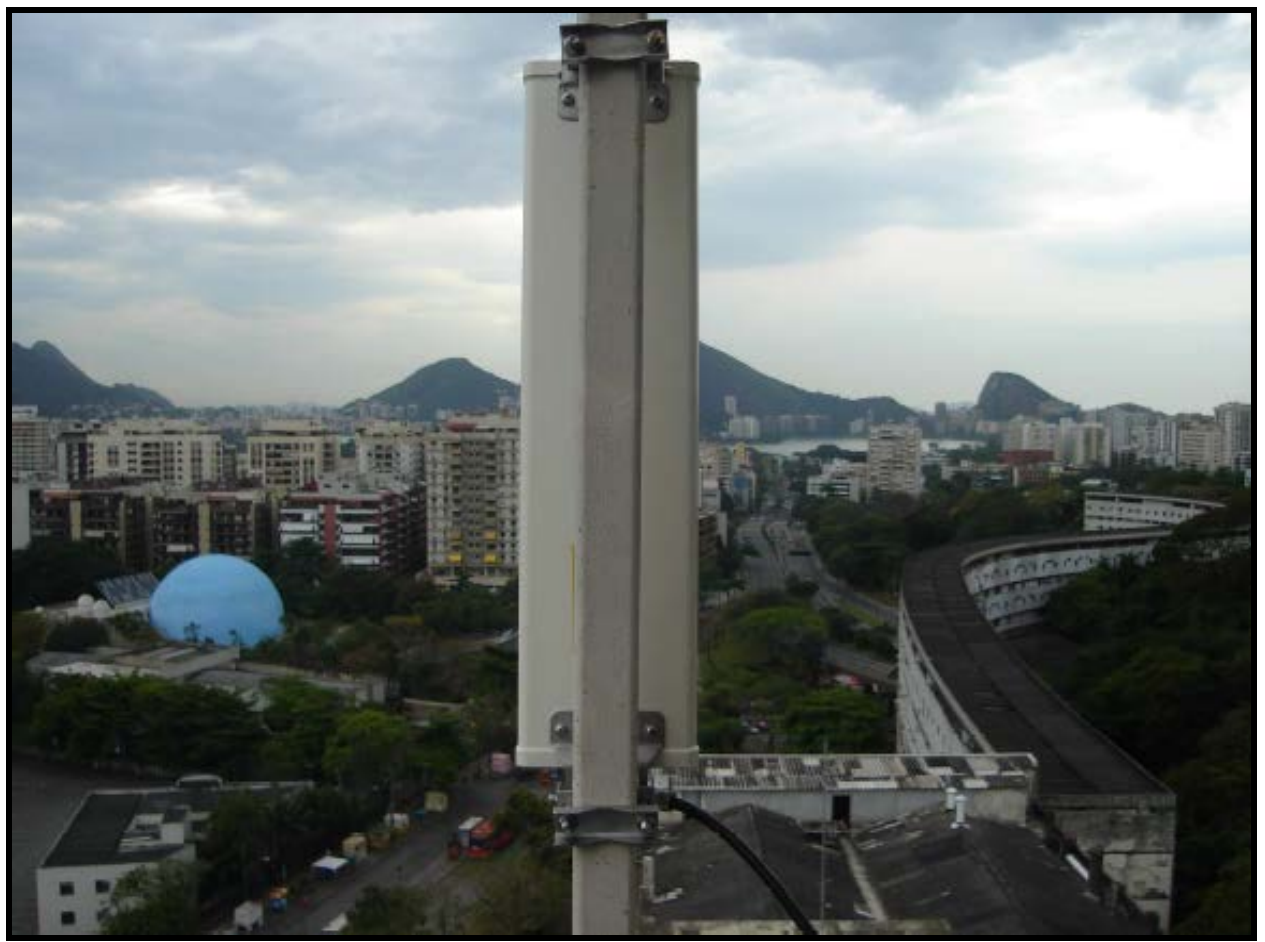

Figura 4.14: Azimute 90 graus NM

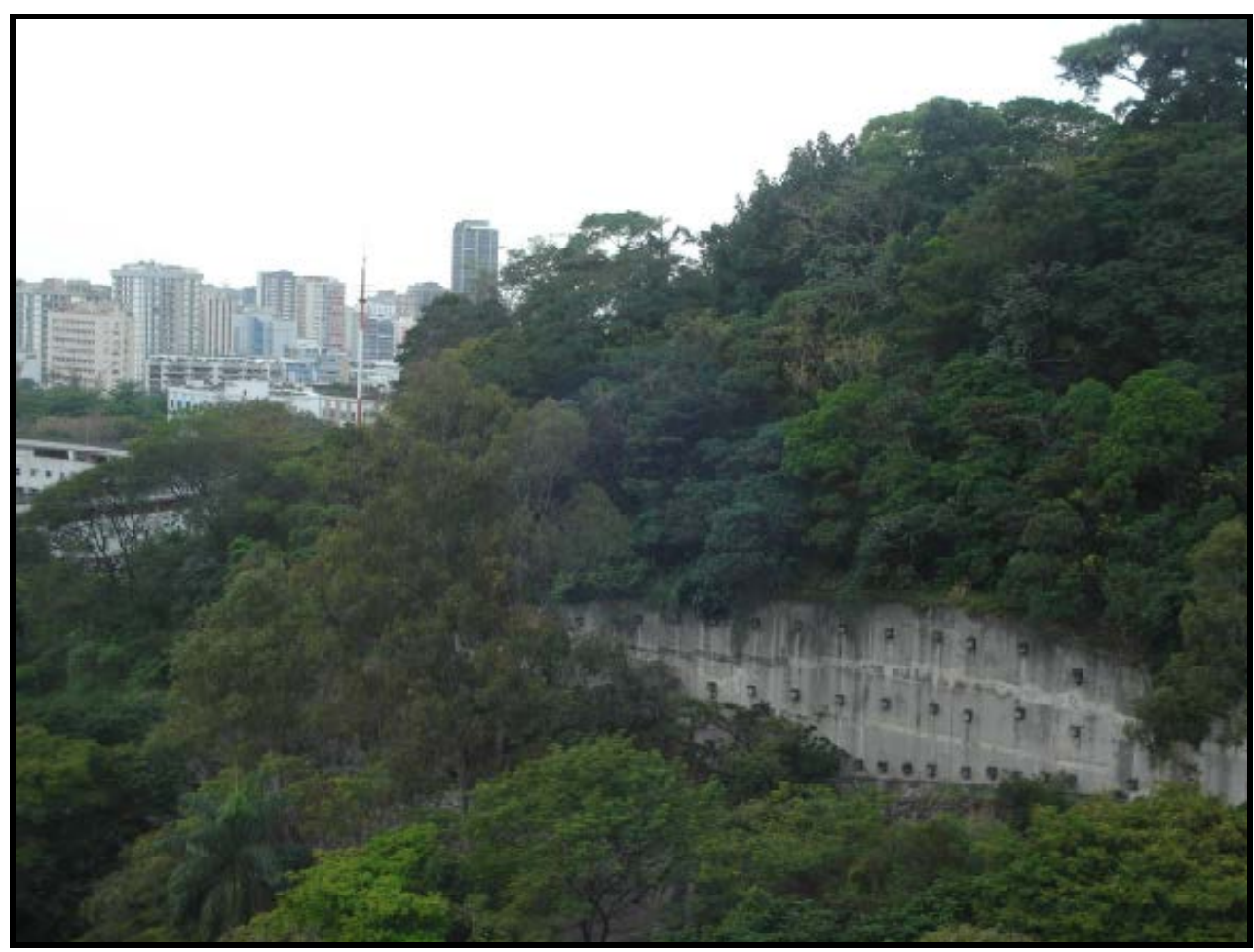

Figura 4.15: Azimute 150 graus NM 


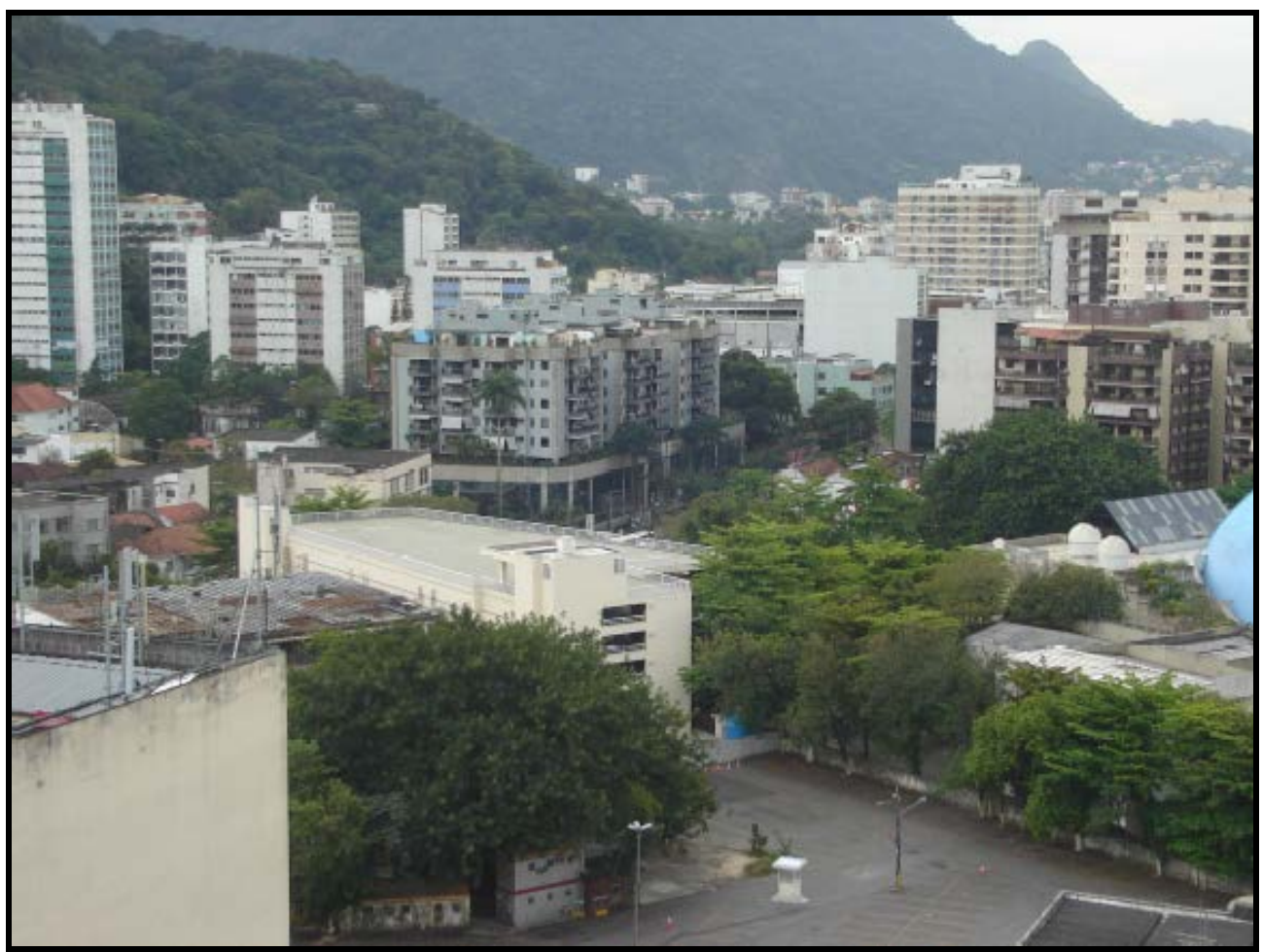

Figura 4.16: Azimute 30 graus NM

A instalação dos equipamentos de transmissão foi realizada no décimo primeiro andar do Prédio LEME da PUC-Rio como indicado na Figura 4.17 [3]:

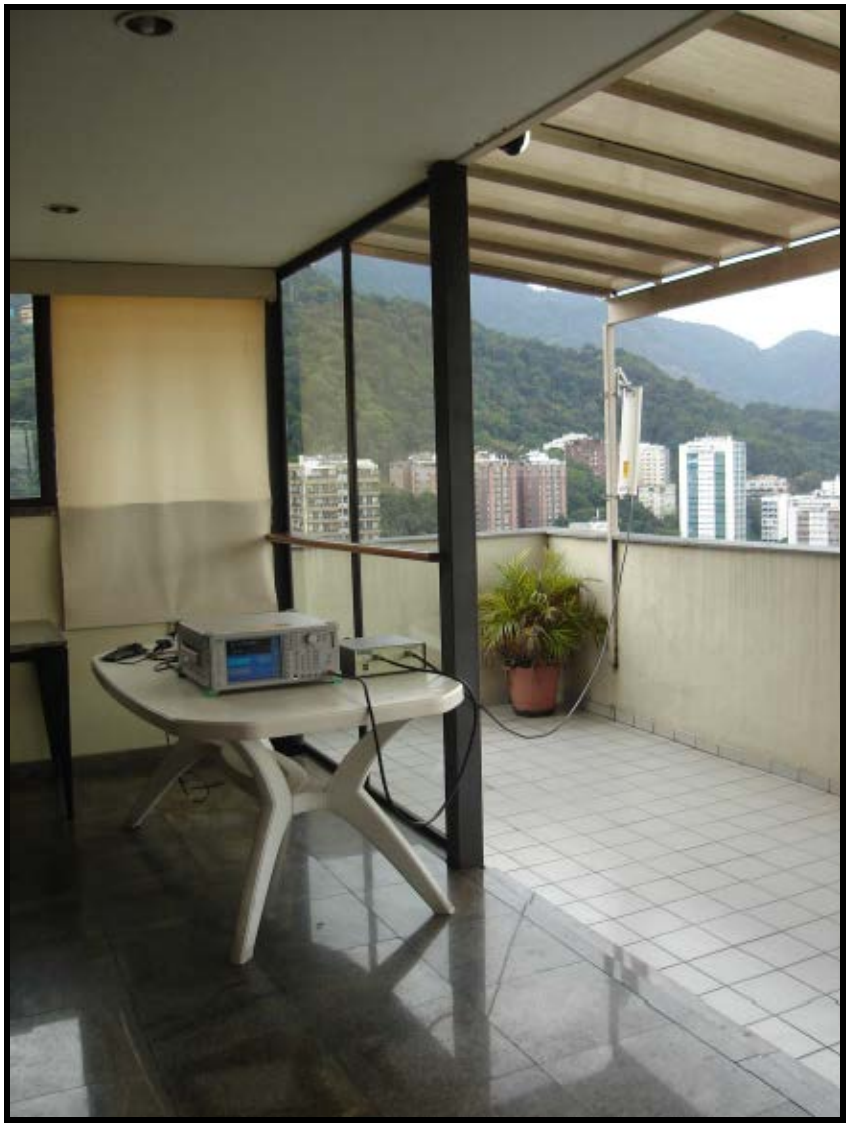

Figura 4.17: Instalação de equipamentos 
De forma a obter a resposta dos equipamentos a serem utilizados nas campanhas de medições, foi realizada uma medição em local aberto no qual o efeito de multipercurso é mínimo, para a obtenção do sinal de calibração. O cenário desta medição, realizada no campus laboratorial do Inmetro, é mostrado na Figura 4.18 [3]:

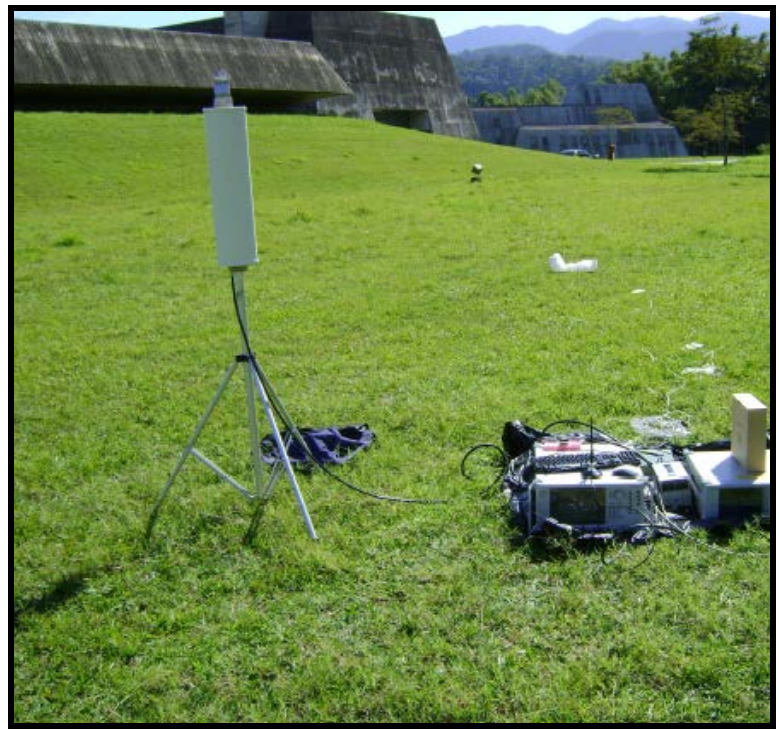

Figura 4.18: Ambiente de medições para calibração

A Figura 4.19 ilustra o sinal transmitido no teste.

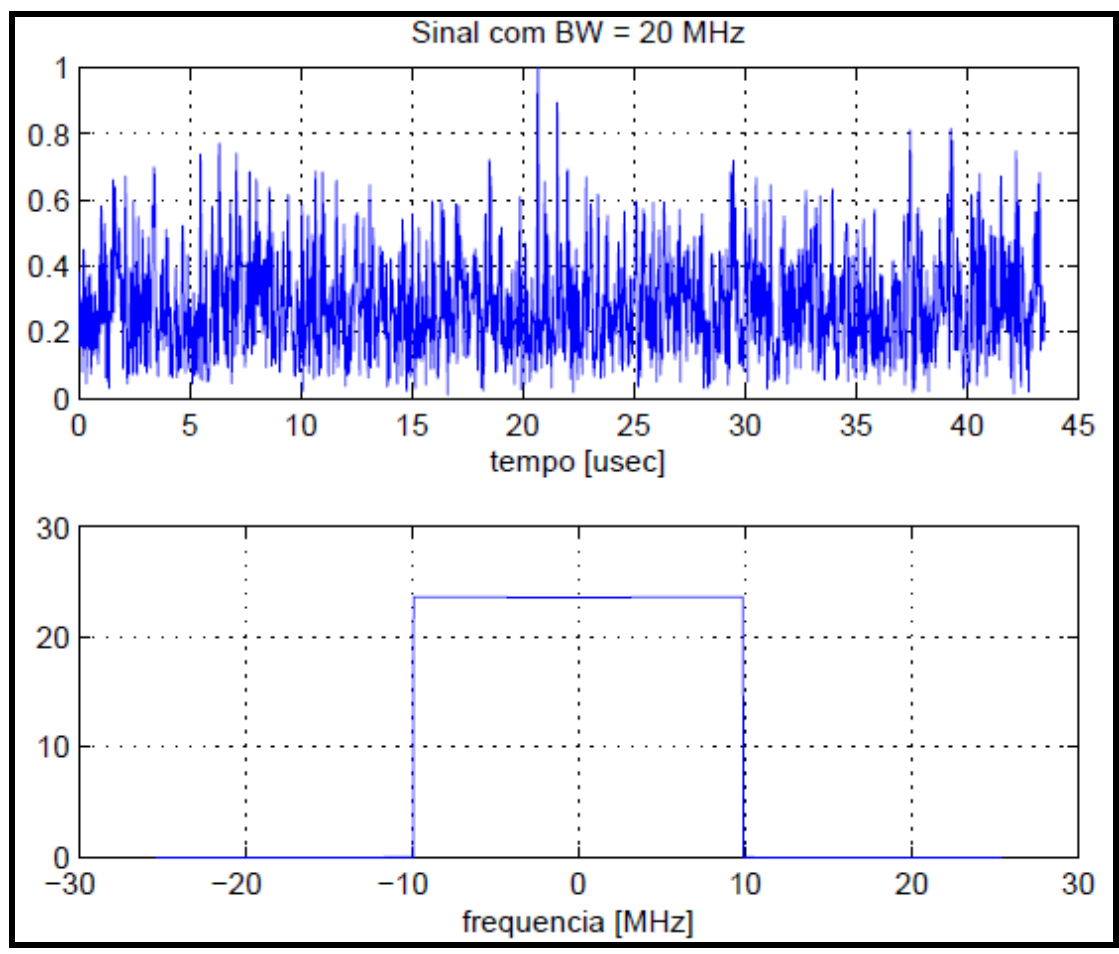

Figura 4.19: Sinal para calibração $20 \mathrm{MHz}$ 
A Figura 4.20 ilustra a resposta dos equipamentos.

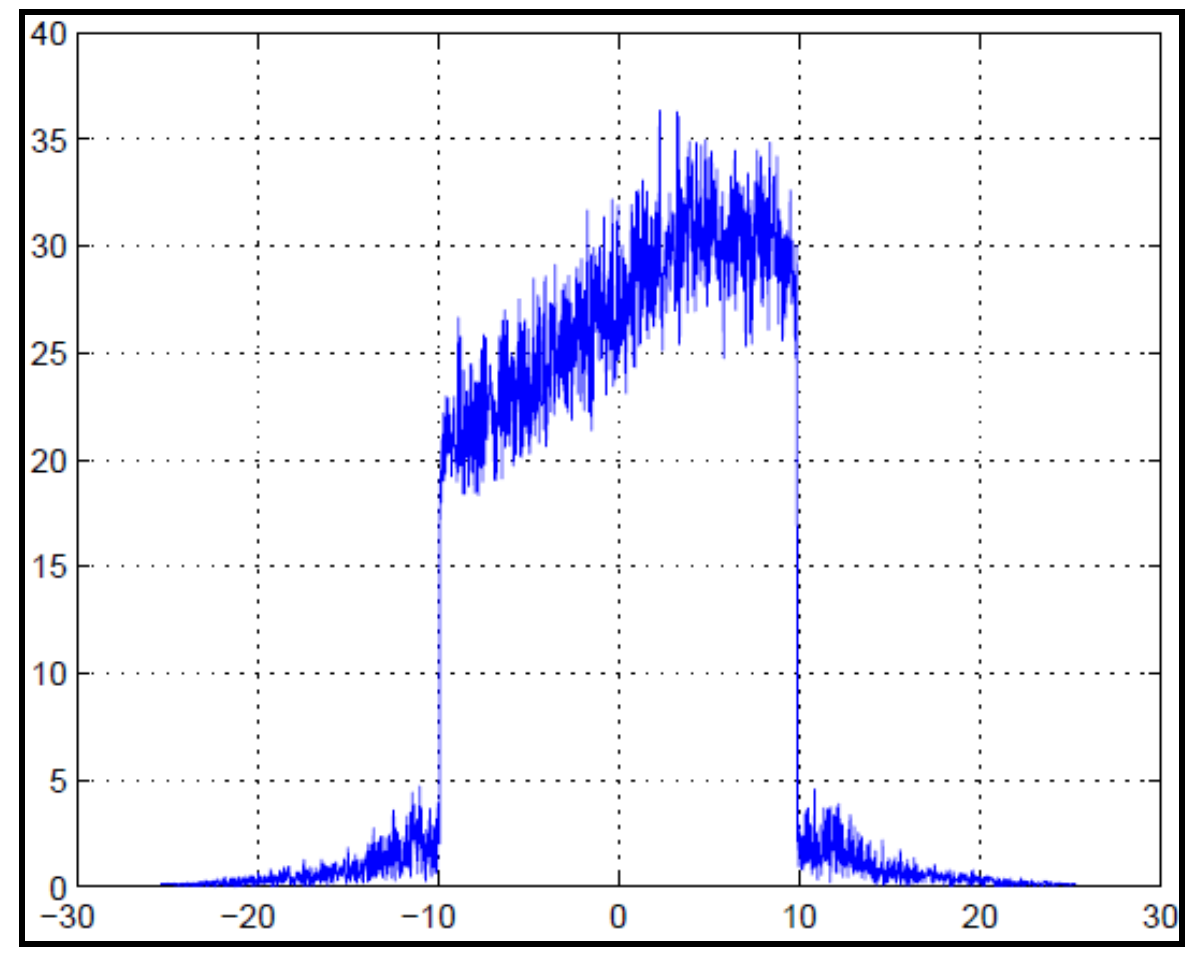

Figura 4.20: Resposta de equipamentos para $20 \mathrm{MHz}$

\subsection{2}

\section{Set-up de Recepção em $3.5 \mathrm{GHz}$}

O set-up de medição é formado pelos seguintes equipamentos:

- Analisador Vetorial de Rede - Anritsu MS2781B;

- Amplificador de baixo ruído;

- Antena Omnidirecional - Hyperlink HG3505RD-RSP;

- GPS - Garmin 60CS;

- Inversor de 800 watt;

- Cabos LMR-400 e LMR-600 - KMP. 


\subsection{3}

\section{Campanha de medida em $3.5 \mathrm{GHz}$}

As medições na faixa de $3.5 \mathrm{GHz}$ em ambiente urbano foram realizadas no bairro da Gávea com a instalação da antena transmissora acima do nível dos prédios próximos e com o objetivo de oferecer cobertura no bairro da Gávea e parte do Alto Leblon [3].

A campanha de medições teve inicio em setembro de 2008 e foi planejado um conjunto de tarefas que consideram os seguintes testes:

- Avaliação da situação espectral (Varredura de Espectro);

- Sincronismo entre ferramentas de captura (GPS e Analisador Vetorial);

- Tempos de captura e armazenamento.

De forma a identificar a faixa de frequências nas quais os testes poderiam ser realizados sem causar e nem receber interferência de outros sistemas, foi feita uma avaliação inicial com consulta do banco de dados do SITAR (Sistema de Informações Técnicas para Administração das Radiocomunicações) da Anatel (Agência Nacional de Telecomunicações), complementada com medições em campo [3].

A consulta no banco de dados do SITAR foi realizada por meio da entrada das coordenadas geográficas do prédio Cardeal LEME (medida com GPS) e da faixa de frequências válidas para os equipamentos de medição (3.4 a $3.6 \mathrm{GHz}$ ). Foi selecionado um raio de 20 quilômetros em torno do prédio [3].

Como resultados da consulta ao banco de dados do SITAR realizada em 12 de setembro de 2008, foram encontrados, conforme apresentado na Figura 4.21, sistemas licenciados operando na região nas seguintes faixas de frequência. 


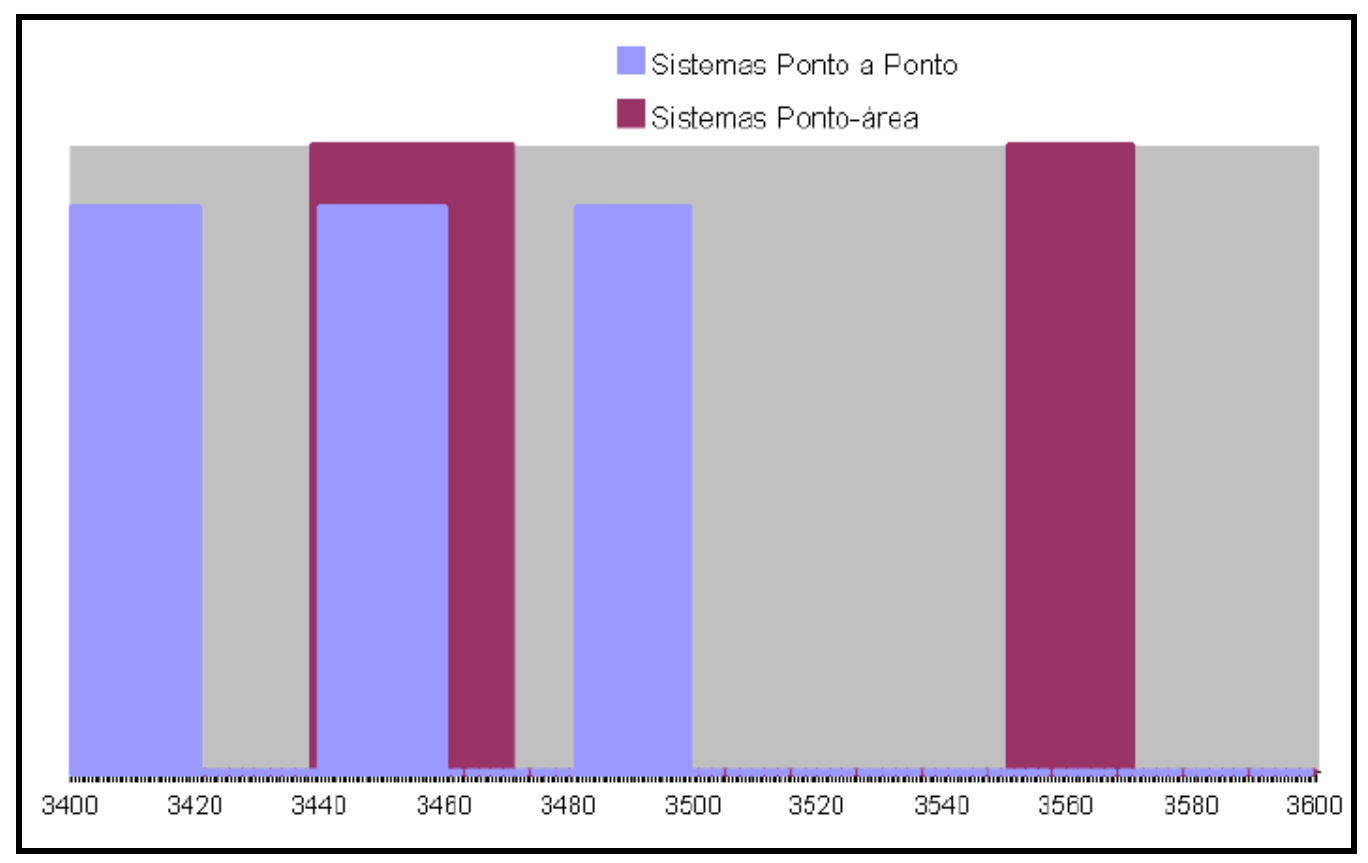

Figura 4.21: Consulta SITAR - Sistemas ponto-a-ponto e ponto-área

Na figura 4.21 observamos que existem várias regiões do espectro livres para solicitação de uso. Em seguida a este primeiro estudo, foram realizadas as medições em campo de forma a selecionar, nas regiões livres identificadas, quais apresentavam o menor ruído interferente [3].

Para a realização de medições foi utilizado o analisador vetorial no modo de analisador de espectros. Usando uma interface em MATLAB, foi preparado um programa que permitia capturar a situação do espectro (em 512 pontos) a cada segundo. Da mesma forma foram realizadas medições com o software de interface com o GPS. De forma a associar os dois arquivos resultantes (GPS e captura), foi sincronizado o relógio do Sistema Operacional do Analisador Vetorial MS2781B com o do GPS [3].

A rota seguida nesta medição é indicada na Figura 4.22 abaixo: 


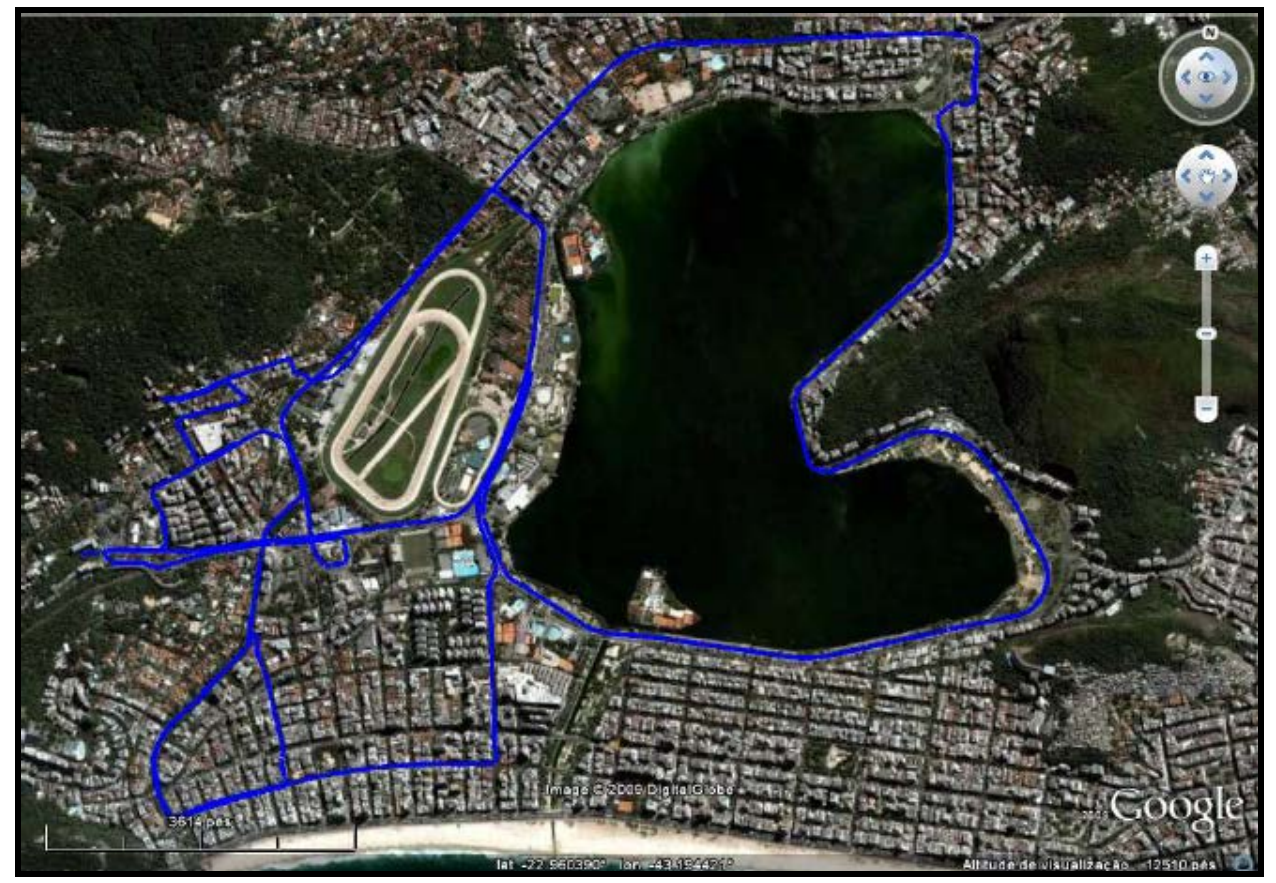

Figura 4.22: Rota realizada para varredura de espectro

Um resumo acumulado de toda a medição apresenta, na Figura 4.23, a ocupação do espectro em toda a área medida. Os valores de sinal apresentados representam a potência média de entrada no analisador vetorial, ou seja, foram compensados com os ganhos dos elementos do set-up de medições (31 dB) [3].

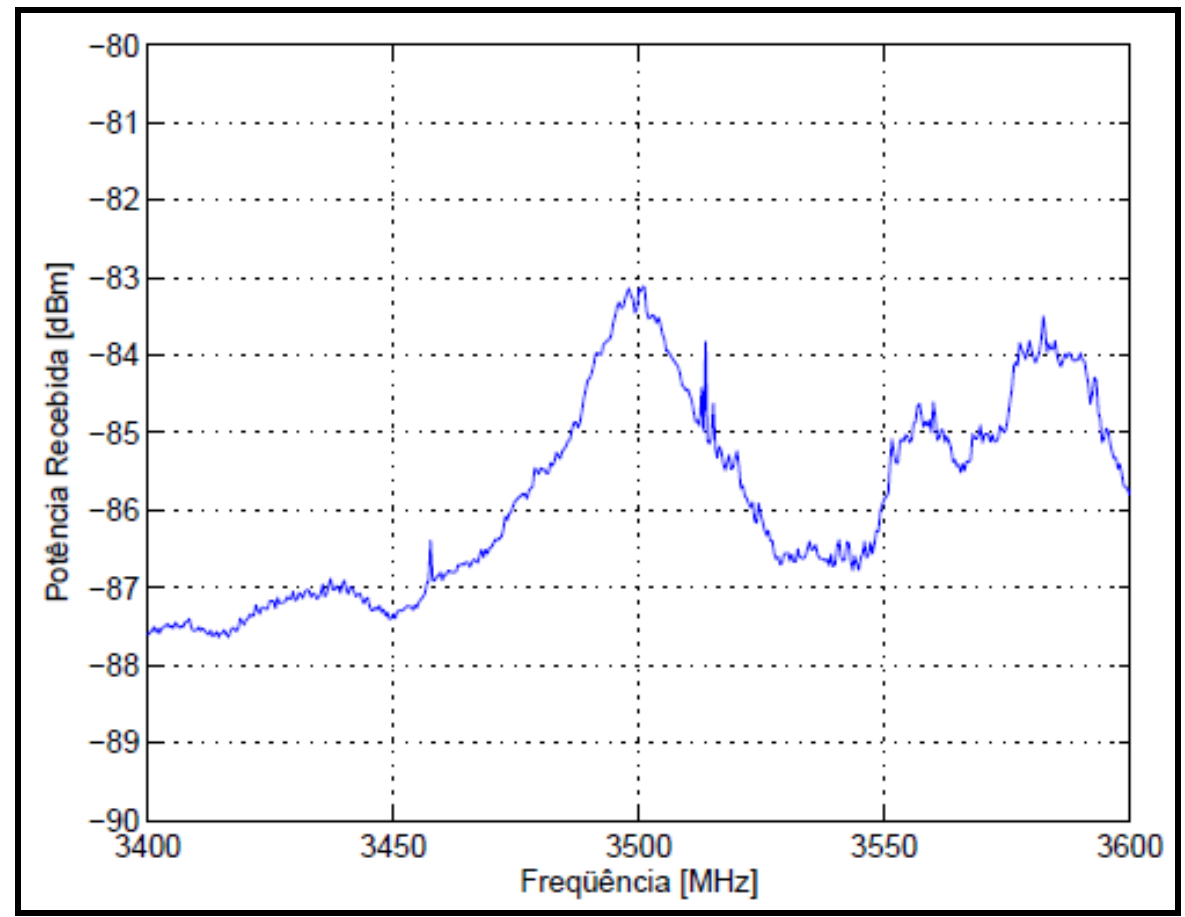

Figura 4.23: Varredura de espectro 
Como pode ser observado na figura 4.23, a região com os mais baixos níveis de potência recebida compreende a faixa de frequências entre $3400 \mathrm{MHz}$ e 3420 MHz. Entretanto, como visto na figura 4.21, esta parte do espectro estava sendo utilizada por outro sistema. De forma a prevenir que uma eventual interferência afete o sistema de medições em pontos específicos do percurso, foi selecionado um segmento de frequências livres no banco de dados do SITAR que também apresentou baixos níveis de ruído na varredura de espectro. Esta seleção compreende as frequências entre $3420 \mathrm{MHz}$ e $3440 \mathrm{MHz}$. Nesta faixa, o resultado da ocupação do espectro, em função da coordenada geográfica é indicado na Figura 4.24 .

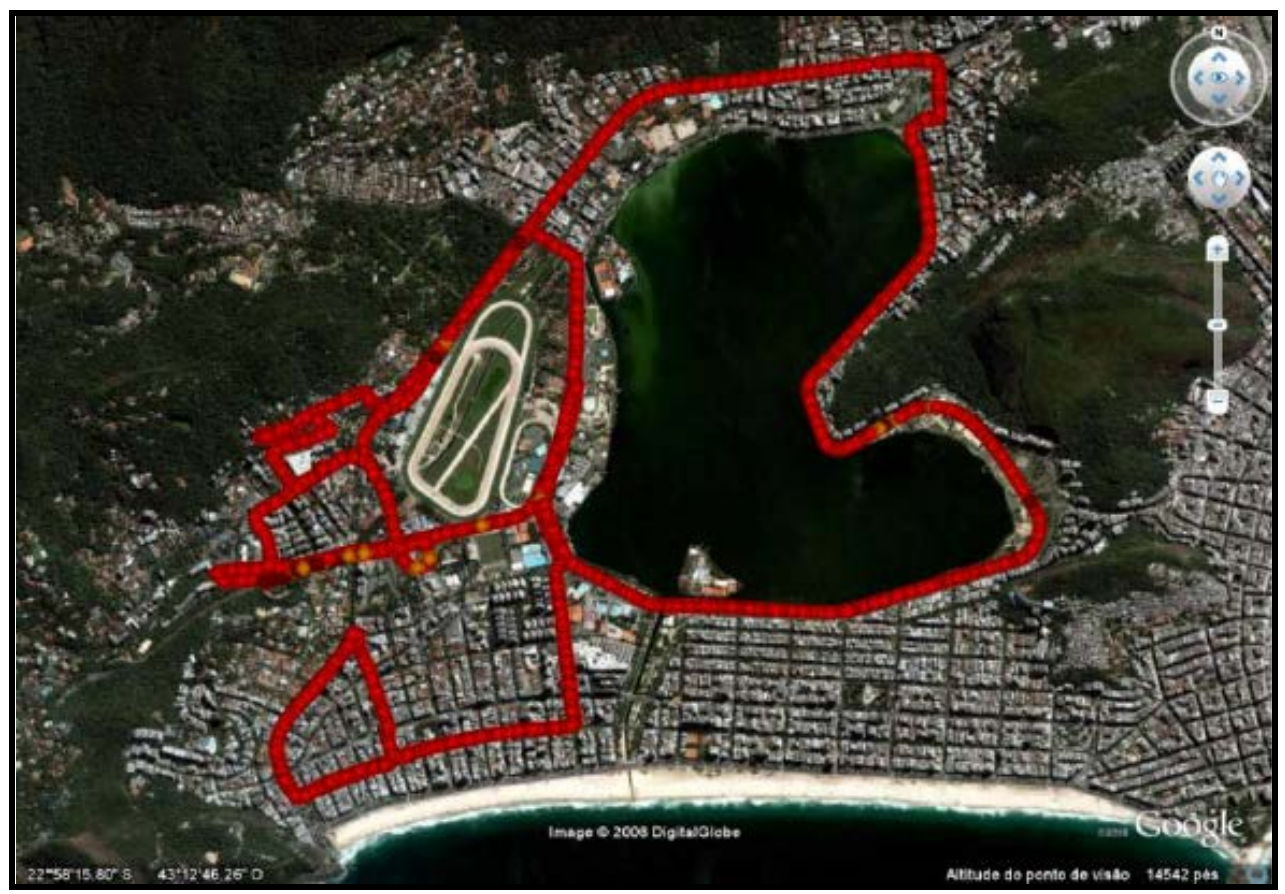

Figura 4.24: Ocupação de espectro

Nesta figura a cor laranja representa o sinal medido mais intenso com $-77.81 \mathrm{dBm}$ e a cor vermelha o sinal mais fraco com valor de $-102.199 \mathrm{dBm}$ [3].

Por se tratar de uma faixa de frequências na qual é necessária autorização de uso, foi solicitada à Anatel uma licencia temporária de uso para a frequência selecionada para fins científicos. A licença foi obtida para a PUC-Rio como Autorização de Uso Temporário de Radiofrequências, conforme ATO N. 5871 de 02 de outubro de 2008. Este ato encontra-se em [3].

Considerando os erros de medida do GPS, foi gerada manualmente uma rota de medição no mapa geográfico. Os dados das coordenadas geográficas medidas 
com o GPS mostram que a maior parte das medições tem um erro médio de 8 metros. Com base neste valor foram agrupadas nas coordenadas da rota de medição todas as medições compreendidas num entorno de 8 metros de raio. A rota resultante é apresentada na Figura 4.25 a seguir [3]:

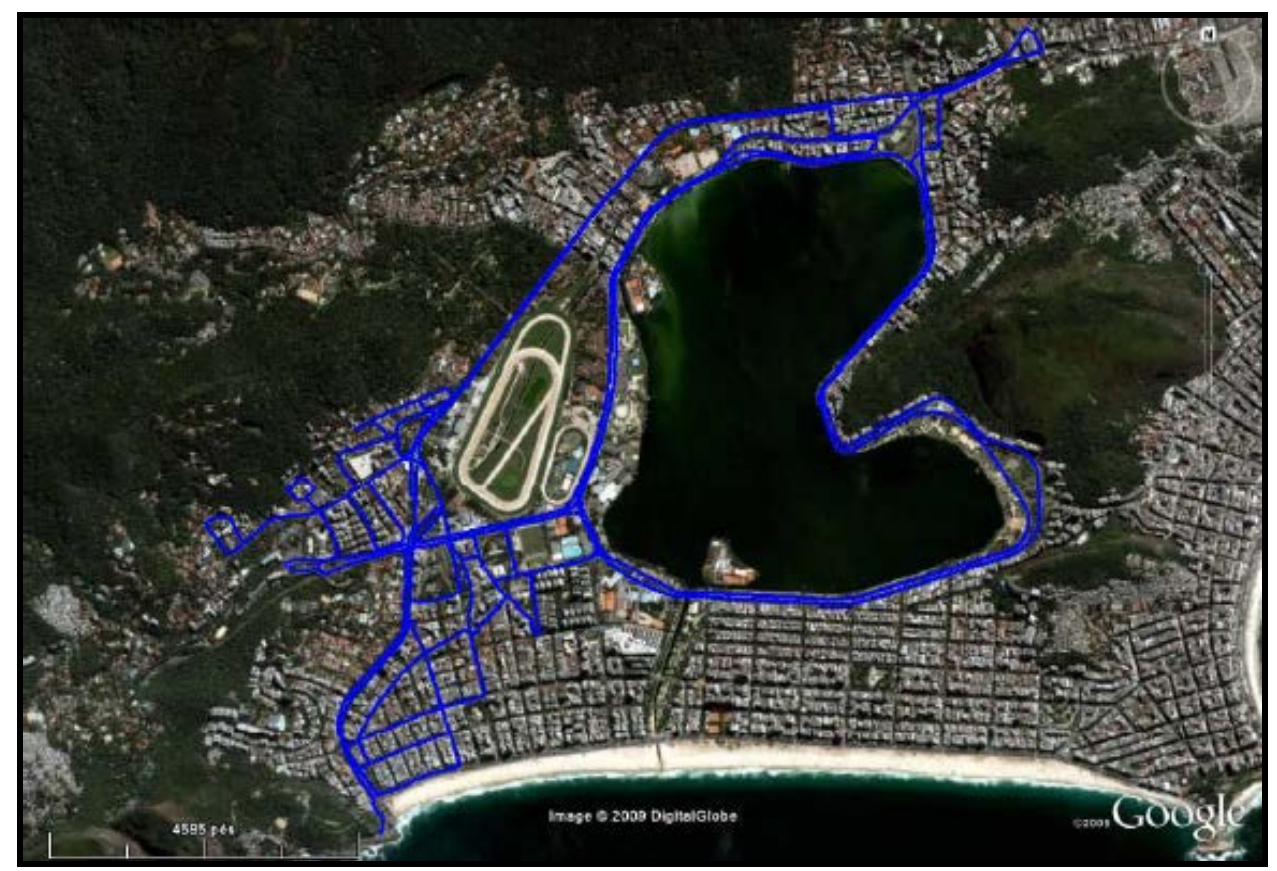

Figura 4.25: Rota realizada para Medições

O local selecionado para o set-up de transmissão foi o décimo segundo andar do prédio LEME da PUC-Rio [3].

\section{3}

\section{Equipamentos utilizados nas campanhas de medição}

Nesse item serão descritos todos os equipamentos utilizados nas medições nas faixas de frequências de $2.5 \mathrm{GHz}$ e $3.5 \mathrm{GHz}$.

\subsection{1}

\section{Analisador de Espectro de Frequência}

Para que as medições possam ser realizadas é necessária a análise do espectro de frequência de forma a descobrir qual é a melhor "janela” de faixa de frequência a ser utilizada de forma a não interferir em outros sistemas existentes 
na região em estudo. Dessa forma foi realizada uma varredura do espectro de frequência em um raio de aproximadamente $5 \mathrm{~km}$ a partir do local onde foi instalada a antena transmissora para a partir desse ponto ser feita a escolha da faixa de frequência a ser utilizada. Foi utilizado o analisador de espectro portátil FSH3-6-18 da marca ROHDE \& SCHWARTZ, ilustrado na Figura 4.26 a seguir.

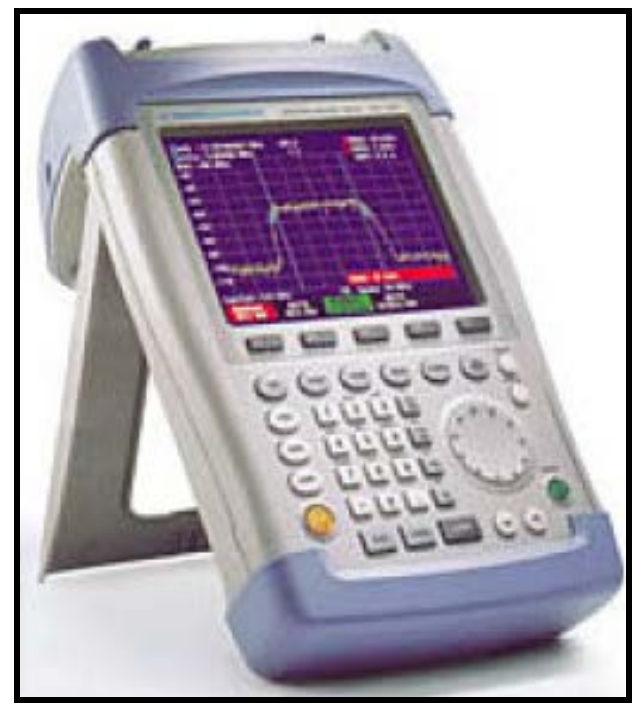

Figura 4.26: Analisador de Espectro Rodge \& Schwartz

\subsection{2}

\section{Gerador de Sinais MG $3700^{\mathrm{a}}$}

O sinal OFDM de $20 \mathrm{MHz}$, que foi gerado no MATLAB e convertido para o formato .wvi pelo IQ Producer da Anritsu, foi transmitido para o gerador de sinais MG 3700A da Anritsu, ilustrado na Figura 4.27, através de cabo de rede utilizando uma conexão ethernet. A frequência central de transmissão utilizada foi de $2.487 \mathrm{GHz}$.

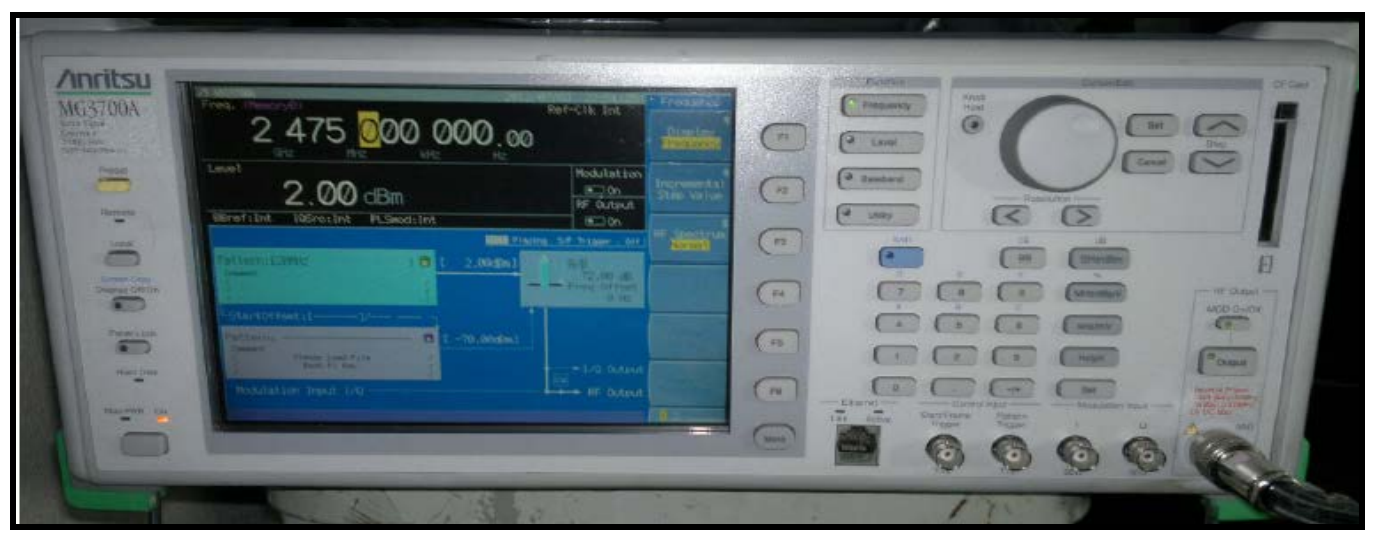

Figura 4.27: Gerador de Sinais MG 3700A 


\subsection{3}

\section{Amplificador de potência}

Foi utilizado para amplificar o sinal gerado pelo MG 3700A o amplificador de potência Milmega AS0204-7B de 7W, ilustrado na Figura 4.28, que opera na faixa de frequência de 2 a $4 \mathrm{GHz}$.

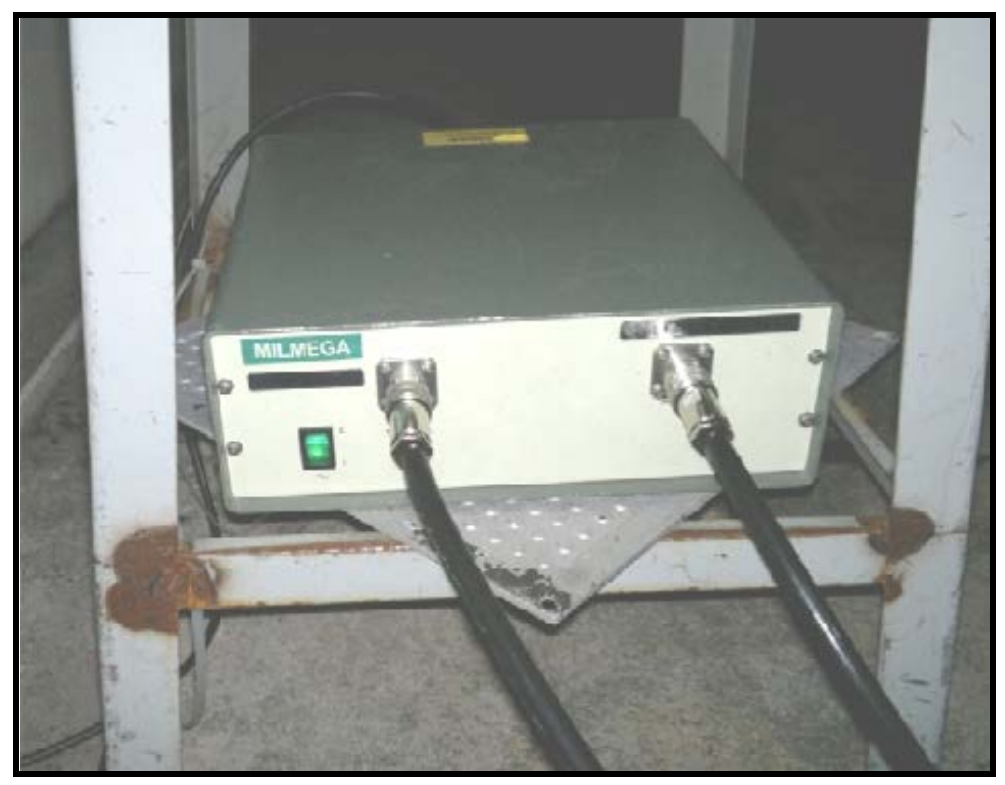

Figura 4.28: Amplificador de Potência Milmega AS0204-7B 7W

Para que seja possível utilizarmos o amplificador tendo o melhor desempenho e sem que ocorra a saturação do amplificador, faz-se necessário traçarmos a sua curva de linearidade, ou seja, para qual faixa de níveis de potência em dBm de entrada o amplificador tem uma resposta em potência na saída com comportamento linear. Quando o amplificador deixa de aumentar o nível de potência de saída na mesma proporção em que o sinal de entrada aumenta a sua potência, isso significa que o mesmo está saturando. Dessa forma, foram traçadas as curvas de linearidade, ilustradas na Figura 4.29 e 4.30, para as faixas de 2.5 $\mathrm{GHz}$ e $3.5 \mathrm{GHz}$ respectivamente. Para a faixa de $2.5 \mathrm{GHz}$ a frequência central utilizada para gerar a curva de linearidade foi de 2,487 GHz. Além da curva de linearidade, foi determinado experimentalmente o ganho real produzido pelo amplificador, tendo como entrada o sinal OFDM utilizado durante as campanhas de medições. Nesse caso, o valor encontrado foi de $46 \mathrm{~dB}$ de ganho com a potência máxima de entrada de $-15 \mathrm{dBm}$ de acordo com a curva de linearidade 
gerada para que não ocorra saturação. Para a faixa de $3.5 \mathrm{GHz}$ foi utilizado um atenuador de $30 \mathrm{~dB}$, cabos de RF do tipo LMR-400. A potência de entrada para o amplificador de forma a permanecer na região linear de operação é de -9 dBm [3].

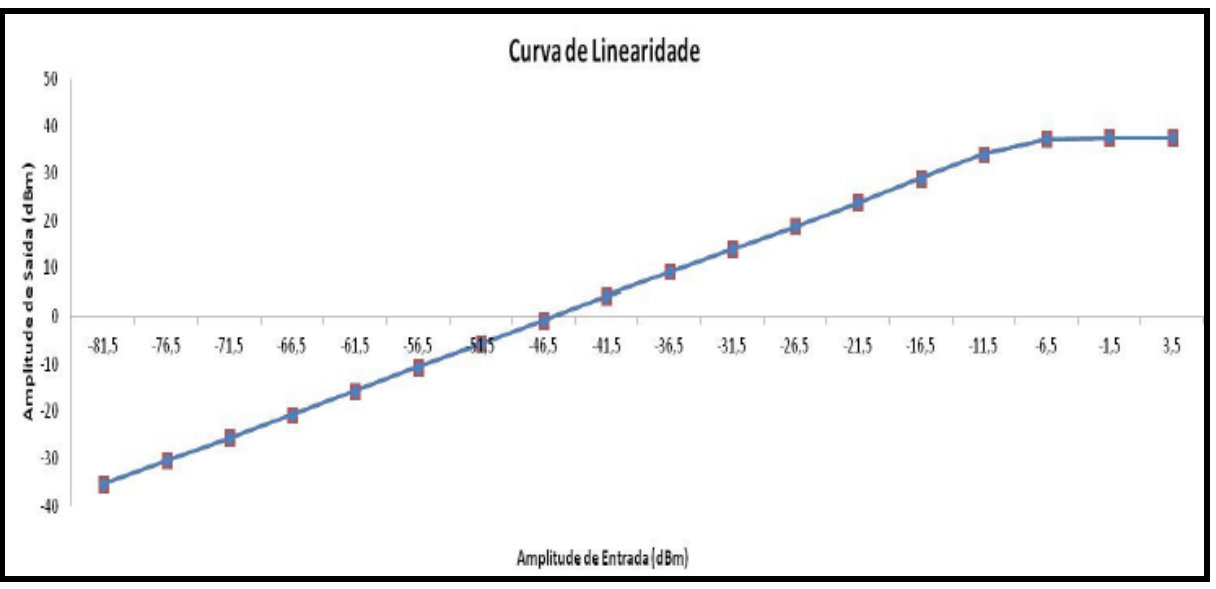

Figura 4.29: Curva de Linearidade do Amplificador Milmega (2.5 GHz)

A Figura 4.30 mostra a curva de linearidade do amplificador para a faixa de $3.5 \mathrm{GHz}[3]$.

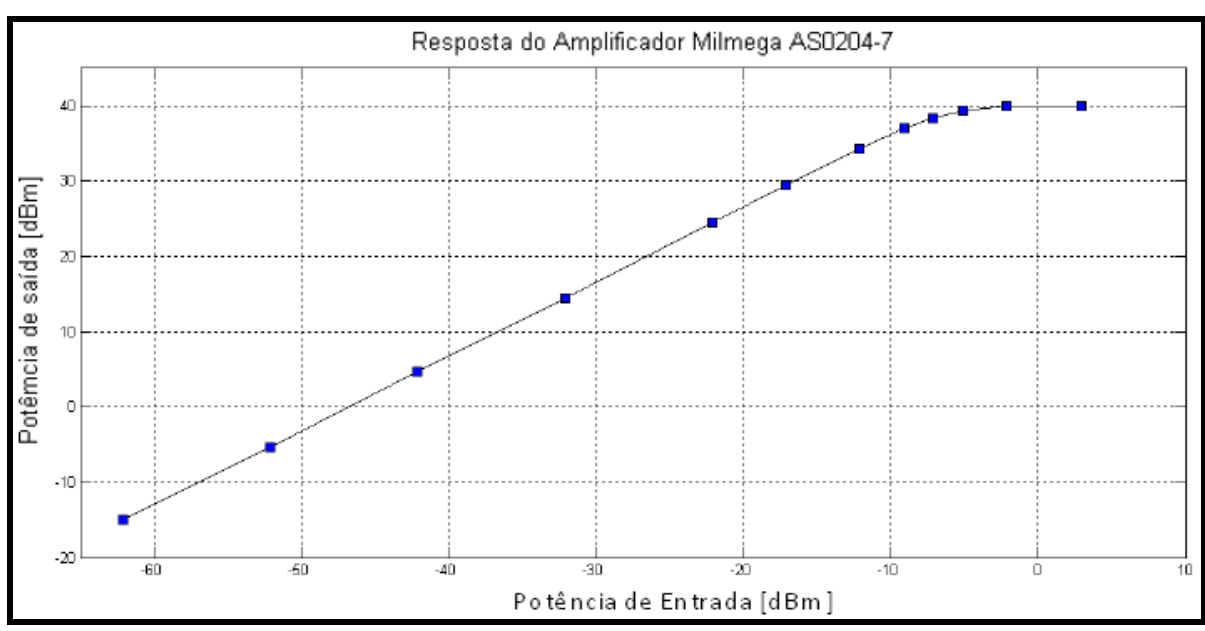

Figura 4.20: Curva de Linearidade do Amplificador Milmega (3.5 GHz)[3]

\subsection{4}

\section{Antena de Transmissão - PCTEL 17VP90NUF (2.5 GHz)}

A antena utilizada no processo de transmissão durante os estudos realizados, foi a setorial modelo 17VP90NUF da PCTEL com polarização vertical, 
frequências de operação entre 2,3 e 2,7 GHz, feixe de abertura azimutal de $90^{\circ} \mathrm{e}$ ganho de $16 \mathrm{dBi}$.

A antena é ilustrada na Figura 4.31 e na Figura 4.32 são ilustrados os diagramas polares de irradiação nos planos azimutal e de elevação.

A potência efetivamente irradiada (EiRP) foi de 43,7dBm, levando-se em consideração a potência de saída do gerador, o ganho do amplificador de potência e o ganho da antena de transmissão. A equação 4.1 demonstra esse resultado.

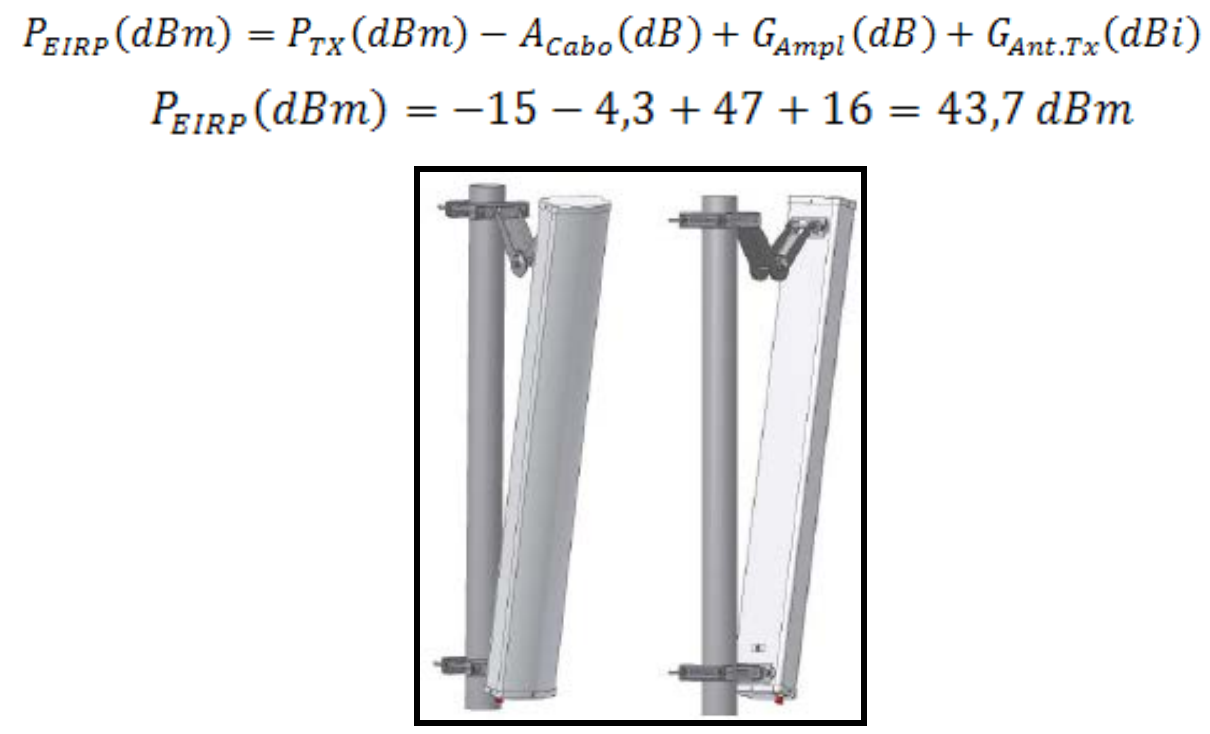

Figura 4.31: Antena de Transmissão PCTEL

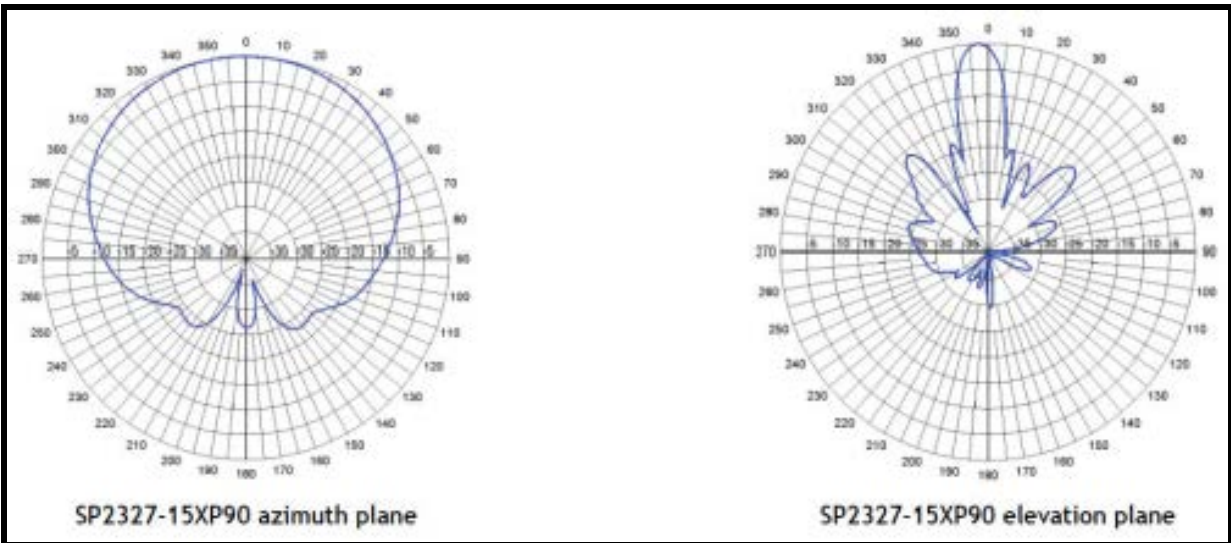

Figura 4.32: Diagramas Polares de Irradiação da Antena de Transmissão 


\subsection{5}

\section{Antena de Transmissão - Hyperlink HG3515P-120 (3.5 GHz)}

Foi utilizada uma antena típica na implementação em redes de sistemas WiMAX na faixa de $3.5 \mathrm{GHz}$. O ganho da antena é de $15 \mathrm{dBi}$ com 120 graus de abertura do lóbulo horizontal e 8 graus de abertura de lóbulo vertical, as características da antena estão indicadas no anexo B.

\subsection{6}

\section{Antena de Recepção para 2.5 GHz}

Foi utilizada uma antena omnidirecional modelo MGRM-WLF da Mobile Mark Communications com ganho de 3 dBi e frequência de operação entre 1,7 a 2,7 GHz para a captação do sinal transmitido, incluindo as componentes de multipercurso. A antena foi fixada na parte superior externa da unidade móvel. Mais informações sobre as especificações técnicas podem ser verificadas no datasheet que está no anexo B. A Figura 4.33 ilustra a antena receptora.

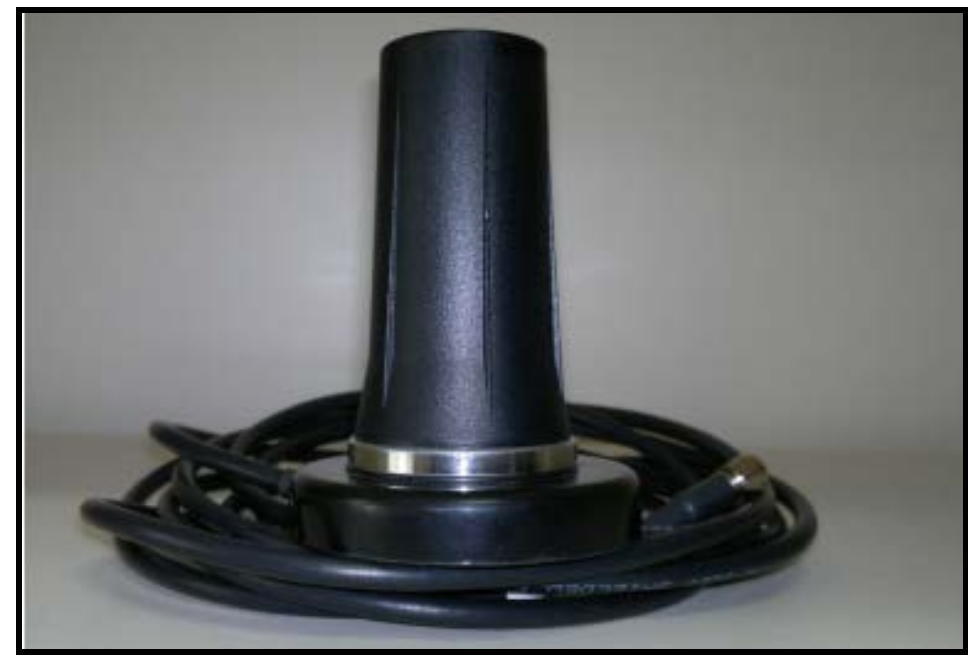

Figura 4.33: Antena omni direcional, modelo MGRM-WLF

\subsection{7}

\section{Antena de Recepção para $3.5 \mathrm{GHz}$}

Na recepção foi utilizada , conforme a Figura 4.34, a antena omnidirecional modelo HG3505RD-RSP da Hyperlink com ganho de $5 \mathrm{dBi}$, frequência de 
operação entre 3.4 GHz e $3.6 \mathrm{GHz}$, abertura horizontal de 360 graus e polarização vertical. A antena tem um kit de montagem magnético (HMA3-NFA10 da Hyperlink) que permite instalar a mesma no topo do veículo [3]. Mais informações sobre as especificações técnicas podem ser verificadas no datasheet que está no anexo B.

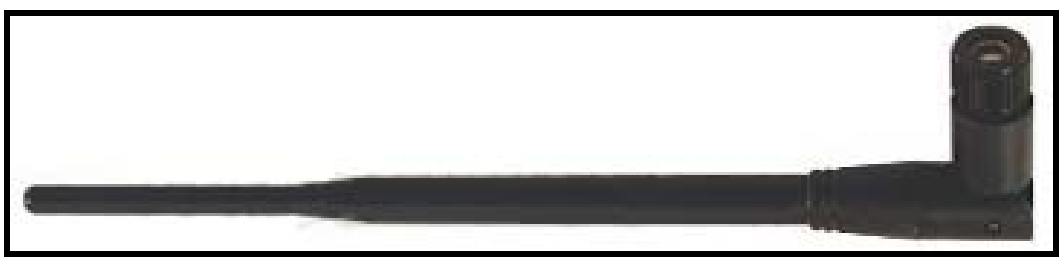

Figura 4.34: Antena omni direcional, modelo HG3505RD-RSP

\subsection{8}

\section{Cabos LMR-400 e LMR-600 - KMP (3.5 GHz)}

Os cabos utilizados e conectores são do fabricante Time Microwave Systems e, conforme a Figura 4.35, cumpre com as seguintes especificações [3].

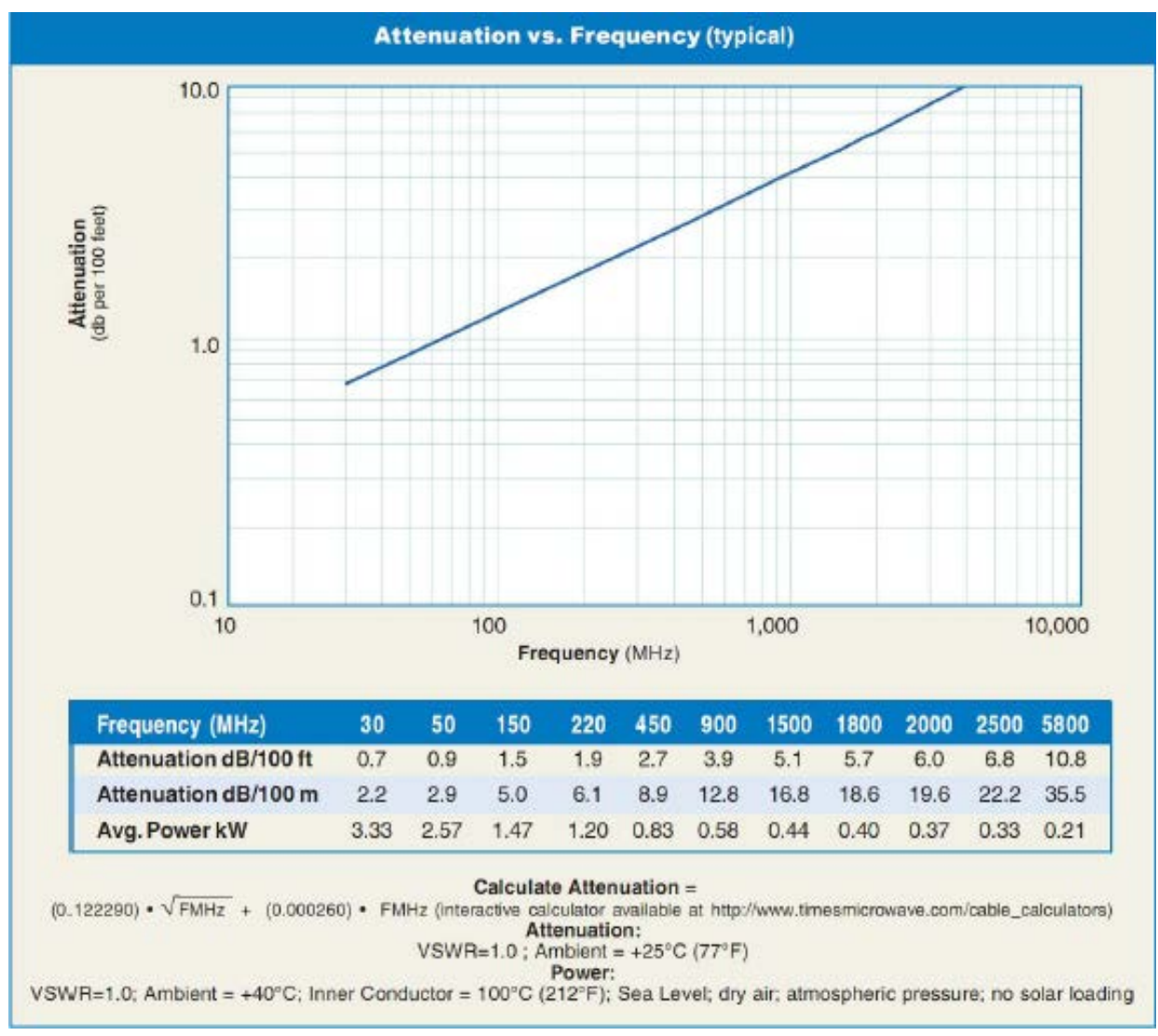

Figura 4.35: Características Elétricas do Cabo LMR-400 
Para o receptor as atenuações obtidas para cada conjunto de cabo e conectores é de $1.9 \mathrm{~dB}$ [3].

\subsection{9}

\section{Amplificador de Baixo Ruído (LNA - 2.5 GHz)}

Para que seja possível ter o sinal que foi anteriormente transmitido com uma potência e qualidade que favoreça a recepção na região onde foram feitos os estudos, faz-se necessário o uso de um amplificador de baixo ruído. Dessa forma o sinal é amplificado na recepção adicionando o mínimo de ruído. Neste trabalho foi utilizado o LNA da marca WENTEQ Microwave Corporation, modelo ABL080012-3315, que opera na faixa de frequências de 1 a $8 \mathrm{GHz}$, possibilitando um ganho nominal na faixa de $2.5 \mathrm{GHz}$ de $33 \mathrm{dBm}$. O datasheet do LNA pode ser encontrado no Anexo B deste trabalho. A Figura 4.36 ilustra o amplificador LNA utilizado.

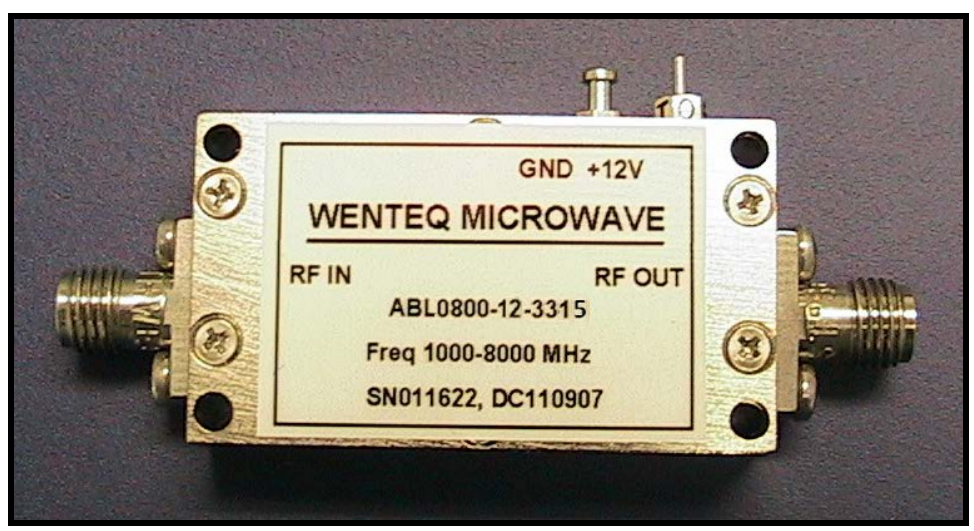

Figura 4.36: LNA WENTEQ Microwave Corp. - ABL0800-12-3315

\subsubsection{0}

\section{Amplificador de Baixo Ruído (LNA - 3.5 GHz)}

Na campanha de medições realizadas para a faixa de $3.5 \mathrm{GHz}$ foi utilizado o amplificador de baixo ruído (LNA - Low Noise Amplifier) modelo DB97-1794 da L-3 Communications Narda Microwave-West que possui a frequência de operação de $3.5 \mathrm{GHz}$, ganho mínimo de $30 \mathrm{~dB}$ e potência máxima de entrada de $20 \mathrm{dBm}$. 


\subsubsection{1}

Global System Position - GPS (2.5 GHz)

Para que os dados capturados no canal fossem georeferenciados, foi utilizado o GPS da marca GARMIN modelo GPSMAP 62 que foi fixado no teto da unidade móvel e ligado ao analisador vetorial de sinais. O software GPS Trackmaker foi instalado no analisador vetorial de sinais para possibilitar assim a sincronização entre os tempos de captura dos dados e o tempo de captura das posições georeferenciadas.

Para ser possível a captura dos dados em tempo real, o GPS precisou ser configurado para trabalhar no modo NMEA (National Marine Eletronics Association), a Figura 4.37 ilustra o GPS utilizado.

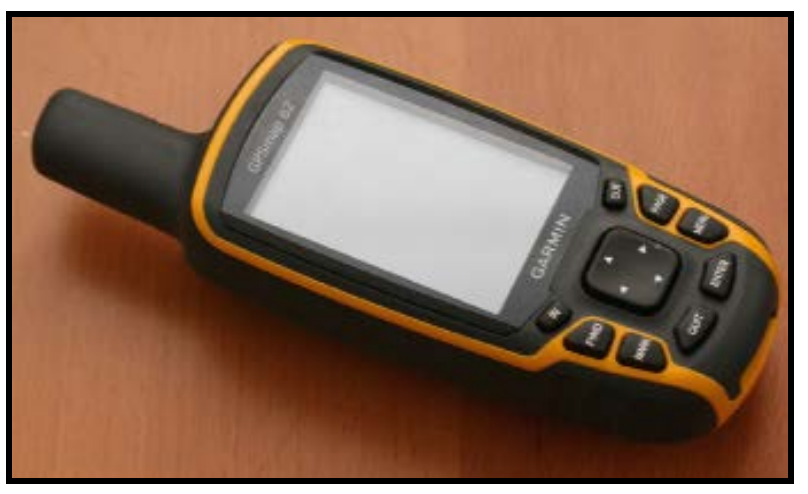

Figura 4.37: GPS da marca GARMIN modelo GPSMAP 62

\subsubsection{2}

\section{Global System Position - GPS (3.5 GHz)}

O GPS utlizado para a coleta de informações de coordenadas geográficas foi o da Marca Garmin, modelo 60 CS, com opção de conexão de antena magnética externa e captura de dados por meio de cabo USB, com conexão de 9600 bps. De forma a capturar e sincronizar as informações foi utilizado o software GPS Trackmaker [3]. 


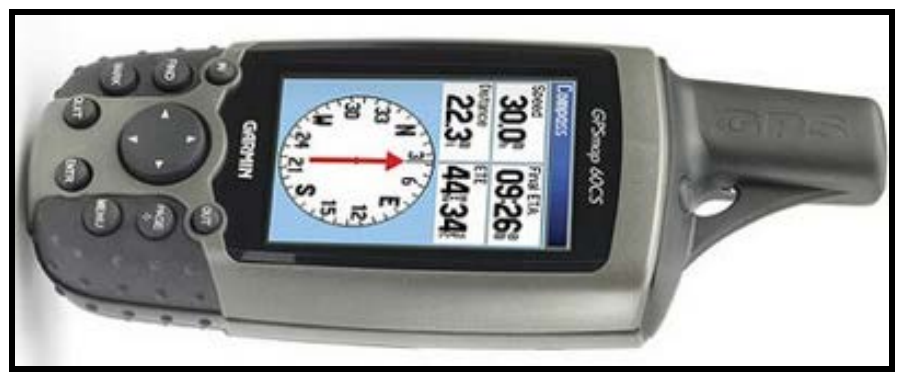

Figura 4.38: GPS da marca GARMIN modelo GPSMAP 60 CS

\subsubsection{3}

\section{Analisador vetorial de sinais}

A Figura 4.39 a seguir ilustra o Analisador vetorial de sinais utilizado.

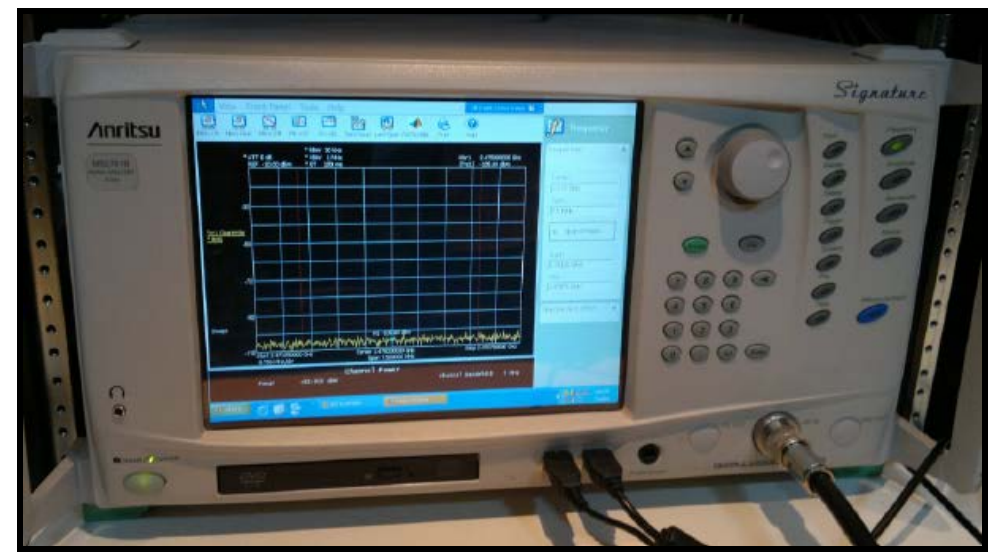

Figura 4.39: Analisador Vetorial de Sinais MS2781B

O Analisador Vetorial de Sinais MS2781B - Signature da Anritsu juntamente com um código desenvolvido em MATLAB, foi utilizado para tratar os dados que foram recebidos pela antena receptora omnidirecional e amplificados pelo LNA, permitindo assim a captura e armazenamento das componentes de fase (I) e quadratura de fase (Q) do sinal transmitido pelo Gerador Vetorial. Para a faixa de $2.5 \mathrm{GHz}$, a captura dos dados foi feita com o tempo de captura $262 \mu$ s a uma taxa de $50 \mathrm{MHz}$. O analisador vetorial de sinais realiza a captura dos dados em intervalos de um segundo o que permitiu coletar três símbolos OFDM, conforme ilustrado na Figura 4.40. 


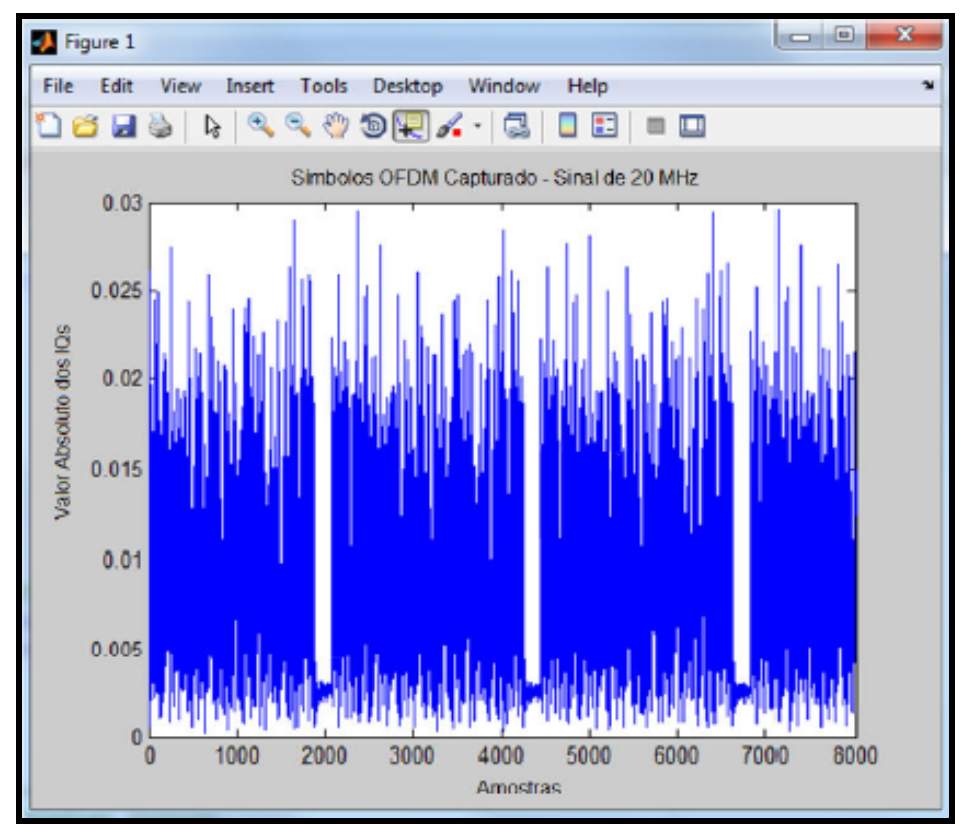

Figura 4.40: Símbolos OFDM Capturados - Sinal de 20 MHz $(2.5 \mathrm{GHz})$

As medições na faixa de $2.5 \mathrm{GHz}$ foram realizadas em dois intervalos ininterruptos de vinte minutos, tempo este suficiente para percorrer toda a rota de varredura proposta a uma velocidade média de $30 \mathrm{~km} / \mathrm{h}$.

Para a faixa de $3.5 \mathrm{GHz}$, a captura foi realizada com duração de $262 \mu$ s com intervalos de um segundo entre cada captura, o tempo de captura permite a coleta de até 3 símbolos OFDM. Com o tempo de captura considerado, uma medição era realizada num intervalo de tempo de 15 minutos, depois dos quais o programa automaticamente começava a armazenar os dados no disco rígido, num tempo aproximado de 15 minutos [3]. 


\section{Análise dos Resultados}

Neste capítulo é apresentada a análise dos resultados alcançados a partir das medições realizadas no cenário urbano descrito anteriormente no capítulo 4. Como já descrito nesse trabalho, o transmissor juntamente com a antena e demais equipamentos envolvidos no processo de transmissão foi fixado a trinta metros de altura para as medições em $2.5 \mathrm{GHz}$ e quarenta e dois metros para as medições em 3.5 GHz. O set-up de recepção foi instalado em uma unidade móvel que fez o percurso de deslocamento por uma rota pré-estabelecida. A taxa de amostragem realizada no processo de aquisição pela sonda no domínio da frequência foi de oito mil amostras IQ do sinal transmitido por segundo, utilizando a técnica de multiportadoras.

Os dados que são analisados nesse capítulo são referentes às campanhas de medições realizadas em 2012 na faixa de $2.5 \mathrm{GHz}$ e em 2008 na faixa de 3.5 de acordo com [3]. A análise foi realizada de forma a obter as curvas de perfil de retardo de potência utilizando filtragem com as técnicas CFAR e CLEAN já discutidas anteriormente, através de script em MATLAB.

As técnicas de filtragem de perfil de retardos permite determinar as componentes de multipercurso válidos $(\tau)$, permitindo posteriormente obter os parâmetros utilizados neste trabalho para a caracterização do canal rádio móvel, que são o retardo médio e o desvio padrão, ambos descritos matematicamente da seguinte forma.

Retardo Médio:

$$
\bar{\tau}=\frac{\sum_{k} P\left(\tau_{k}\right) \tau_{k}}{\sum_{k} P\left(\tau_{k}\right)}
$$

Desvio Padrão: $\quad \sigma_{t}=\sigma_{r m s}=\sqrt{\frac{\sum_{k}\left(\tau_{k}-\bar{\tau}\right)^{2} P\left(\tau_{k}\right)}{\sum_{k} P\left(\tau_{k}\right)}}$

onde:

$\mathrm{P}\left(\tau_{\mathrm{k}}\right)=$ potência da componente $\mathrm{k}$ de multipercurso. 
$\tau_{\mathrm{k}}=$ atraso de propagação da k-ésima onda em relação à incidência do primeiro sinal.

$\tau=$ retardo excedido médio.

\section{1}

\section{Análise com a técnica CFAR}

Conforme mencionado no item 3.3, a técnica CFAR procura estabelecer um limiar de nível de potência a partir do qual os pontos de uma dada medida com valores absolutos entre o valor de pico e o de limiar calculado é considerado a princípio como possível ponto válido caso contrário é considerado ruído, para que esse ponto de medida seja efetivamente considerado multipercurso válido é necessário que esse comportamento ocorra nas medidas anterior e posterior.

Primeiramente serão mostrados os resultados obtidos através dos gráficos encontrados no processo computacional ao aplicar está técnica através do MATLAB.

A Figura 5.1 ilustra a resposta impulsiva do canal na faixa de $2.5 \mathrm{GHz}$ para todas as amostras coletadas durante a campanha de medida.

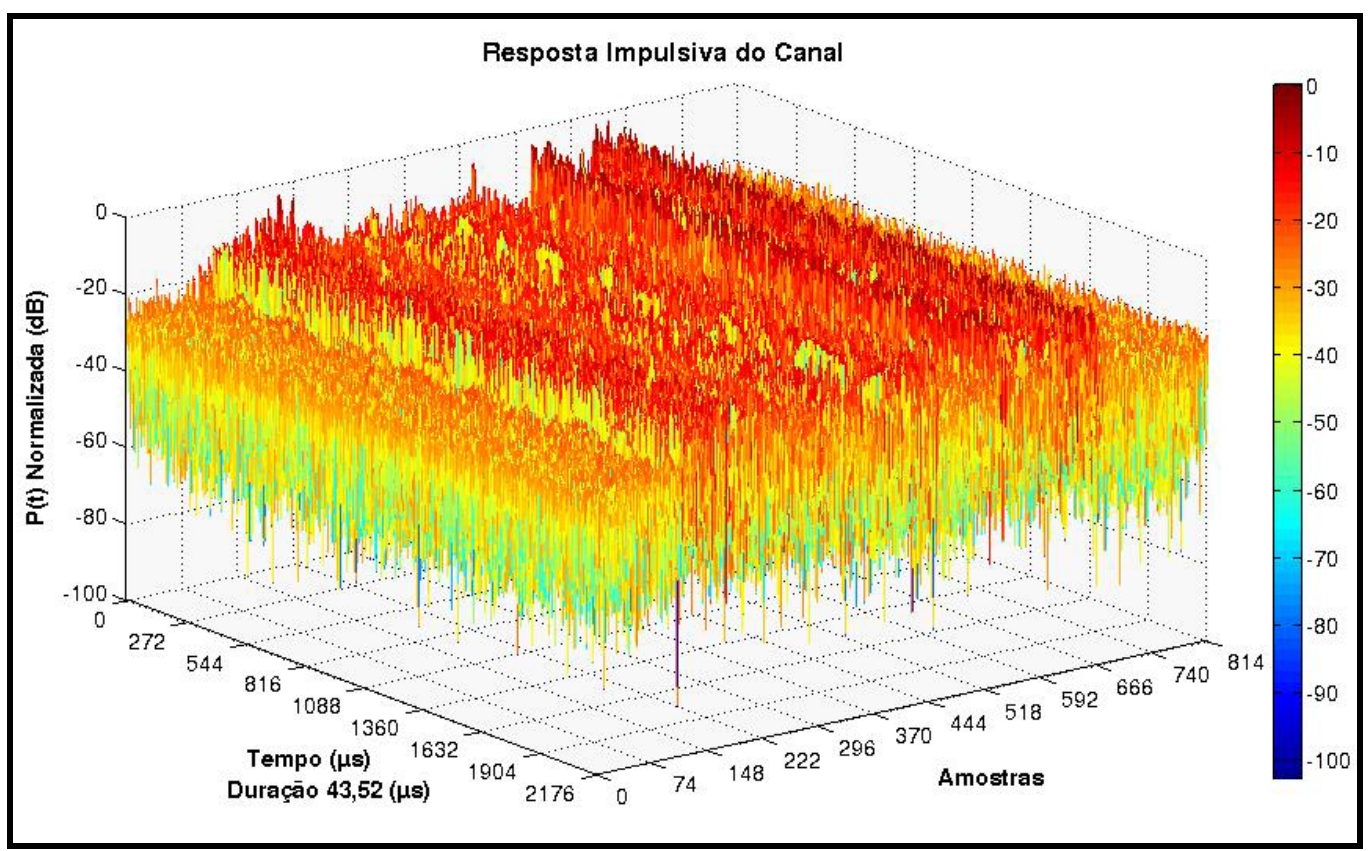

Figura 5.1: Resposta Impulsiva do Canal $(2.5 \mathrm{GHz})$ 
Para facilitar o entendimento da resposta impulsiva do canal e a sua respectiva caracterização será utilizada uma das amostras, nesse caso a amostra 189, para a análise gráfica conforme a Figura 5.2.

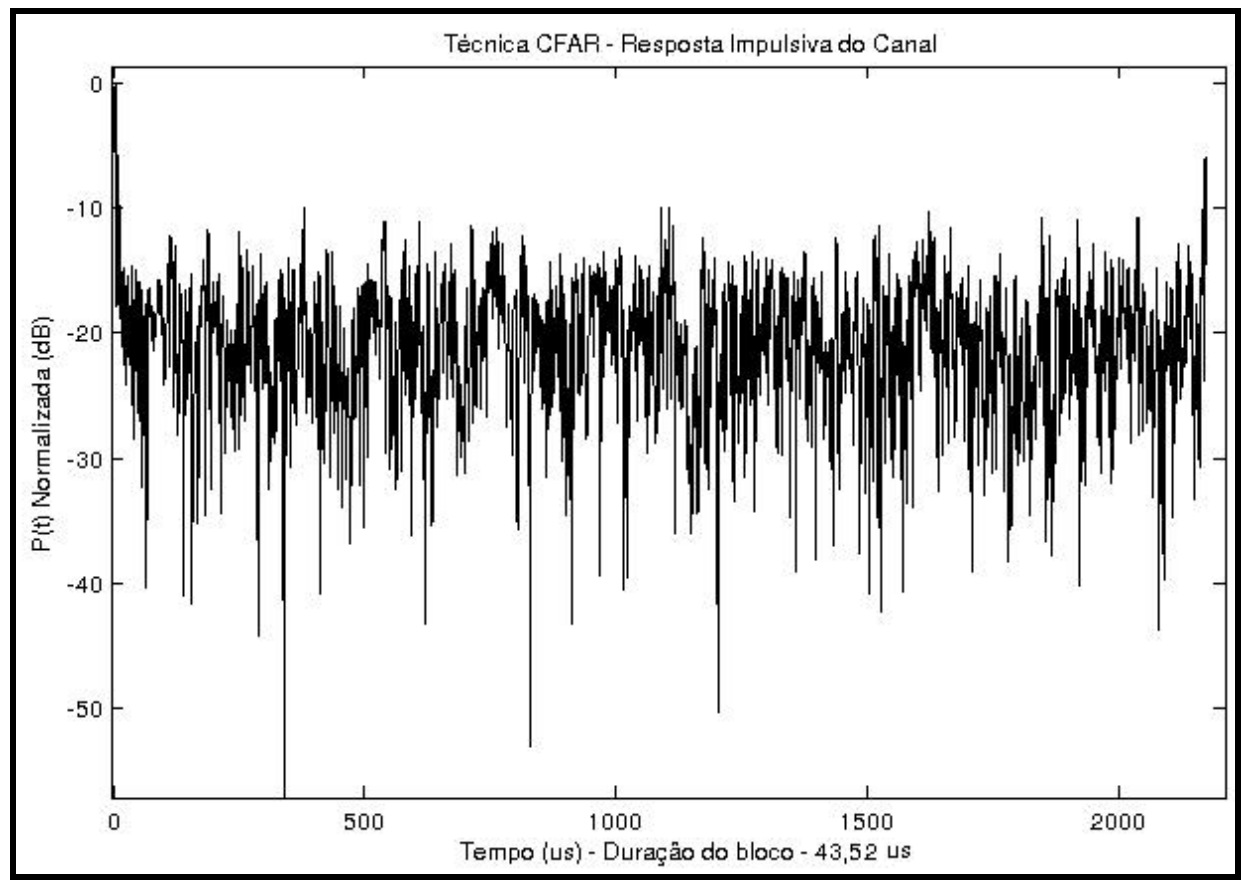

Figura 5.2: Resposta Impulsiva do Canal CFAR (2.5 GHz) - amostra 189

A Figura 5.3 ilustra os pontos considerados multipercursos válidos na amostra 189 após a aplicação da técnica CFAR de filtragem.

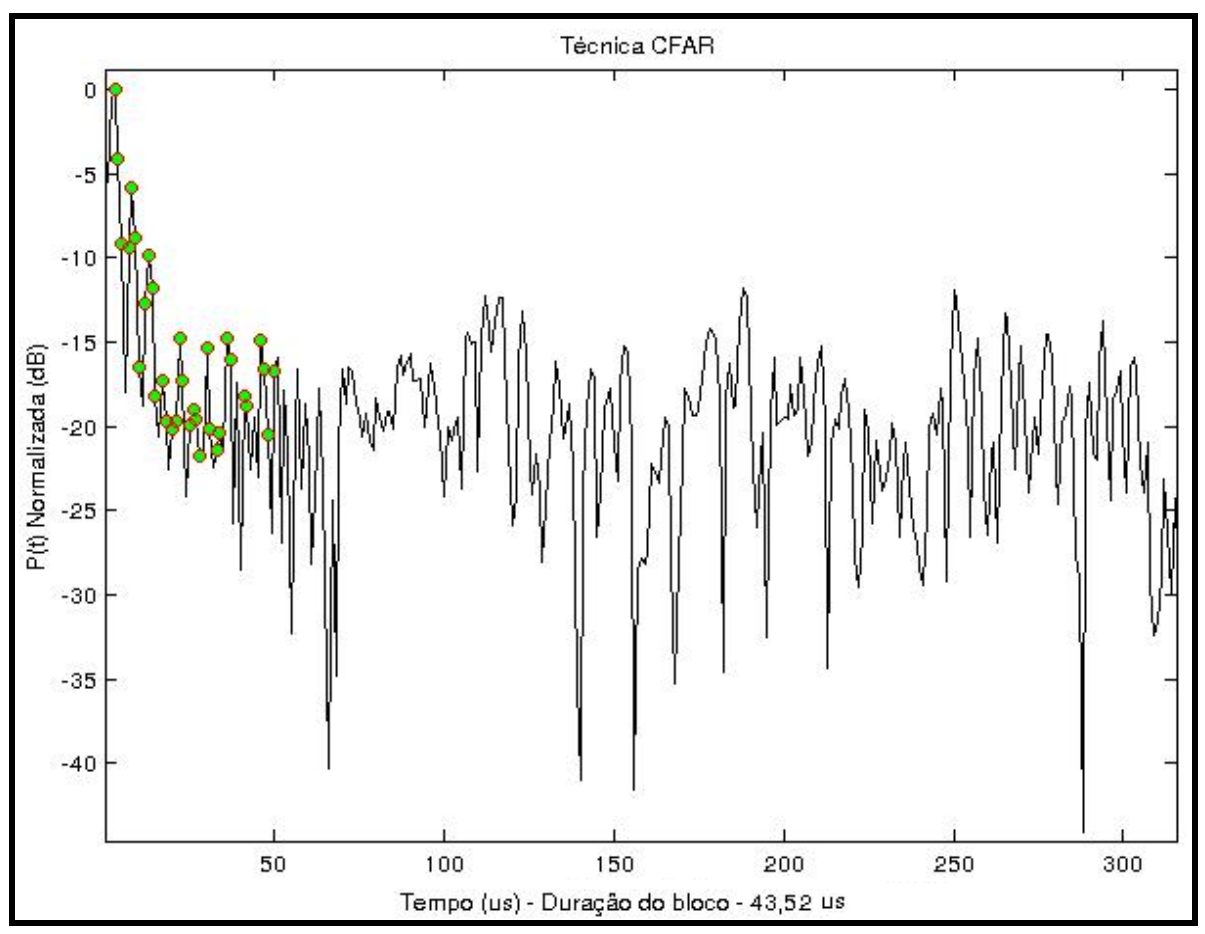


Figura 5.3: Multipercursos válidos pela técnica CFAR (2.5 GHz) - amostra 189

Pode-se observar pela Figura 5.3 que foram considerados multipercursos válidos pontos que estão acima do piso de ruído. Além disso, quando a resposta do canal tem um comportamento "plano" em torno do piso de ruído, a técnica CFAR não considera como multipercursos válidos, pois provavelmente trata-se de nível de ruído e não um multipercurso do sinal original.

A Figura 5.4 ilustra a resposta impulsiva do canal na faixa de $3.5 \mathrm{GHz}$ para todas as amostras coletadas durante a campanha de medida do dia 04/11/2008 parte 1 , nesse caso foram coletadas 102 amostras.

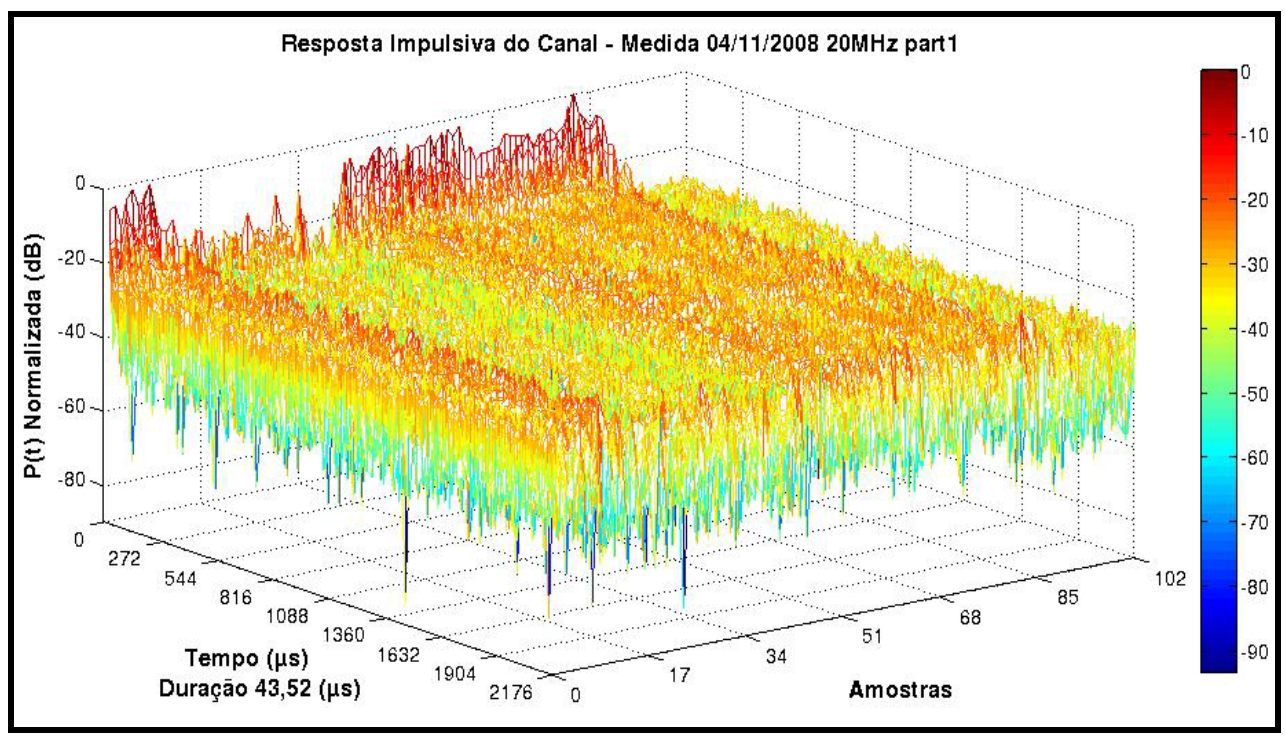

Figura 5.4: Resposta Impulsiva do Canal (3.5 GHz)

Para facilitar o entendimento da resposta impulsiva do canal e a sua respectiva caracterização será utilizada uma das amostras, nesse caso a amostra 72, para a análise gráfica conforme a Figura 5.5 a seguir. 


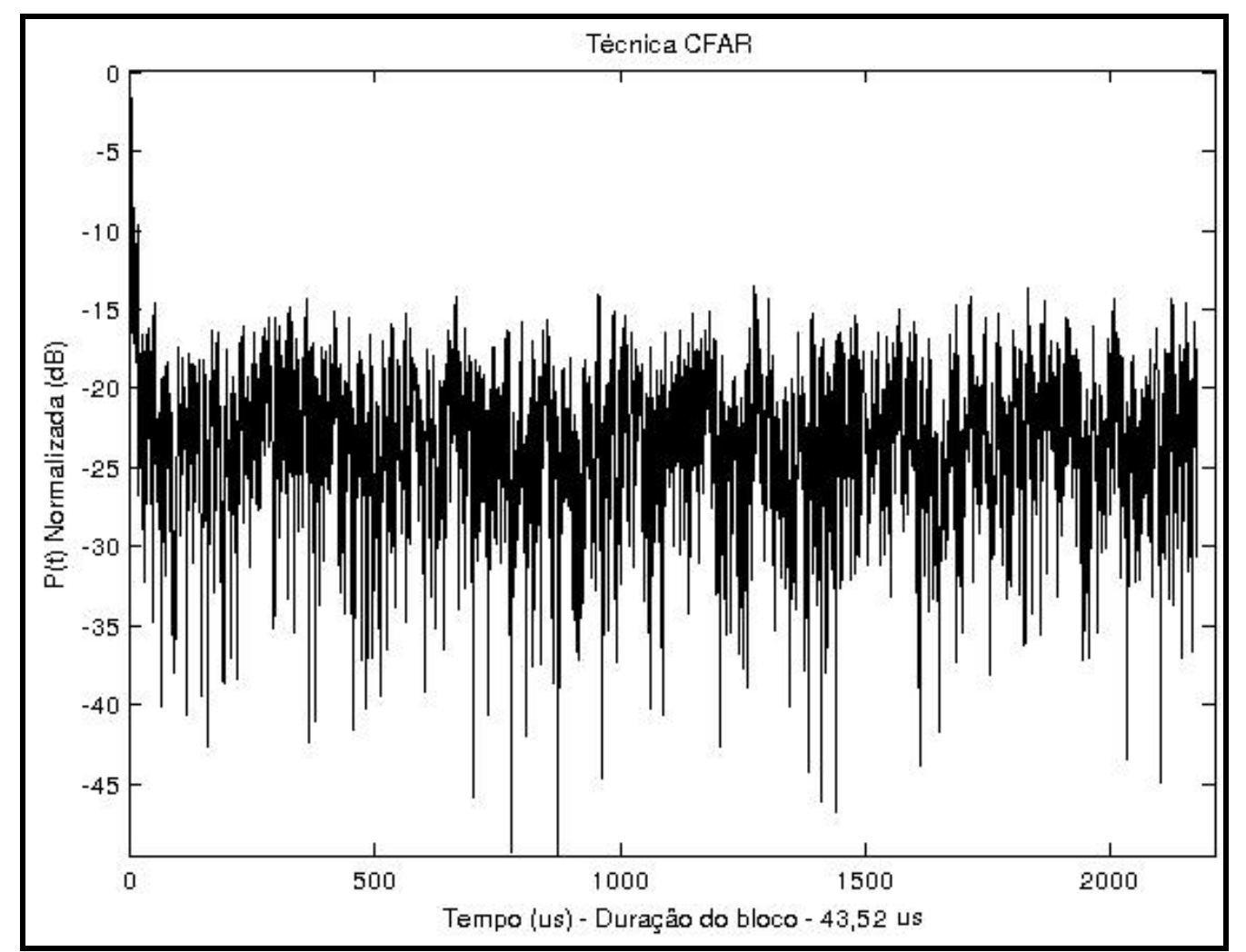

Figura 5.5: Resposta Impulsiva do Canal CFAR (3.5 GHz) - amostra 72

A Figura 5.6 ilustra os pontos considerados multipercursos válidos conforme a técnica CFAR.

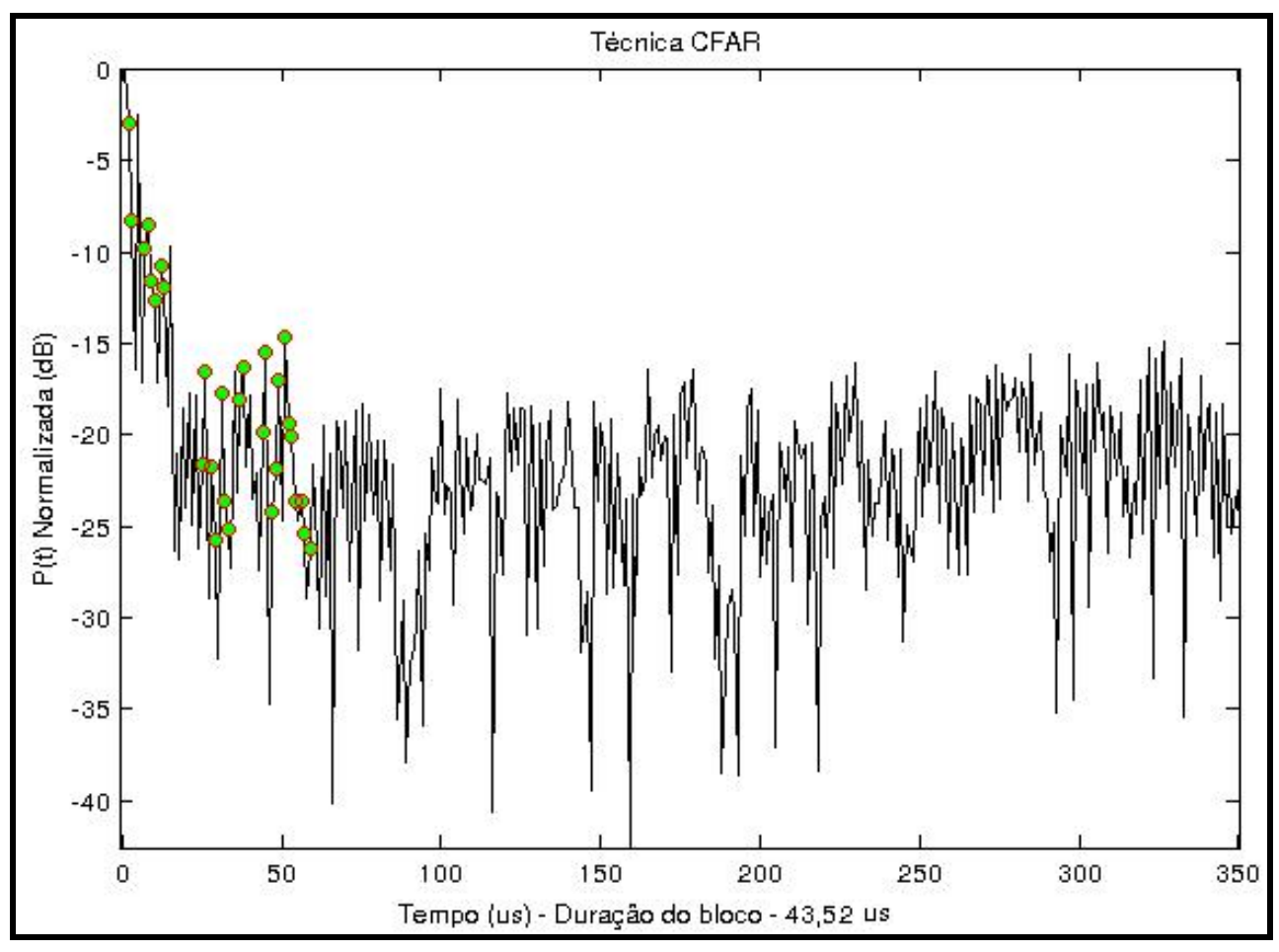

Figura 5.6: Multipercursos válidos pela técnica CFAR $(3.5 \mathrm{GHz})$ - amostra 72 
Podemos observar um comportamento muito semelhante ao encontrado para a faixa de $2.5 \mathrm{GHz}$ o que corrobora para a validação da técnica CFAR para ambas as faixas de frequência.

Uma análise importante a ser feita é com relação aos resultados numéricos do retardo médio e desvio padrão e a partir desses valores é possível calcular a distância média entre os espalhadores. Essa distância deve estar coerente com o ambiente de medição.

A seguir é exibida a tabela 5.1 com as repostas da caracterização para $2.5 \mathrm{GHz}$.

Tabela 5.1: Resposta da Caracterização para $2.5 \mathrm{GHz}$

\begin{tabular}{|l|c|c|c|}
\hline \multirow{2}{*}{ Parâmetro } & \multicolumn{3}{|c|}{ Resultado para $2.5 \mathrm{GHz}$} \\
\cline { 2 - 4 } & Tempo $(\mu \mathrm{s})$ & $\begin{array}{c}\text { Distancia média entre os } \\
\text { espalhadores }(\mathrm{m})\end{array}$ & Prefixo Cíclico \\
\hline Retardo Médio & 0,1010 & 30,3 & $1 / 32(1 / 43)$ \\
\hline Desvio Padrão & 0,1022 & $\mathrm{~N} / \mathrm{A}$ & $\mathrm{N} / \mathrm{A}$ \\
\hline
\end{tabular}

A seguir é exibida a tabela 5.2 com as repostas da caracterização para $3.5 \mathrm{GHz}$.

Tabela 5.2: Resposta da Caracterização para $3.5 \mathrm{GHz}$

\begin{tabular}{|l|c|c|c|}
\hline \multirow{2}{*}{ Parâmetro } & \multicolumn{3}{|c|}{ Resultado para 3.5 GHz } \\
\cline { 2 - 4 } & Tempo $(\mu \mathrm{s})$ & $\begin{array}{c}\text { Distancia média entre os } \\
\text { espalhadores }(\mathrm{m})\end{array}$ & Prefixo Cíclico \\
\hline Retardo Médio & $0,1960[3]$ & 58,8 & $1 / 16(1 / 22)$ \\
\hline Desvio Padrão & $0,1610[3]$ & $\mathrm{N} / \mathrm{A}$ & $\mathrm{N} / \mathrm{A}$ \\
\hline
\end{tabular}

A partir dos valores encontrados de retardo médio e considerando a velocidade de propagação de $3 \times 10^{8} \mathrm{~m} / \mathrm{s}$ podemos encontrar a distância média entre os espalhadores de 30,3 m para a análise na faixa de $2.5 \mathrm{GHz}$ e 58,8 m para a análise na faixa de $3.5 \mathrm{GHz}$. Neste caso as medições incluem pontos no entorno da Lagoa Rodrigo de Freitas, onde a distância média entre espalhadores é maior. Assim, os valores encontrados estão bem coerentes com a região urbana objeto de estudo nesse trabalho.

Considerando que o sinal utilizado possui as seguintes características: 
- Largura de banda de $20 \mathrm{MHz}$;

- $\mathrm{N}_{\mathrm{FFT}}$ igual a 1024 amostras;

- Fator de amostragem igual a dois;

- Prefixo cíclico igual a 1/16 amostras;

- Frequência de Amostragem igual a 50 MHz.

Podemos encontrar o tempo de duração de um bloco ou tempo de um símbolo OFDM (Ts), conforme a seguir:

$$
\begin{gathered}
T_{s}=\frac{\left(N_{F F T}+C S * N_{F F T}\right) * n}{F_{s}} \\
T_{s}=\frac{\left(1024+\left(\frac{1}{16}\right) * 1024\right) * 2}{50 * 10^{6}}=43,52 \mu \mathrm{s}
\end{gathered}
$$

Onde,

$\mathrm{N}_{\mathrm{FFT}}=$ número de amostras;

CS = prefixo cíclico;

Fs = frequência de amostragem

$\mathrm{n}=$ fator de amostragem

Ts = tempo de um símbolo OFDM ou duração de um bloco.

É recomendado um tempo de prefixo cíclico de pelo menos dez vezes o tempo do retardo médio encontrado, nesse caso de 0,1010 $\mu$ s. Dessa forma, precisa-se de um tempo de prefixo cíclico de pelo menos $1,010 \mu$ s e a partir desse valor aproxima-se para o valor mais próximo dentre os valores tipicamente utilizados de 1/64, 1/32, 1/16 e 1/8 da duração do bloco encontrado [3, 19].

Com o valor mínimo imposto de 1,010 $\mu$ s para a faixa de $2.5 \mathrm{GHz}$, temos o valor de aproximadamente 1/43 do tempo de duração do bloco. Nesse caso, dentre os valores típicos de prefixo cíclico, o que melhor atende é o de 1/32. No caso da faixa de $3.5 \mathrm{GHz}$, o valor mínimo imposto é de 1,960 $\mu$ s e com isso o valor de aproximadamente 1/22 do tempo de duração do bloco. Nesse caso, dentre os valores típicos de prefixo cíclico, o que melhor atende é o de 1/16. Podemos concluir que com esse resultado numérico encontrado é viável utilizar a técnica CFAR por possuir retardo médio que atende os valores de prefixo cíclicos comumente utilizados. 
Para ser avaliado o comportamento do retardo RMS e do retardo médio, as Figuras 5.7 a 5.12 mostram a variação em função da distância para ambas as faixas de frequência.

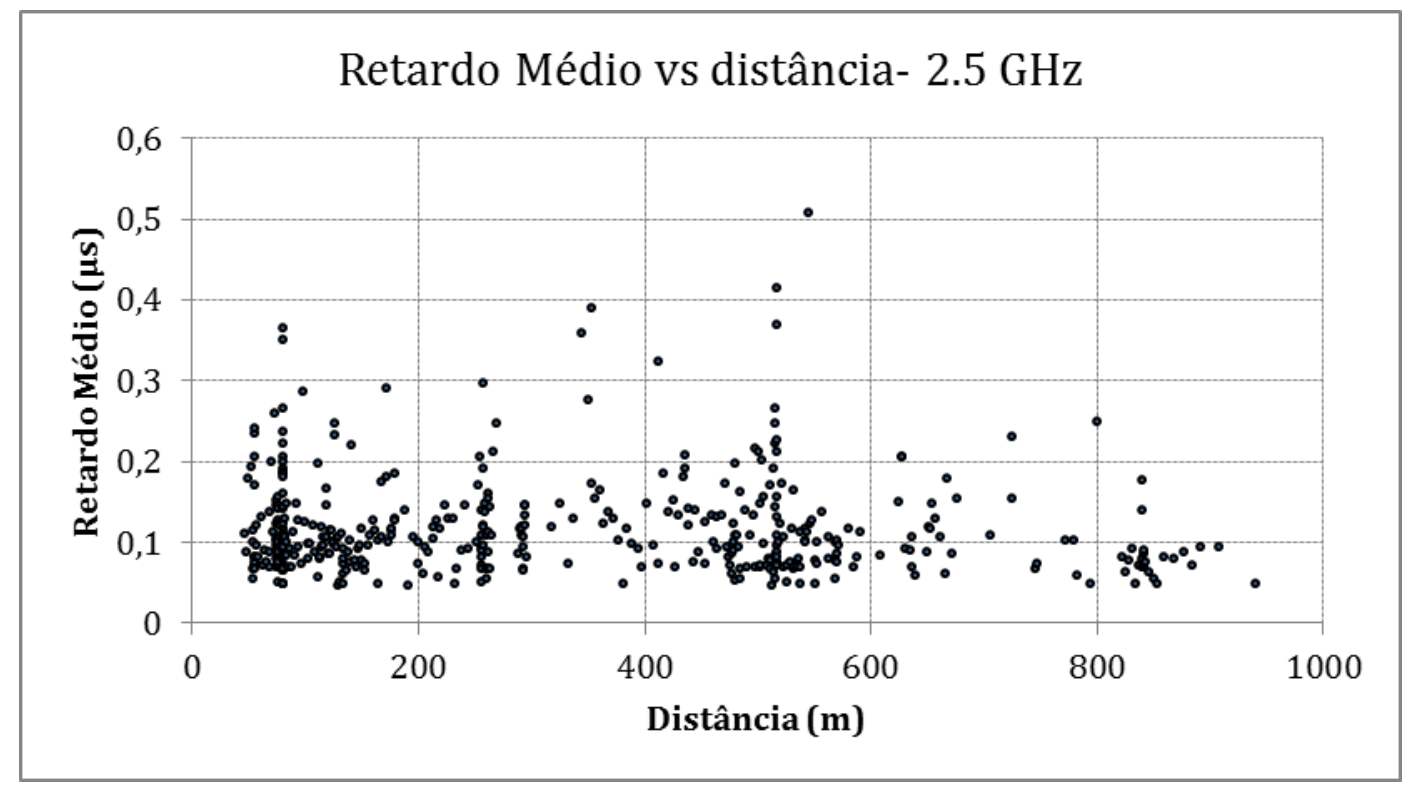

Figura 5.7: Retardo Médio vs Distância (2.5 GHz)

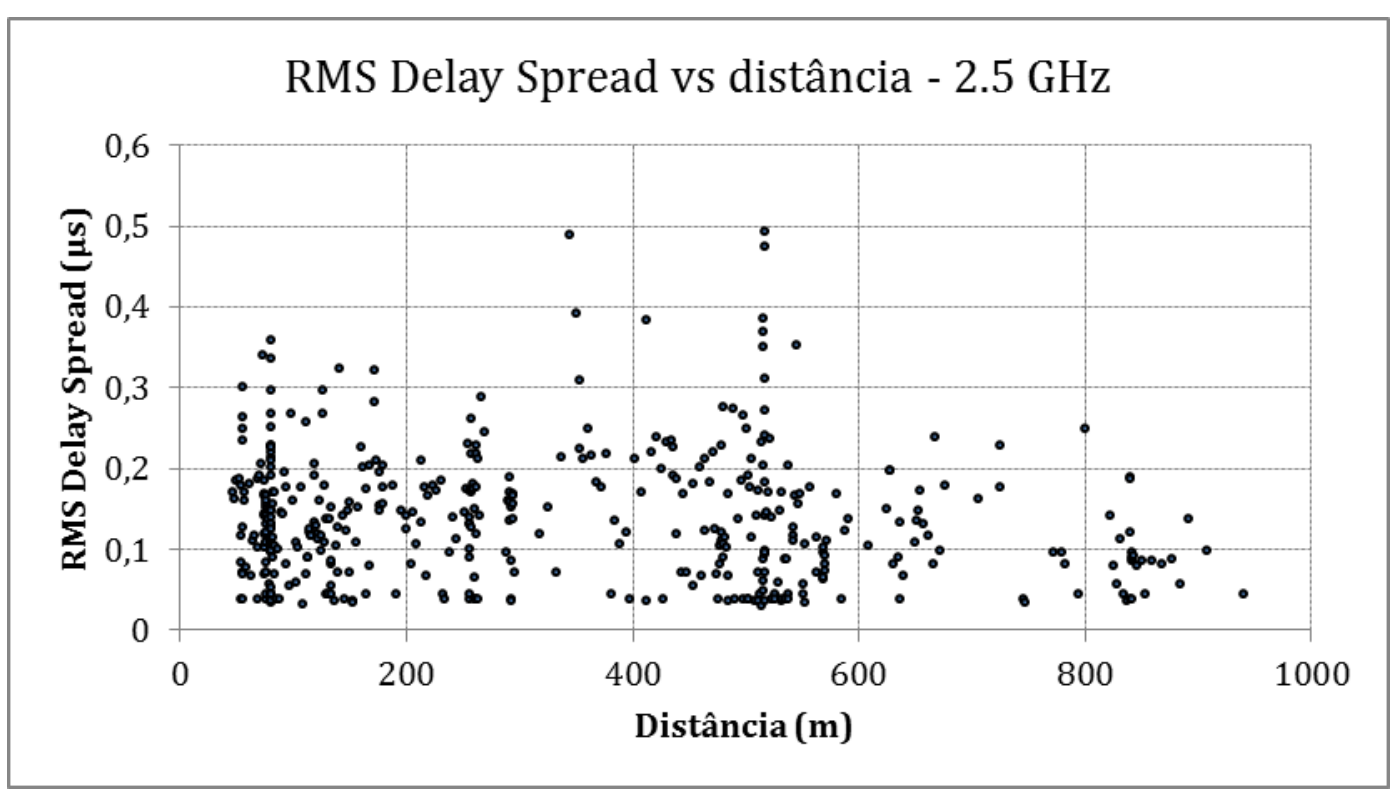

Figura 5.8: RMS Delay Spread vs Distância (2.5 GHz) 


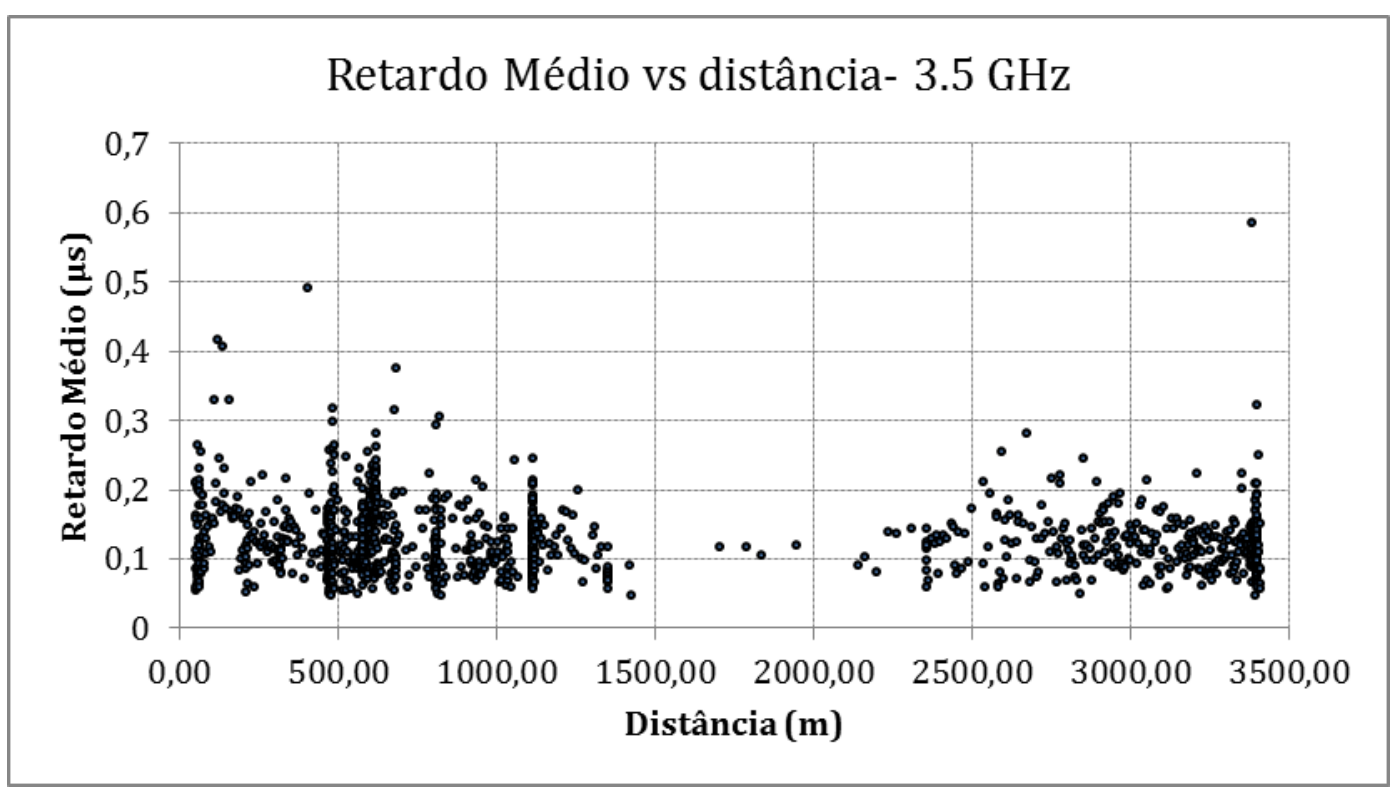

Figura 5.9: Retardo Médio vs Distância (3.5 GHz)

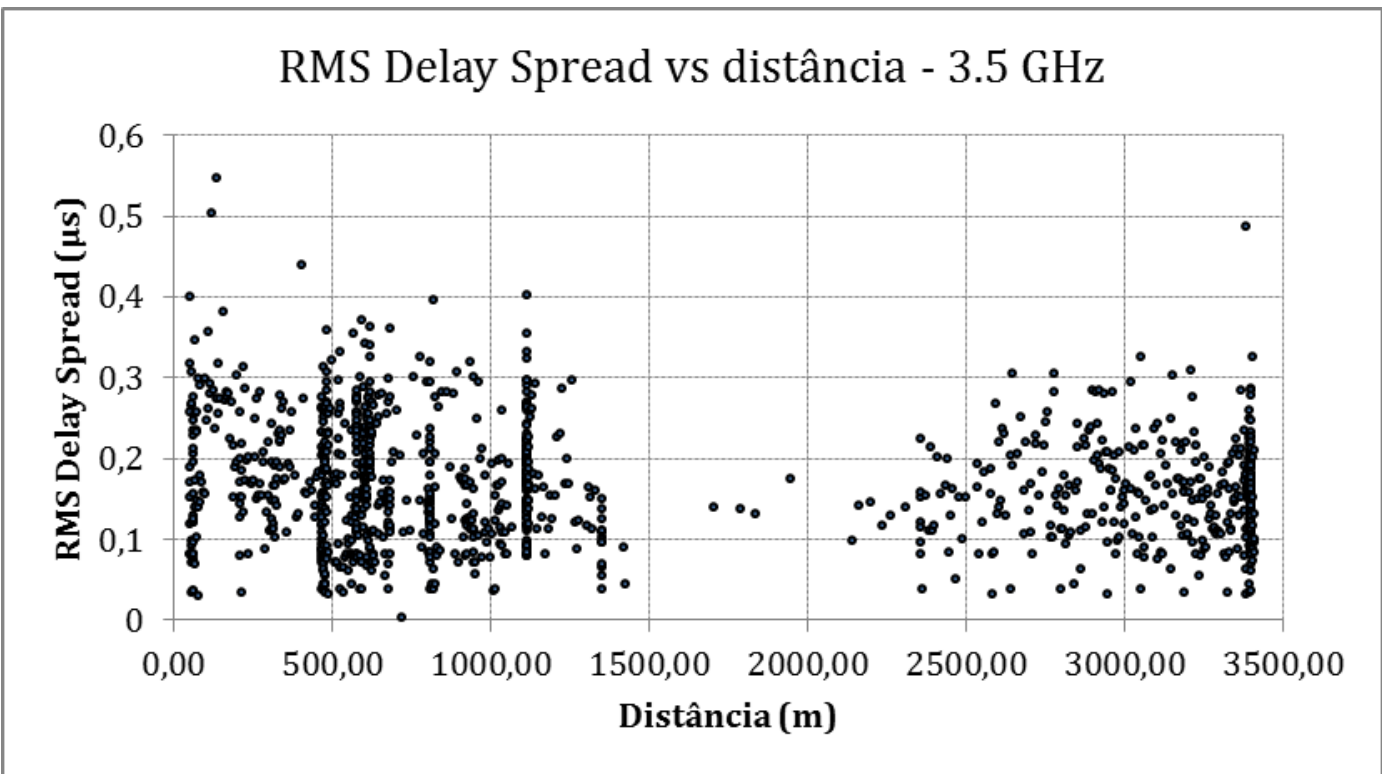

Figura 5.10: RMS Delay Spread vs Distância $(3.5$ GHz) 


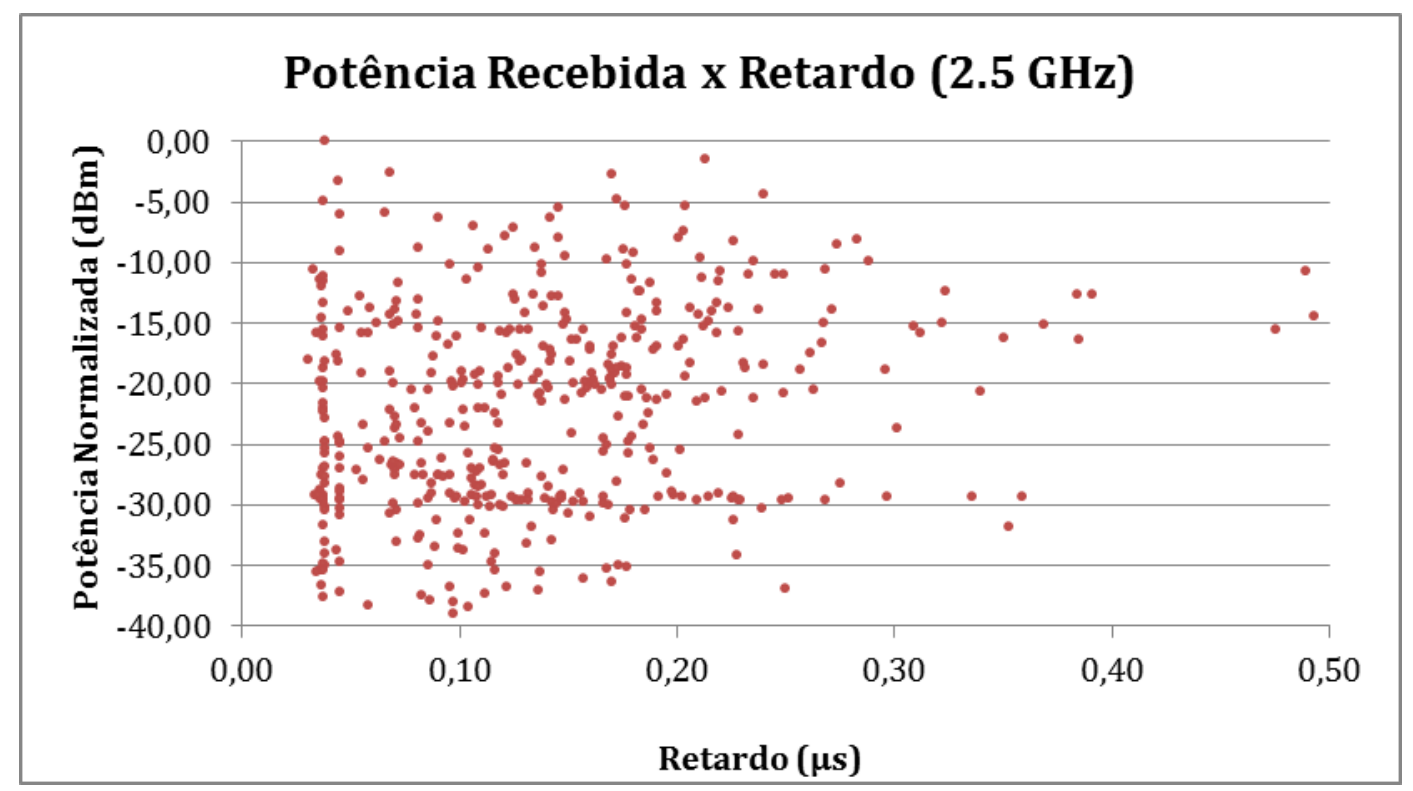

Figura 5.11: Potência Recebida vs Retardo - dBm (2.5 GHz)

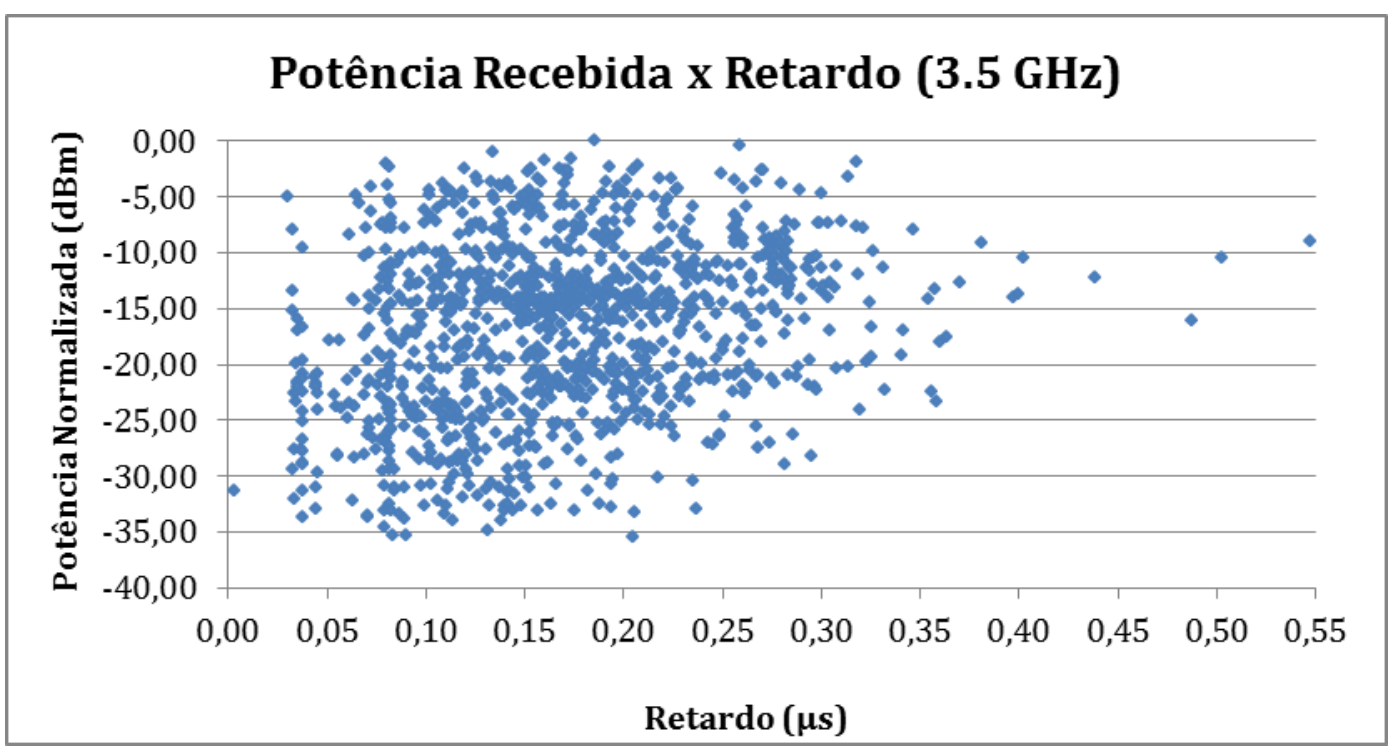

Figura 5.12: Potência Recebida vs Retardo - dBm (3.5 GHz)

Pode-se observar que em ambas as faixas de frequência não existe uma depend6encia clara do retardo com a distância. Este comportamento aleatório dos valores de retardo médio, espalhamento de retardo RMS e potência são justificáveis pelo fato de existirem componentes medidas em condições LOS e NLOS durante todo o percurso das medições. As componentes que sofreram efeitos de multipercursos em maior intensidade apresentam valores de retardo médio e espalhamento de retardo RMS mais elevados. No caso dos gráficos relacionados à relação entre potência e retardo as componentes medidas com 
maior nível de potência provavelmente sofreram efeito construtivo dos multipercursos gerados. Em ambas as faixas de frequência não é possível verificar uma dependência entre os níveis de potência e o retardo medido.

\section{2}

\section{Análise com a técnica CLEAN}

Conforme explicado anteriormente, a técnica CLEAN executa uma comparação entre o sinal recebido durante a campanha de medições e um sinal de referência ou de calibração. O sinal de calibração deve ser obtido em um ambiente controlado, onde a probabilidade de ocorrência de multipercursos seja praticamente nula. Nesse trabalho, o sinal de calibração foi obtido no estacionamento da PUC-RJ durante um domingo, em que existe pouca movimentação.

O sinal de calibração tem como principal função caracterizar o sinal gerado e dessa forma reduzir a probabilidade de erros em relação aos multipercursos gerados pelos equipamentos transmissores e receptores, que poderiam ser interpretados erroneamente, evitando que sejam tratados como multipercursos válidos. Após ser realizada a filtragem pela técnica CLEAN torna-se possível caracterizar o canal através de seus fatores dispersivos.

Primeiramente serão mostrados os resultados obtidos através dos gráficos encontrados no processo computacional ao aplicar está técnica através do MATLAB. A Figura 5.13 ilustra a resposta impulsiva do canal na faixa de 2.5 GHz. 


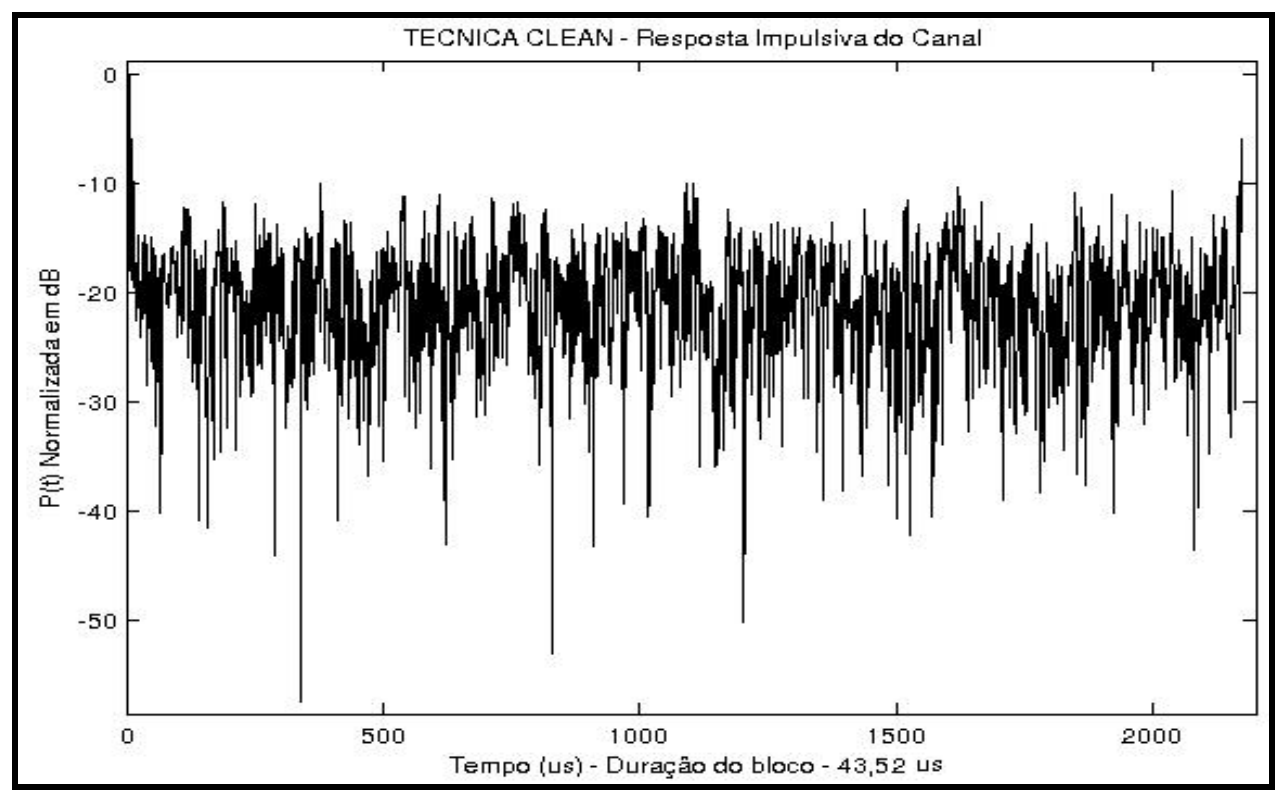

Figura 5.13: Resposta Impulsiva do Canal - CLEAN (2.5 GHz) - amostra 189

Os pontos circulares em verde na Figura 5.14 são os que foram selecionados primeiramente pele técnica CLEAN, mas que ainda serão correlatados com o sinal de calibração para verificar se são ou não multipercursos válidos.

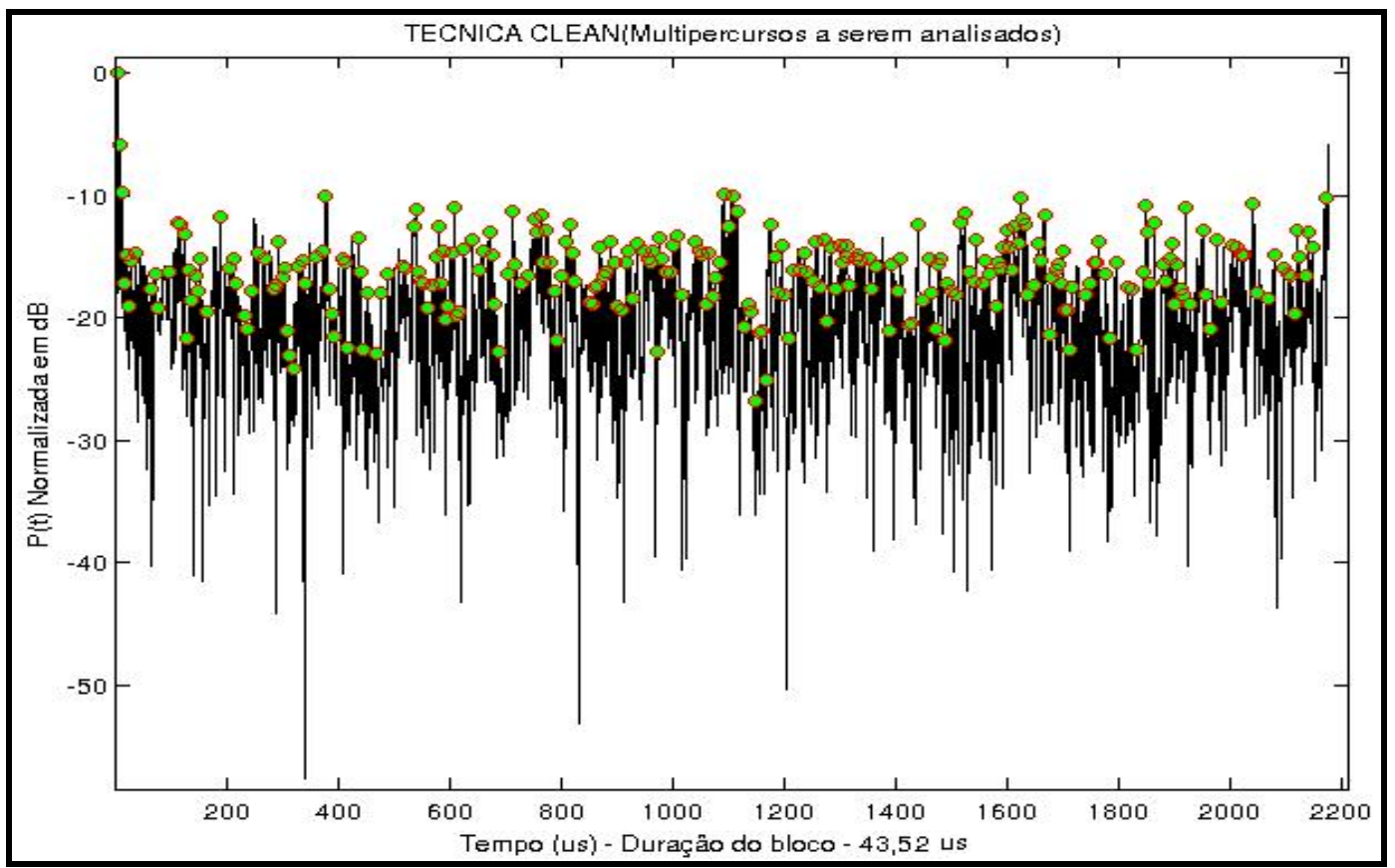

Figura 5.14: Possíveis Multipercursos válidos - CLEAN (2.5 GHz) 
A figura 5.15 ilustra os pontos circulares vermelhos que foram correlatados com o sinal de calibração e dessa forma considerados multipercursos válidos após a aplicação da técnica CLEAN.

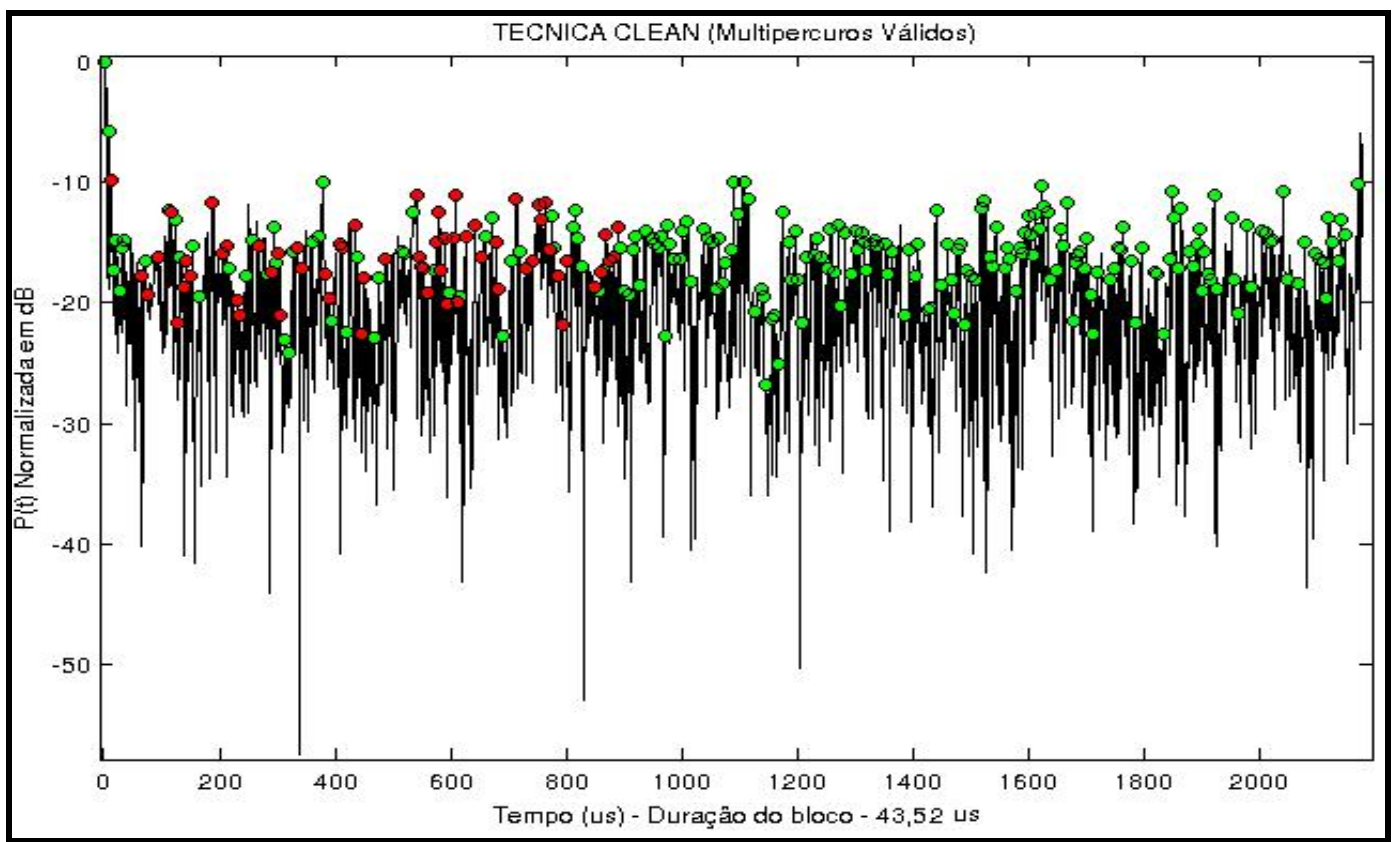

Figura 5.15: Multipercursos válidos - CLEAN (2.5 GHz) - amostra 189

Pode-se observar pelos gráficos gerados nas figuras 5.13 a 5.15 que a técnica CLEAN não é eficiente para escolher os multipercursos válidos uma vez que validou sinais como sendo multipercursos na região de piso de ruído.

A Figura 5.16 ilustra a caracterização da dispersão temporal utilizando a técnica CLEAN para cada uma das 814 amostras coletadas. Os pontos vermelhos no gráfico mostram os valores de retardo em microssegundos de cada amostra coletada durante as medições. Os pontos azuis no gráfico mostram os valores de espalhamento de retardo RMS de cada amostra coletada durante as medições. As linhas em azul mostram os valores médios de retardo e espalhamento de retardo RMS nos seus respectivos gráficos. 


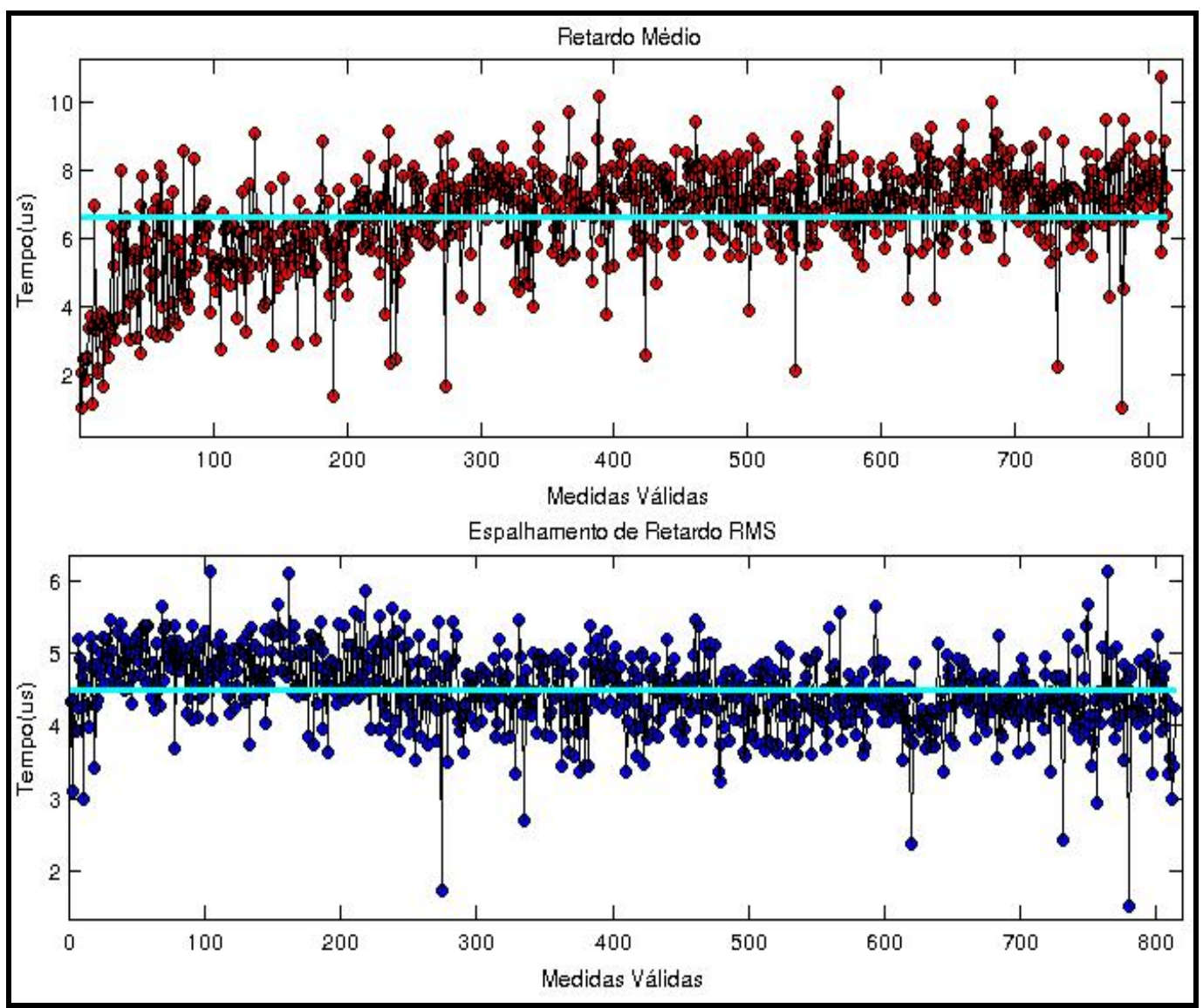

Figura 5.16: Caracterização Temporal do Canal - CLEAN (2.5 GHz)

A Figura 5.17 ilustra a resposta impulsiva do canal na faixa de $3.5 \mathrm{GHz}$.

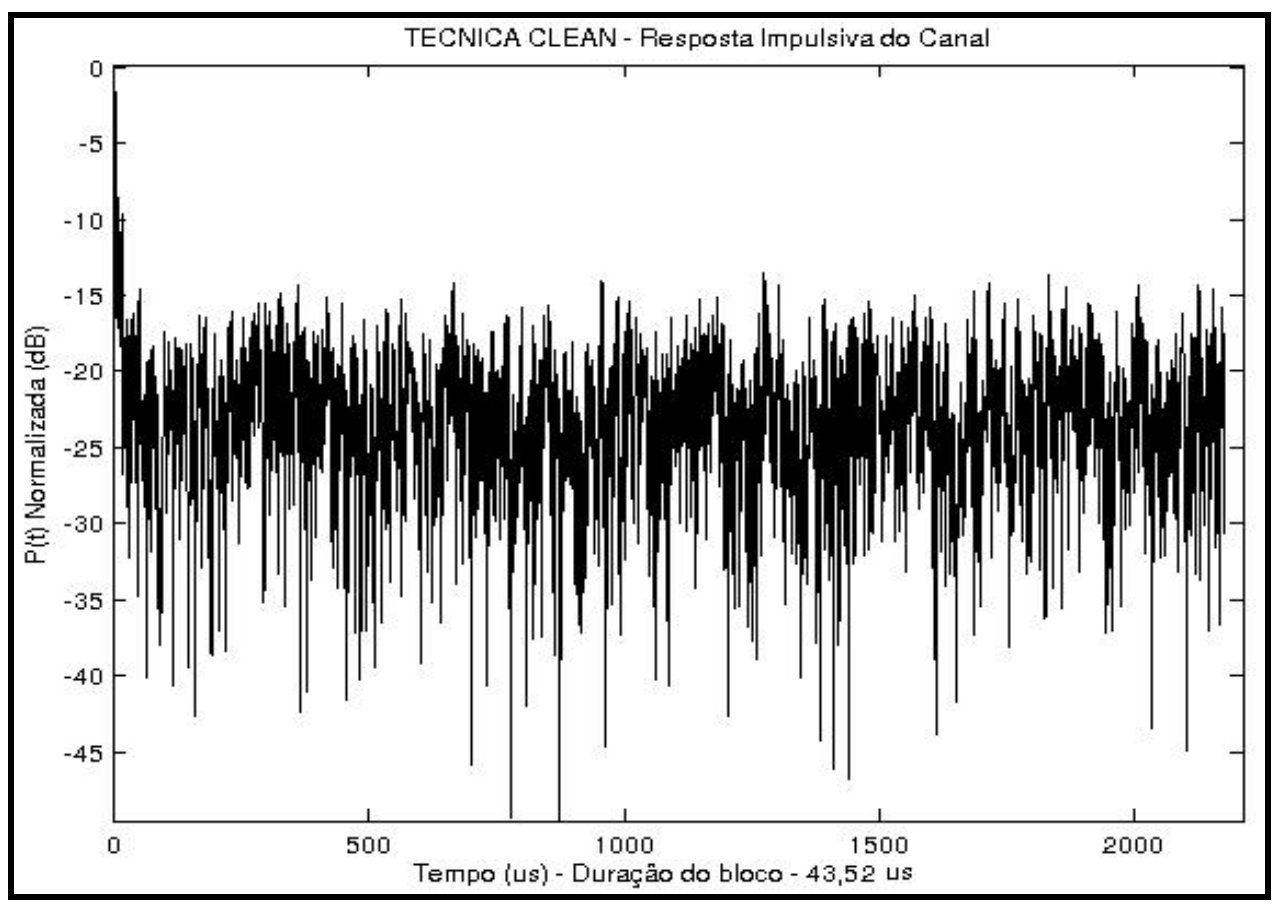

Figura 5.17: Resposta Impulsiva do Canal - CLEAN (3.5 GHz) - amostra 72 
Os pontos circulares em verde na Figura 5.18 são os que foram selecionados primeiramente pele técnica CLEAN, mas que ainda serão correlatados com o sinal de calibração para verificar se são ou não multipercursos válidos.

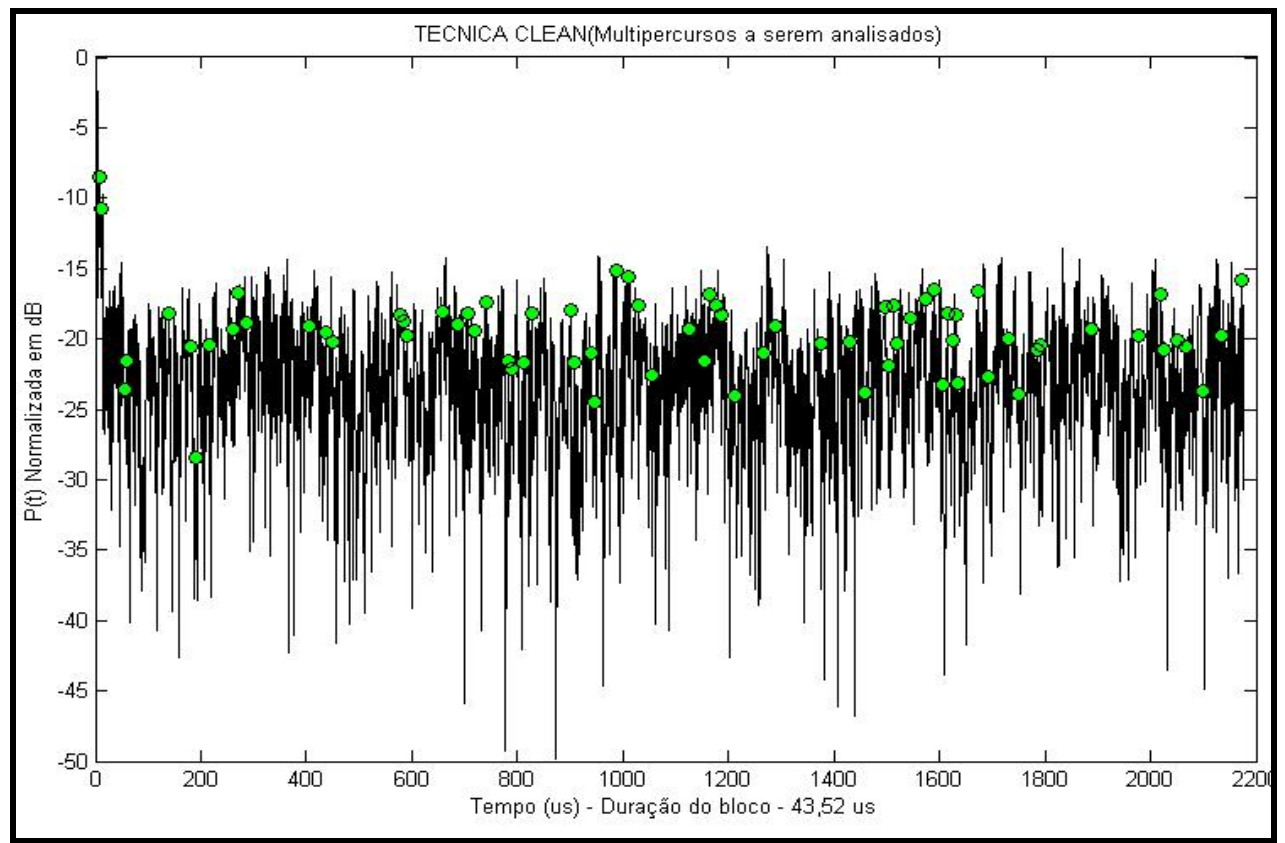

Figura 5.18: Possíveis Multipercursos válidos - CLEAN (3.5 GHz)

A Figura 5.19 ilustra os pontos circulares vermelhos que foram correlatados com o sinal de calibração e dessa forma considerados multipercursos válidos após a aplicação da técnica CLEAN.

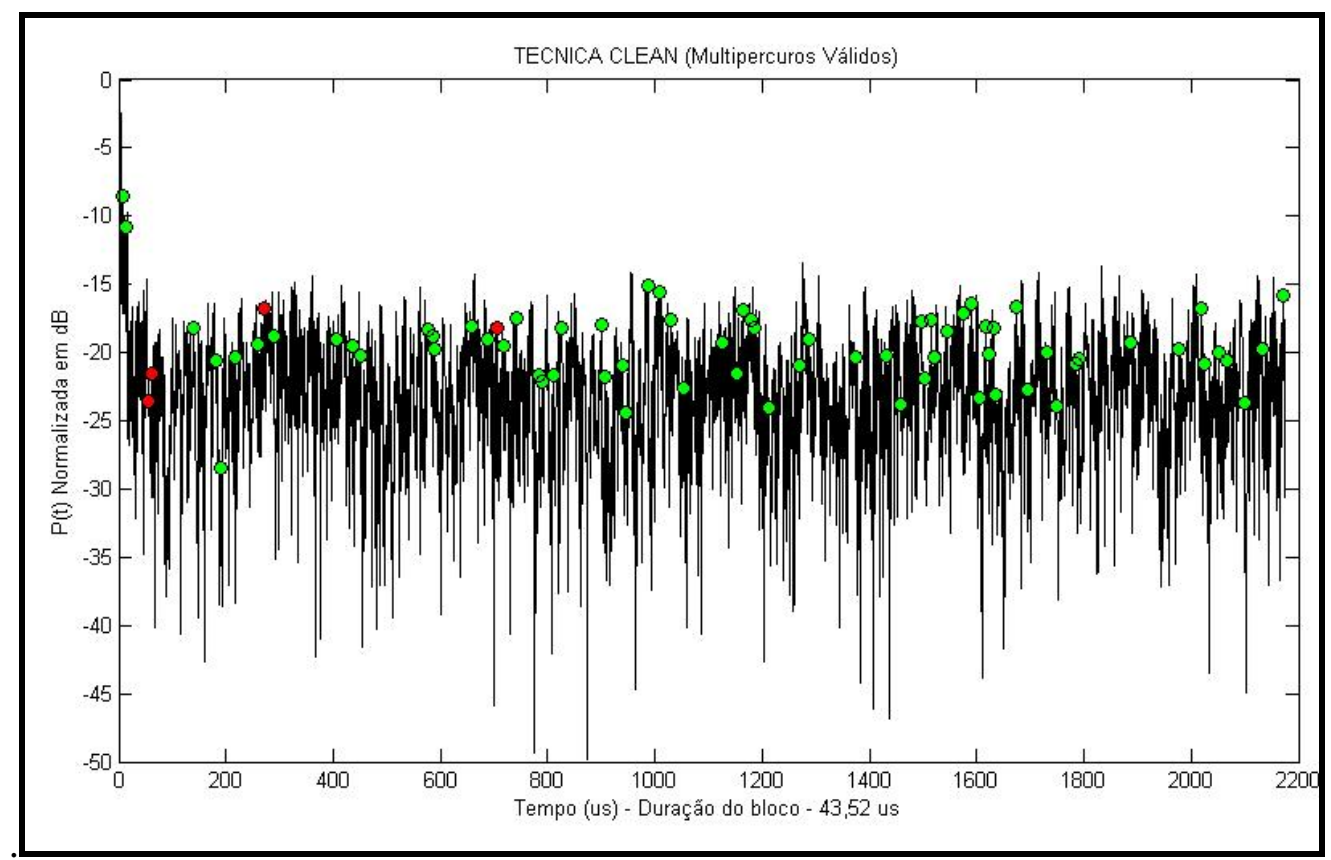

Figura 5.19: Multipercursos válidos - CLEAN $(3.5 \mathrm{GHz})$ - amostra 72 
A Figura 5.20 ilustra a caracterização da dispersão temporal utilizando a técnica CLEAN para cada uma das 102 amostras coletadas. Os pontos vermelhos no gráfico intitulado Retardo Médio, demonstram os valores de retardo em microssegundos de cada amostra coletada durante as medições. Os pontos azuis no gráfico intitulado Espalhamento de Retardo RMS, demostram os valores de Espalhamento de Retardo RMS de cada amostra coletada durante as medições. A linha em azul mostra os valores médios de Retardo e Espalhamento de Retardo RMS nos seus respectivos gráficos.

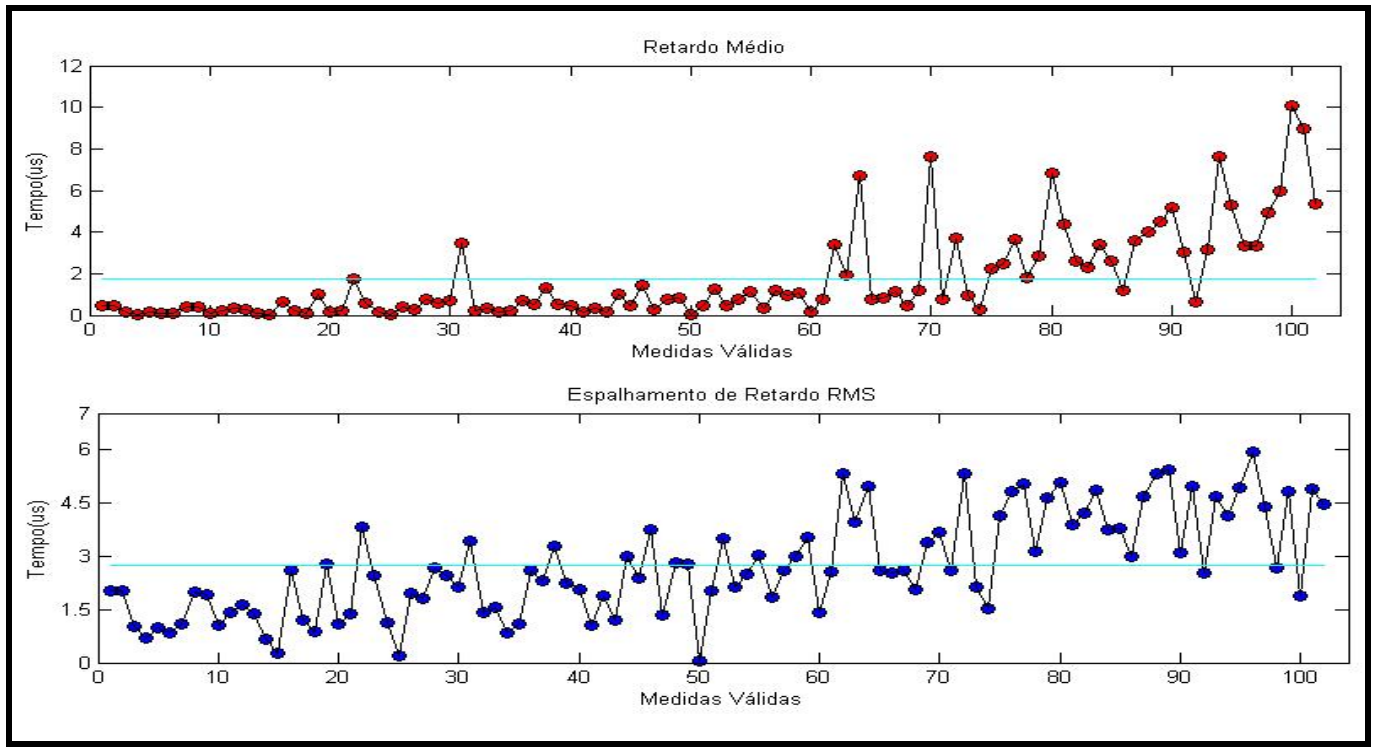

Figura 5.20: Caracterização Temporal do Canal - CLEAN (3.5 GHz)

É necessário que seja feita a análise numérica da mesma forma que foi realizada para o CFAR.

A seguir é exibida a tabela 5.3 com as repostas da caracterização para $2.5 \mathrm{GHz}$

Tabela 5.3: Resposta da Caracterização para 2.5 GHz

\begin{tabular}{|l|c|c|c|}
\hline \multirow{2}{*}{ Parâmetro } & \multicolumn{3}{|c|}{ Resultado para 2.5 GHz } \\
\cline { 2 - 4 } & Tempo $(\mu \mathrm{s})$ & $\begin{array}{c}\text { Distancia média entre os } \\
\text { espalhadores }(\mathrm{m})\end{array}$ & Prefixo Cíclico \\
\hline Retardo Médio & 6,6076 & 1982,28 & Inviável \\
\hline Desvio Padrão & 4,4844 & $\mathrm{~N} / \mathrm{A}$ & $\mathrm{N} / \mathrm{A}$ \\
\hline
\end{tabular}


A tabela 5.4 ilustra os valores de Retardo Médio e Desvio padrão calculados para cada trecho medido, segundo [3], na faixa de $3.5 \mathrm{GHz}$ utilizando a técnica CLEAN.

Tabela 5.4: Caracterização Temporal para 3.5 GHz

\begin{tabular}{|c|c|c|}
\hline Medida & Retardo Médio RMS [ $\mu$ s] & Desvio padrão do retardo RMS [ $\mu s]$ \\
\hline $02 / 11 / 200820 \mathrm{MHz}$ part1 & 1,8039 & 2,6467 \\
\hline $02 / 11 / 200820 \mathrm{MHz}$ part2 & 4,2761 & 3,9678 \\
\hline $02 / 11 / 200820 \mathrm{MHz}$ part3 & 3,6540 & 3,7697 \\
\hline $02 / 11 / 200820 \mathrm{MHz}$ part4 & 2,1300 & 2,9851 \\
\hline $02 / 11 / 200820 \mathrm{MHz}$ part5 & 2,9552 & 3,2993 \\
\hline $04 / 11 / 200820 \mathrm{MHz}$ part1 & 1,7401 & 2,7211 \\
\hline $04 / 11 / 200820 \mathrm{MHz}$ part2 & 3,7279 & 3,5858 \\
\hline $04 / 11 / 200820 \mathrm{MHz}$ part3 & 3,2408 & 3,8104 \\
\hline $04 / 11 / 200820 \mathrm{MHz}$ part4 & 1,7694 & 2,7237 \\
\hline $04 / 11 / 200820 \mathrm{MHz}$ part5 & 1,7357 & 2,7490 \\
\hline $04 / 11 / 200820 \mathrm{MHz}$ part6 & 2,3732 & 3,1552 \\
\hline $06 / 11 / 200820 \mathrm{MHz}$ part1 & 7,1105 & 4,3267 \\
\hline $06 / 11 / 200820 \mathrm{MHz}$ part2 & 6,9563 & 4,3818 \\
\hline Valor Médio & 3,3441 & 3,3940 \\
\hline
\end{tabular}

A tabela 5.5 exibe as repostas da caracterização para 3.5GHz.

Tabela 5.5: Resposta da Caracterização para $3.5 \mathrm{GHz}$

\begin{tabular}{|l|c|c|c|}
\hline \multirow{2}{*}{ Parâmetro } & \multicolumn{3}{|c|}{ Resultado para 3.5 GHz } \\
\cline { 2 - 4 } & Tempo $(\mu \mathrm{s})$ & $\begin{array}{c}\text { Distancia média entre os } \\
\text { espalhadores }(\mathrm{m})\end{array}$ & Prefixo Cíclico \\
\hline Retardo Médio & 3,3441 & 1003,23 & Inviável \\
\hline Desvio Padrão & 3,3940 & $\mathrm{~N} / \mathrm{A}$ & $\mathrm{N} / \mathrm{A}$ \\
\hline
\end{tabular}

Fazendo a mesma análise descrita no item 5.1, chega-se a conclusão que as distâncias encontradas entre os espalhadores de 1982,28 m e 1003,23 m respectivamente para as faixas de $2.5 \mathrm{GHz}$ e $3.5 \mathrm{GHz}$ mostram que a técnica CLEAN não reproduz um resultado satisfatório nesse aspecto, uma vez que a área em estudo é urbana com distâncias muito inferiores entre os espalhadores. Os valores necessários de prefixo cíclico seriam muito elevados ficando totalmente fora dos valores normalmente utilizados. 


\section{3}

\section{Comparação com a Recomendação ITU-R P.1411-6}

Como foi observada a técnica mais apropriada para a caracterização do canal é a CFAR. Assim, nesse item será feita a análise da caracterização do canal realizada através dessa técnica com diversos valores típicos da recomendação ITU-R P.1411-6. O objetivo é concluir se os resultados obtidos são coerentes e também sugerir novos valores com base nas características específicas das medições realizadas nesse trabalho.

\subsection{1}

\section{Recomendação ITU-R P.1411-6}

A análise e comparação serão feitas em relação às três tabelas existentes na recomendação ITU-R P.1411-6 onde são tratadas características referentes a modelos de multipercursos para ambientes de propagação sobre telhados (overrooftops). Segundo esta recomendação, a mediana do valor de espalhamento de atraso rms denotada por S é dada por [20]:

$$
S_{u}=\exp (A \cdot L+B) \quad \text { ns }
$$

onde:

A e B são coeficientes de espalhamento de atraso rms

L é a perda de propagação no caminho (path loss)

A tabela 5.6, que foi extraída da recomendação, lista valores típicos de coeficientes de espalhamento de atraso rms para medições realizadas com distâncias entre transmissor e receptor de 100 a 1000 metros [20].

Tabela 5.6: Valores Típicos de Coeficientes RMS

\begin{tabular}{|c|c|c|c|c|}
\hline \multicolumn{3}{|c|}{ Condições de Medição } & \multicolumn{2}{c|}{ Coeficientes de espalhamento de atraso rms } \\
\hline Area & Frequência (GHz) & Range (m) & A & B \\
\hline \multirow{3}{*}{ Urbana } & $3.650-3.750$ & $100-1000$ & 0.031 & 2.091 \\
\cline { 2 - 5 } & $1.920-1.980$ & $100-1000$ & 0.038 & 2.3 \\
& $2.110-2.170$ & & & \\
\hline
\end{tabular}


A tabela 5.7 lista os valores encontrados nas medições em $2.5 \mathrm{GHz}$ e 3.5 GHz.

Tabela 5.7: Valores encontrados de Coeficientes RMS CFAR

\begin{tabular}{|c|c|c|c|c|}
\hline \multicolumn{3}{|l|}{ Condições de Medição } & \multicolumn{2}{c|}{ Coeficientes de espalhamento de atraso rms } \\
\hline Area & Frequência $\mathrm{GHz}$ & Range $(\mathrm{m})$ & $\mathrm{A}$ & $\mathrm{B}$ \\
\hline \multirow{2}{*}{ Urbana } & 2.5 & $46-940$ & 0.0197 & 2.3955 \\
\cline { 2 - 5 } & 3.5 & $51-3412$ & 0.0201 & 2.4981 \\
\hline
\end{tabular}

Analisando os valores encontrados é possível perceber que, se comparados em ordem de grandeza, os valores estão coerentes com os valores típicos referenciados na recomendação. Dessa forma, pode-se concluir que os valores encontrados de atraso rms durante as medições, para ambas as faixas de frequência, são válidos. Além disso, os valores de coeficientes de espalhamento de atraso rms encontrados podem ser utilizados como referência para medições futuras que tenham as mesmas características das realizadas nesse trabalho.

Outra análise incluída na recomendação trata dos valores típicos de espalhamento de atraso rms onde a probabilidade cumulativa é 50\% e 95\%, de acordo com as condições de medições referenciadas na tabela 5.8.

Tabela 5.8: Valores Típicos de Espalhamento de Atraso RMS [20]

\begin{tabular}{|c|c|c|c|c|c|c|c|}
\hline \multicolumn{6}{|c|}{ Condições de Medição } & \multicolumn{2}{|c|}{ Espalhamento de Atraso rms (ns) } \\
\hline \multirow{2}{*}{ Area } & \multirow{2}{*}{ Cenário } & \multirow{2}{*}{ Frequência $\mathrm{GHz}$} & \multicolumn{2}{|c|}{ Altura da Antena } & \multirow{2}{*}{ Range $(\mathrm{m})$} & \multirow{2}{*}{$50 \%$} & \multirow{2}{*}{$95 \%$} \\
\hline & & & hbs $(m)$ & $\mathrm{hr}(\mathrm{m})$ & & & \\
\hline \multirow{2}{*}{$\begin{array}{c}\text { Urbana } \\
\text { muito elevado }\end{array}$} & LoS & \multirow{2}{*}{2,5} & \multirow{2}{*}{100} & \multirow{2}{*}{2} & \multirow{2}{*}{$100-1000$} & 208 & 461 \\
\hline & NLOS & & & & & 407 & 513 \\
\hline \multirow{2}{*}{ Urbana } & & \multirow{2}{*}{3,7} & 60 & 2 & $100-1000$ & 232 & 408 \\
\hline & & & 40 & 2 & $100-1000$ & 121 & 357 \\
\hline \multirow{2}{*}{ Suburbana } & & 3,7 & 20 & 2 & $100-1000$ & 125 & 542 \\
\hline & & 5,2 & 20 & 2,8 & $100-1000$ & 189 & 577 \\
\hline
\end{tabular}

A tabela 5.9 lista os valores encontrados nas medições em $2.5 \mathrm{GHz}$ e 3.5 GHz.

Tabela 5.9: Valores encontrados de Espalhamento de atraso RMS

\begin{tabular}{|c|c|c|c|c|c|c|c|}
\hline \multicolumn{5}{|c|}{ Condições de Medição } & \multicolumn{2}{c|}{ Espalhamento de Atraso rms (ns) } \\
\hline \multirow{2}{*}{ Area } & \multirow{2}{*}{ Cenário } & Frequência GHz & Altura da Antena & \multirow{2}{*}{ Range $(\mathrm{m})$} & $50 \%$ & \multirow{2}{*}{$95 \%$} \\
\cline { 3 - 6 } & & 2.5 & 30 & 3 & $46-940$ & 126 & 269 \\
\hline \multirow{2}{*}{ Urbana } & & 3.5 & 42 & 2 & $51-3412$ & 161 & 290 \\
\cline { 3 - 6 } & & &
\end{tabular}


Analisando os valores encontrados é possível perceber que os valores são muito próximos dos recomendados, o que valida às medições realizadas. Os valores encontrados podem ser considerados uma contribuição deste trabalho para relacionar novos valores de referência dentro das condições de medições, onde as alturas das antenas e frequências são diferentes dos encontrados na recomendação ITU-R P.1411-6.

A última análise que será feita nesse item trata da estimativa do número de componentes de sinal, ou seja, um componente dominante mais os componentes de multipercursos, que chegam ao receptor. O número de componentes de sinal podem ser representados a partir do perfil de atraso como o número de picos cujas amplitudes estão dentro de uma faixa $\mathrm{A}$ em $\mathrm{dB}$ entre o pico mais alto e acima do piso de ruído. A Figura 5.21 ilustra graficamente essa relação.

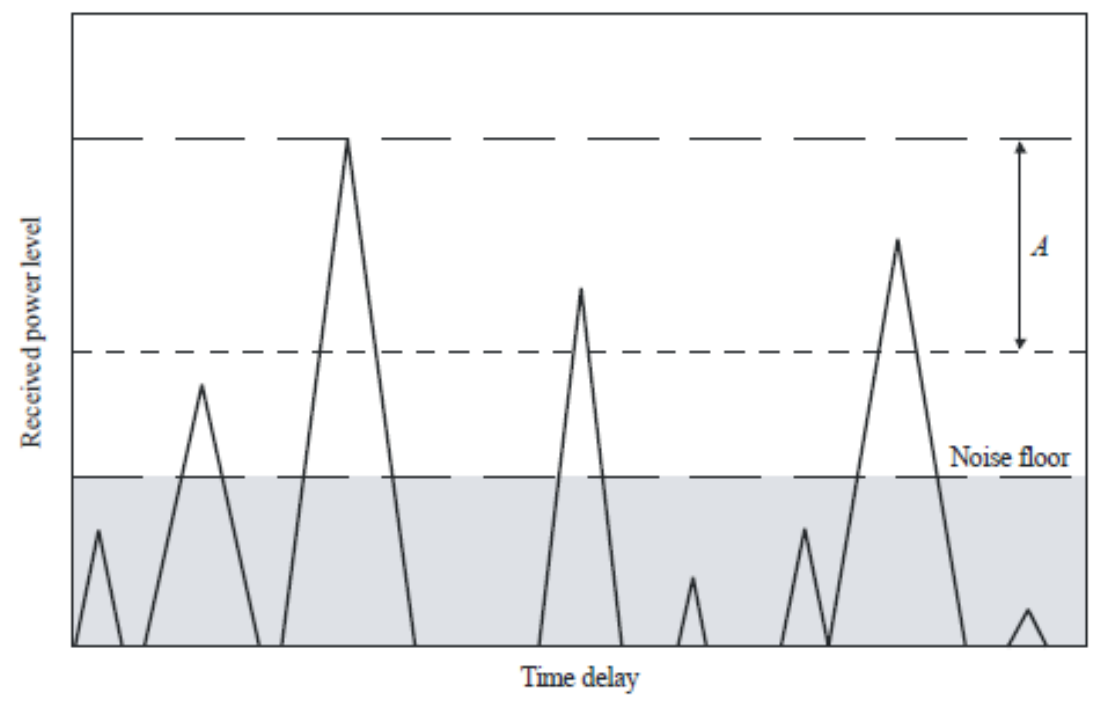

Figura 5.21: Determinação do número de picos ITU-R P.1411-6 [20]

A tabela 5.10 ilustra os resultados para o número de componentes do sinal a partir de medições em diferentes cenários para diferentes alturas da antena, ambientes e para diferentes frequências segundo recomendação ITU-R P.1411-6. 
Tabela 5.10: Número máximo de Componentes de sinal ITU-R P.1411-6 [20]

\begin{tabular}{|c|c|c|c|c|c|c|c|c|c|c|c|}
\hline \multicolumn{6}{|c|}{ Condições de Medição } & \multicolumn{6}{|c|}{ Número Máximo de Componentes } \\
\hline \multirow{3}{*}{$\begin{array}{c}\text { Tipo de } \\
\text { ambiente }\end{array}$} & \multirow{3}{*}{$\begin{array}{c}\text { Resolução de } \\
\text { tempo de atraso }\end{array}$} & \multirow{3}{*}{$\begin{array}{l}\text { Frequência } \\
\text { GHz }\end{array}$} & \multicolumn{2}{|c|}{ Altura da antena } & \multirow{3}{*}{ Range (m) } & \multirow{2}{*}{\multicolumn{2}{|c|}{$3 \mathrm{~dB}$}} & \multirow{2}{*}{\multicolumn{2}{|c|}{$5 \mathrm{~dB}$}} & \multirow{2}{*}{\multicolumn{2}{|c|}{$10 \mathrm{~dB}$}} \\
\hline & & & $\mathrm{L}_{\mathrm{h}=}=\mathrm{m} \mathrm{m}$ & $\mathrm{hr}(\mathrm{m})$ & & & & & & & \\
\hline & & & Inos (mil) & (III) (III) & & $80 \%$ & $95 \%$ & $80 \%$ & $95 \%$ & $80 \%$ & $95 \%$ \\
\hline Urbana & $200 \mathrm{~ns}$ & $1.9-2.1$ & 46 & 1.7 & $100-1600$ & 1 & 2 & 1 & 2 & 2 & 4 \\
\hline Suburbana & $175 \mathrm{~ns}$ & 2.5 & 12 & 1 & $200-1500$ & 1 & 2 & 1 & 2 & 2 & 4 \\
\hline \multirow{3}{*}{ Urbana } & \multirow{3}{*}{$20 \mathrm{~ns}$} & \multirow{3}{*}{3.35} & \multirow{2}{*}{4} & \multirow{2}{*}{1.6} & $0-200$ & 2 & 3 & 2 & 4 & 5 & 6 \\
\hline & & & & & $0-1000$ & 2 & 3 & 2 & 4 & 5 & 9 \\
\hline & & & 55 & 2.7 & $150-590$ & 2 & 2 & 2 & 3 & 3 & 13 \\
\hline Residencial & $20 \mathrm{~ns}$ & 3.35 & 4 & 2.7 & $0-480$ & 2 & 2 & 2 & 2 & 2 & 3 \\
\hline Suburbana & $175 \mathrm{~ns}$ & 3.5 & 12 & 1 & $200-1500$ & 1 & 2 & 1 & 2 & 1 & 5 \\
\hline Suburbana & $50 \mathrm{~ns}$ & 3.67 & 40 & 2.7 & $0-5000$ & 1 & 2 & 1 & 3 & 3 & 5 \\
\hline Suburbana & $100 \mathrm{~ns}$ & 5.8 & 12 & 1 & $200-1500$ & 1 & 2 & 3 & 5 & 4 & 5 \\
\hline \multirow{3}{*}{ Urbana } & \multirow{3}{*}{$20 \mathrm{~ns}$} & \multirow{3}{*}{8.45} & \multirow{2}{*}{4} & \multirow{2}{*}{1.6} & $0-200$ & 1 & 3 & 2 & 3 & 4 & 6 \\
\hline & & & & & $0-1000$ & 1 & 2 & 2 & 4 & 4 & 8 \\
\hline & & & 55 & 2.7 & $150-590$ & 2 & 2 & 2 & 3 & 3 & 12 \\
\hline \multirow{2}{*}{ Urbana } & \multirow{2}{*}{$20 \mathrm{~ns}$} & \multirow{2}{*}{15.75} & \multirow{2}{*}{4} & \multirow{2}{*}{1.6} & $0-200$ & 1 & 3 & 2 & 3 & 4 & 5 \\
\hline & & & & & $0-1000$ & 2 & 3 & 2 & 4 & 6 & 10 \\
\hline
\end{tabular}

A tabela 5.11 lista os valores encontrados nas medições em $2.5 \mathrm{GHz}$ e 3.5 $\mathrm{GHz}$.

Tabela 5.11: Número máximo de Componentes de sinal encontrados

\begin{tabular}{|c|c|c|c|c|c|c|c|c|c|c|c|c|c|c|}
\hline \multicolumn{6}{|c|}{ Condições de Medição } & \multicolumn{9}{|c|}{ Número Máximo de Componentes } \\
\hline \multirow{2}{*}{$\begin{array}{c}\text { Tipo de } \\
\text { ambiente }\end{array}$} & \multirow{2}{*}{$\begin{array}{l}\text { Resolução } \\
\text { de tempo } \\
\text { de atraso }\end{array}$} & \multirow{2}{*}{$\begin{array}{c}\text { Frequência } \\
\text { GHz }\end{array}$} & \multicolumn{2}{|c|}{$\begin{array}{c}\text { Altura } \\
\text { da antena }\end{array}$} & \multirow{2}{*}{ Range $(\mathrm{m})$} & \multirow{2}{*}{\multicolumn{3}{|c|}{$3 \mathrm{~dB}$}} & \multirow{2}{*}{\multicolumn{3}{|c|}{$5 \mathrm{~dB}$}} & \multirow{2}{*}{\multicolumn{3}{|c|}{$10 \mathrm{~dB}$}} \\
\hline & & & hbs (m) & $\mathrm{hr}(\mathrm{m})$ & & & & & & & & & & \\
\hline \multirow{4}{*}{ Urbana } & \multirow{4}{*}{$20 \mathrm{~ns}$} & \multirow{2}{*}{2.5} & \multirow{2}{*}{30} & \multirow{2}{*}{3} & \multirow{2}{*}{$46-940$} & $89 \%$ & $97 \%$ & $99 \%$ & $71 \%$ & $88 \%$ & $95 \%$ & $80 \%$ & $87 \%$ & $94 \%$ \\
\hline & & & & & & 1 & 2 & 3 & 1 & 2 & 3 & 4 & 5 & 7 \\
\hline & & \multirow{2}{*}{3.5} & \multirow{2}{*}{42} & \multirow{2}{*}{2} & \multirow{2}{*}{$51-3412$} & $71 \%$ & $94 \%$ & $99 \%$ & $81 \%$ & $93 \%$ & $97 \%$ & $79 \%$ & $94 \%$ & $97 \%$ \\
\hline & & & & & & 0 & 1 & 2 & 1 & 2 & 3 & 3 & 5 & 6 \\
\hline
\end{tabular}

É possível perceber que os resultados estão coerentes devido à proximidade encontrada se comparados com a recomendação ITU-R P.1411-6. As medições realizadas nesse trabalho possuem algumas diferenças de características como, por exemplo: altura das antenas e faixa de distâncias entre o transmissor e receptor, dessa forma, já é esperado que os valores não fossem os mesmos. Os resultados apresentados na tabela 5.11 podem ser considerados nova referência, sendo também mais uma das contribuições desse trabalho. 


\section{Conclusões}

Para apresentar as conclusões é importante recordar os objetivos principais deste trabalho. O principal objetivo é caracterizar o canal de radiopropagação móvel levando em consideração os efeitos dispersivos encontrados e comparando dados estatísticos encontrados com a recomendação ITU-R P.1411-6. Um objetivo secundário foi determinar a técnica de filtragem de perfil de retardos de potência a ser adotada, como ferramenta na seleção dos multipercursos que serão considerados nas análises relacionadas à recomendação ITU-R P.1411-6.

Como foi demonstrado no item 5, Análise de Resultados, ficou claro que a técnica CFAR teve resultado satisfatório em relação aos valores encontrados para a distância média entre os espalhadores, retardo médio, desvio padrão e prefixo cíclico. No caso da técnica CLEAN os valores encontrados para os mesmos parâmetros não foram coerentes com o ambiente urbano em estudo. Dessa forma podemos concluir que a técnica de filtragem de perfil de retardos de potência CFAR realmente se comportou de forma adequada para medições outdoor. Já a técnica CLEAN não se mostrou adequada para esse tipo de ambiente no processo de identificação dos multipercursos válidos. Sendo assim, a técnica de filtragem de perfil de retardos de potência considerada como adequada na seleção dos multipercusos válidos foi a CFAR.

Em relação ao objetivo principal desse trabalho foram feitas três análises principais:

i. Encontrar os coeficientes de espalhamento de atraso rms A e B a partir da mediana do valor de espalhamento de atraso rms chamada de $S_{\mathrm{u}}$ :

Para essa análise, cada amostra medida de multipercurso considerado válido, foram calculados os coeficientes de espalhamento de atraso rms, A e B em função da perda de propagação e atraso rms medidos. Os valores encontrados de A e B que atendiam a mediana $S_{u}$ ficaram próximos dos valores utilizados na recomendação, o que corrobora para a validação dos resultados 
encontrados. Dessa forma pode-se concluir que os valores encontrados para A e B além de serem válidos podem ser utilizados como referência para as faixas de $2.5 \mathrm{GHz}$ e $3.5 \mathrm{GHz}$ levando-se em conta também as novas faixas de distâncias consideradas.

ii. Encontrar os valores típicos de espalhamento de atraso rms: Para essa análise, foi realizada estatística cumulativa dos valores de atraso rms dentro das faixas percentuais de $50 \%$ e $95 \%$, os valores encontrados para ambas as faixas de $2.5 \mathrm{GHz}$ e $3.5 \mathrm{GHz}$ se mostraram coerentes. Vale ressaltar que principalmente as alturas das antenas de transmissão e recepção são diferentes das utilizadas pela recomendação ITU-R P.1411-6. Sendo assim, espera-se encontrar a variação observada entre os valores recomendados e os encontrados. Os valores encontrados podem ser considerados referência para as medições que sejam feitas levando-se em consideração as mesmas características das medições realizadas nesse trabalho.

iii. Encontrar os valores estatísticos cumulativos para o número de componentes por amostra que estão afastadas em $3 \mathrm{~dB}, 5 \mathrm{~dB}$ e $10 \mathrm{~dB}$ em relação a componente com valor de pico.

Para essa análise, foram analisadas todas as amostras consideradas multipercurso válido em ambas as faixas de frequência $2.5 \mathrm{GHz}$ e 3.5 GHz. Foram analisadas todas as componentes de cada uma das amostras. A análise estatística cumulativa mostrada ficou coerente com os valores recomendados pela norma ITU-R P.1411-6 podendo ser considerados novos valores de referência para as medições que sejam feitas levando-se em consideração as mesmas características das medições realizadas nesse trabalho. 


\section{Sugestões para trabalhos futuros}

i. Seria interessante realizar as mesmas análises realizadas neste trabalho em outras faixas de frequência. Assim sugere-se as mesmas análises em faixas de frequências de interesse estratégico da comunidade acadêmica.

ii. -.+Seria interessante realizar outras análises em relação a outros parâmetros da recomendação ITU-R P.1411-6 que sejam de interesse da comunidade acadêmica tanto para as faixas de frequências utilizadas neste trabalho quanto para outras faixas que sejam de interesse da comunidade acadêmica. 


\section{8}

\section{Referências Bibliográficas}

[1] J. D. Parsons, The Mobile Radio Propagation Channel, 2.ed, New York: John Wiley \& Sons, 2000.

[2] BARROS, F. J. B. Medidas e Análise da Dispersão Temporal do Canal de Propagação UWB Indoor em Vários Tipos de Ambientes. Rio de Janeiro, 2005. 122 f. Dissertação (Mestrado em Engenharia de Telecomunicações) - Centro de Estudos em Telecomunicações, PUCRio, Rio de Janeiro, 2005.

[3] RON, C.V.R. Caracterização do Canal Rádio em Banda Larga na faixa de 3,5GHz em Ambiente Urbano, Tese de Doutorado, Pontifícia Universidade Católica do Rio de Janeiro, Rio de Janeiro, Setembro de 2009.

[4] BELLO,P.A, Randomly Time-Variant Linear Channels, IEEE Trans. On Com. Systems, vol. 11,pp. 360-393, December 1963.

[5] V. K. Garg and Joseph E. Wilkes, "Wireless and Personal Communications Systems,” Prentice Hall, 1996.

[6] Notas de Aula do Curso de Canal de Propagação Rádio Móvel Professor Gláucio Lima Siqueira, CETUC - PUC/Rio.

[7] T. S. Rappaport, “Comunicações sem fio - Princípios e práticas”, 2.ed, São Paulo: Pearson - Prentice Hall, 2009.

[8] YANCOUB, M. D., “Foundations of Mobile Radio Engineering”, CRC Press, New York, 1993.

[9] ACOSTA-MARUM, Guillermo. Measurements, Modeling, and OFDM Synchronization for the Wideband Mobile-to-Mobile Channel, Thesis of PhD, Georgia Institute of Technology, 2007.

[10] DA COSTA, R. B. F., Dissertacao de Mestrado: Estudo e Simulação de Técnicas de Localização de Terminais em Ambientes Microcelulares. PUC-Rio 2003.

[11] "Wimax - general information about the standard 802.16”, Rohde \& Schwartz Product Application Note, 2006 3.3.1. 
[12] J. B. Andersen, COST 231 Final Report, Chapter 2: Radio Channel Characterisation. Denmark: Aalborg University, 1999. 3

[13] J. M. Albornoz, “A wideband channel sounder,” 2001. 3.2

[14] SOUZA, C. F. Análise da dispersão temporal de canais de banda ultralarga (UWB) através de medidas realizadas em ambientes internos e externos. Niterói,2006. 251 f. Dissertação (Mestrado em Engenharia de Telecomunicações) - Escola de Engenharia, Universidade Federal Fluminense, Niterói, 2006.

[15] S. E. J. V. D. C., "Delay spread measurements for the digital cellular channel in toronto," IEEE Transactions on veicular tecnhnology, vol 43. No 4, pp. 837-847, Nov. 1994. 3.3.2.

[16] P. V. G. Castellanos, “Caracterização do canal de propagação banda larga na faixa UHF para aplicações de tv digital,” Ph.D. dissertation, Departamento de Engenharia Elétrica, PUC-Rio, 2009. 3.3.2.

[17] L. J. de Matos, "Influência da vegetação na dispersão dos sinais rádiomóveis,“ Ph.D. dissertation, Departamento de Engenharia Elétrica, PUC-Rio, 2005. 3.3.2.

[18] G. Acosta, “Ofdm simulation using MATLAB," Smart Antenna Research Laboratory, Georgia Institute of Technology, 2000. 4.2

[19] "Wimax - general information about the standard 802.16”, Rohde \& Schwartz Product Application Note, 2006 3.3.1.

[20] Propagation data and prediction methods for the planning of shortrange outdoor radiocommunication systems and radio local area networks in the frequency range $300 \mathrm{MHz}$ to $100 \mathrm{GHz}$," Recommendation ITU-R P.1411-6, 2012. 2.1.1 
9

Anexo A: Códigos em MATLAB

Rotina Principal para o Cálculo com a técnica CFAR

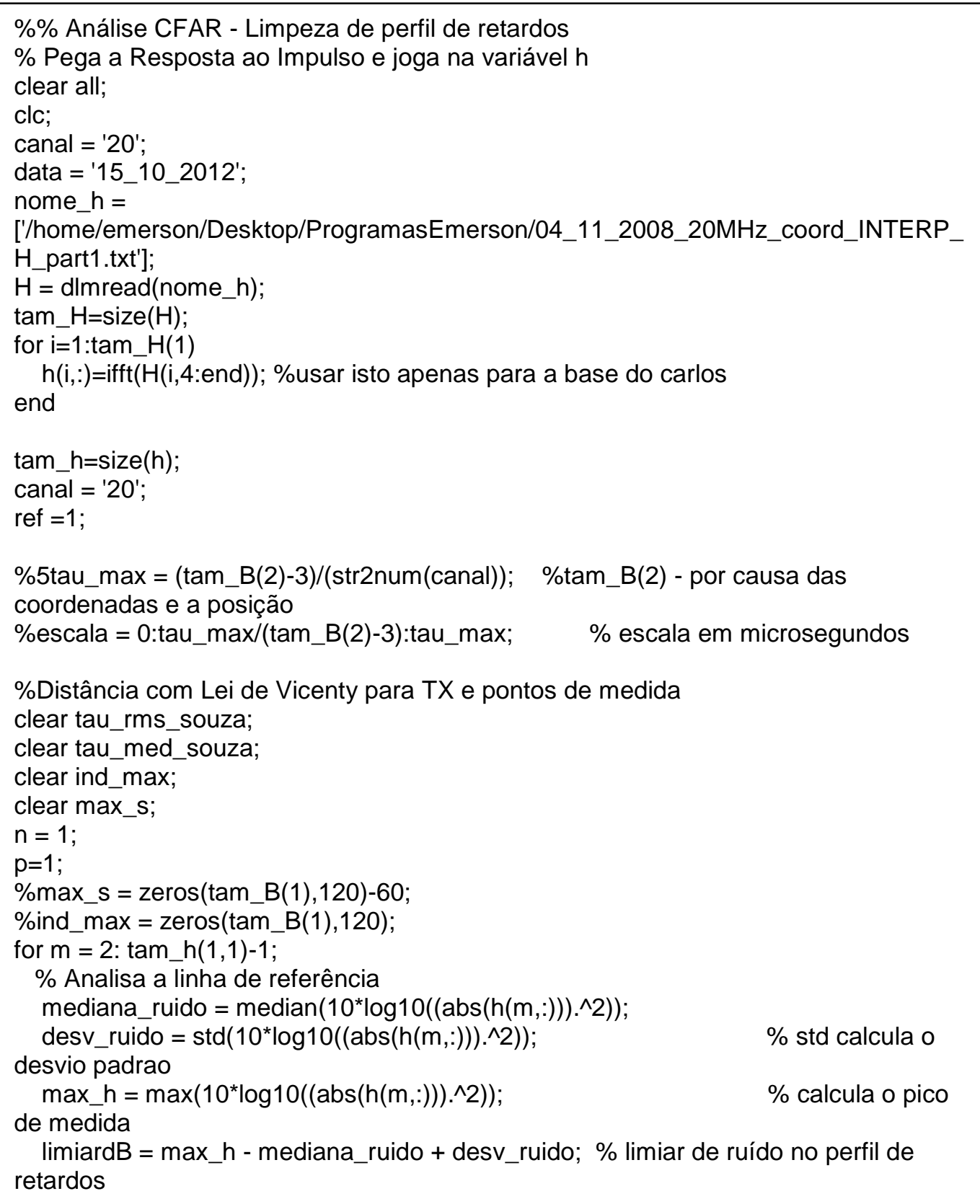


$\%$ Analisa a linha de referência -1

mediana_ruido $=\operatorname{median}\left(10^{*} \log 10\left((\operatorname{abs}(\mathrm{h}(\mathrm{m}-1, \mathrm{:}))) .^{\wedge} 2\right)\right)$;

desv_ruido $=\operatorname{std}\left(10^{\star} \log 10\left((\operatorname{abs}(\mathrm{h}(\mathrm{m}-1, \mathrm{n}))) \cdot^{\wedge} 2\right)\right) ;$

$\max \_\mathrm{h}=\max \left(10^{\star} \log 10\left((\operatorname{abs}(\mathrm{h}(\mathrm{m}-1, \mathrm{i}))) \cdot{ }^{\wedge} 2\right)\right)$;

limiardB_menos $=\max \_\mathrm{h}-$ mediana_ruido + desv_ruido;

$\%$ Analisa a linha de referência +1

mediana_ruido $=\operatorname{median}\left(10^{\star} \log 10\left((\operatorname{abs}(\mathrm{h}(\mathrm{m}+1,:))) \cdot{ }^{\wedge} 2\right)\right)$;

desv_ruido $=\operatorname{std}\left(10^{*} \log 10\left((\operatorname{abs}(\mathrm{h}(\mathrm{m}+1, \mathrm{)}))) \cdot{ }^{\wedge} 2\right)\right)$;

$\max \_h=\max \left(10^{*} \log 10\left((\operatorname{abs}(\mathrm{h}(\mathrm{m}+1,:))) \wedge^{\wedge} 2\right)\right)$;

limiardB_mais $=\max \_\mathrm{h}-$ mediana_ruido + desv_ruido;

clear maxim novo souza;

clear index_novo_souza;

clear maxim_souza;

clear index_max_souza;

clear maxim normal;

clear index_max_normal;

[maxim_souza, index_max_souza] $=$ PDP_souza $(\mathrm{h}, \mathrm{m}$,limiardB,

limiardB_menos,limiard $\bar{B}_{-}$mais);

$\mathrm{j}=1$;

index_novo_souza $(1)=0$;

maxim_novo_souza $(1)=0$;

$\%$ Se existem indices válidos adjacentes...

for $i=2$ : length(index_max_souza)-1;

\%if index_max_souza(i+1) == index_max_souza(i)+1 || index_max_souza(i-1)

$==$ index_max_souza(i)-1;

index_novo_souza(j) = index_max_souza(i);

maxim_novo_souza $(\mathrm{j})=$ maxim_souza $(\mathrm{i})$;

end

$$
\mathrm{j}=\mathrm{j}+\overline{1} \text {; }
$$

Quant = size(index_novo_souza);

VetorQuantVal $(\mathrm{m})=$ Quant $(1,2)$;

if $j>1$;

[tau_rms_souza(n), tau_med_souza(n)] = Delay_Spread $($ canal, $h, m$,

maxim_novo_souza, index_novo_souza);

$\mathrm{n}=\mathrm{n}+1$

end

end

$\% \%$ GERA GRAFICO MONOGRAFIA

ValorMelhor $=\max ($ VetorQuantVal $)$

PosMelhor $=$ find $($ VetorQuantVal==ValorMelhor)

$\%$ Analisa a linha de referência

mediana_ruido $=$ median $\left(10^{\star} \log 10\left((\operatorname{abs}(\mathrm{h}(\right.\right.$ PosMelhor,$\left.\left.:))) \cdot{ }^{\wedge} 2\right)\right)$;

mediana ruido

desv_ruido $=\operatorname{std}\left(10^{\star} \log 10((\operatorname{abs}(\mathrm{h}(\right.$ PosMelhor,::))).^2));\% std calcula o desvio

padrao

desv_ruido

$\max \_$h $=\max \left(10^{*} \log 10((\operatorname{abs}(\mathrm{h}(\right.$ PosMelhor,::))).^2));

$\%$

calcula o pico de medida

max_h

limiardB $=$ max_h - mediana_ruido + desv_ruido;

\% limiar de ruído

no perfil de retardos

$\%$ Analisa a linha de referência -1

mediana_ruido $=$ median $\left(10 * \log 10\left((\operatorname{abs}(\right.\right.$ h $($ PosMelhor $\left.\left.-1,:))) \cdot{ }^{\wedge} 2\right)\right)$;

desv_ruido $=\operatorname{std}\left(10^{\star} \log 10\left(\left(\operatorname{abs}\left(\mathrm{h}(\text { PosMelhor-1,:))) })^{\wedge} 2\right)\right)\right.\right.$;

$\max \_h=\max \left(10^{*} \log 10((\operatorname{abs}(\mathrm{h}(\right.$ PosMelhor-1,:))).^2));

limiardB_menos = max_h - mediana_ruido + desv_ruido;

$\%$ Analisa a linha de referência +1

mediana_ruido $=\operatorname{median}\left(10^{*} \log 10\left((\operatorname{abs}(\mathrm{h}(\right.\right.$ PosMelhor $\left.\left.+1,:))) \cdot{ }^{\wedge} 2\right)\right)$;

desv_ruido $=\operatorname{std}\left(10^{\star} \log 10\left((\operatorname{abs}(\mathrm{h}(\right.\right.$ PosMelhor $\left.\left.+1,:))) .^{\wedge} 2\right)\right)$;

$\left.\max \_h=\max \left(10^{\star} \log 10((\operatorname{abs}(\mathrm{h}(\text { PosMelhor }+1,:))))^{\wedge} 2\right)\right)$;

limiardB_mais $=$ max_h - mediana_ruido + desv_ruido; 
clear maxim_novo_souza;

clear index_novo_souza;

clear maxim_souza;

clear index_max_souza;

clear maxim_normal;

clear index_max_normal;

[maxim_souza, index_max_souza] = PDP_souza(h, PosMelhor,limiardB,

limiardB_menos,limiardB_mais);

$\mathrm{j}=1$;

index_novo_souza $(1)=0$

maxim_novo_souza $(1)=0$

$\%$ Se existem indices válidos adjacentes...

for $i=2$ : length(index_max_souza)-1

if index_max_souza $(i+1)==$ index_max_souza(i)+1 || index_max_souza(i-1) ==

index_max_souza(i)-1

index_novo_souza $(\mathrm{j})=$ index_max_souza(i);

maxim_novo_souza(j) $=$ maxim_souza(i); $\mathrm{j}=\mathrm{j}+\overline{1}$;

end

end

figure (1)

$\mathrm{AA}=\left(10^{*} \log 10\left(\operatorname{abs}\left(\mathrm{h}\left(\right.\right.\right.\right.$ PosMelhor,:)) $\left.\left.{ }^{\wedge} 2\right)\right)$

valor_MAX=max $(A A(:))$

Val_ref_normatiza $=((20 * \log 10(\operatorname{abs}(\mathrm{h}($ PosMelhor,::))) $)$-valor_MAX);

Val_normatizado=((Val_ref_normatiza(:,:)));

plot((Val_normatizado),'-'-'')

title(' Técnica CFAR ')

xlabel(' Tempo $(\mu \mathrm{s})$ ')

ylabel(' P(t) Normalizada (dB) ')

hold on

maxim_novo_souza=(maxim_novo_souza-valor_MAX)

plot(index_novo_souza,maxim_novo_souza,'o','linewidth',1,'Markeredgecolor','r','mark ersize',6,'markerfacecolor','g')

hold on

\% Calcula Atraso Médio e DesvioPadrao

AtrasoMedio $=$ mean(tau_med_souza)

DesvioPadrao $=$ mean $($ tau_rms_souza $)$

soma $=0$

tamanho $=$ length (tau_rms_souza)

for $\mathrm{tt}=1$ : length(tau_rms_souza)

soma $=$ soma + tau_rms_souza(tt)

end

mediasoma $=$ soma $/$ tamanho

figure(2)

$\left.\mathrm{BB}=\left(10^{\star} \log 10(\operatorname{abs}(\mathrm{h}(:,:)))^{\wedge} 2\right)\right)$;

valor_MAX_1=max(BB(:));

Val_ref_normatiza_BB $=\left(\left(20^{\star} \log 10(\operatorname{abs}(\mathrm{h}(:,:)))\right)\right.$-valor_MAX_1 $)$;

Val_normatizado_BB=((Val_ref_normatiza_BB(:,:)));

$\mathrm{SS}=$ size (BB);

NLinhas $=S S(1,1)$

NColunas $=S S(1,2)$;

$[X, Y]=$ meshgrid(1:1:NColunas, 1:1:NLinhas);

Val_normatizado_BB_new=Val_normatizado_BB'

mesh(Val_normatizado_BB_new $)$;

title(' Resposta Impulsiva do Canal - Medida 04/11/2008 20MHz part1')

xlabel(' Tempo ( $\mu \mathrm{s})$ ')

ylabel(' Amostras ')

zlabel(' P(t) Normalizada (dB) ') 
Rotina para a técnica CFAR

function [maxim, index_max] = PDP_souza $(h$, amostra, limiardB, menos, mais)

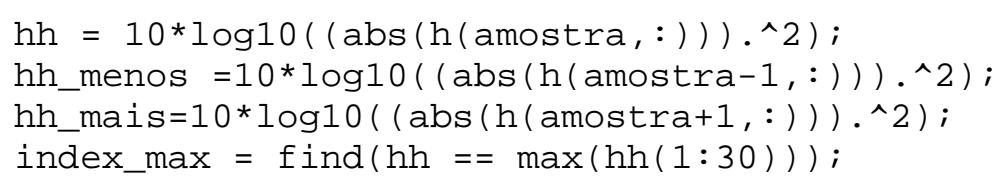

for $a=2$ : length $(h(\operatorname{amostra},:))-1$

h_a $(a)=10^{*} \log 10\left((\operatorname{abs}(h(\operatorname{amostra}, a)))^{\wedge} 2\right)$;

h_a_menos $(a)=10^{*} \log 10\left((\operatorname{abs}(h(\operatorname{amostra}-1, a)))^{\wedge} 2\right)$;

h_a_mais $(a)=10^{*} \log 10\left((\operatorname{abs}(h(\operatorname{amostra}+1, a)))^{\wedge} 2\right)$;

h_a $(a+1)=10^{*} \log 10\left((\operatorname{abs}(h(\text { amostra }, a+1)))^{\wedge} 2\right)$;

$\%$ o primeiro if so verifica se dentro de uma linha nao estamos num vale

if h_a(a) $>$ h_a(a-1) \&\& h_a(a)>h_a(a+1) ||$h \_a(a)>$

$h \_a(a-1) \quad \& \& h \_a(a)<h \_a(a+1)|| h \_a(a)<h \_a(a-1) \& \&$

h_a $(a)>h \_a(a+1) \%$ Esse cara faz a análise dos perfis post e ant conforme nomeclatura CFAR.

$\%$ o segundo if se a dif local de amp do pico da

linha e da amostra

\% local estao maiores que o limiar para ser

observado, e ainda para

$\%$ alinha anterior e posterior

if $\max (\mathrm{hh})$ - h_a(a) < limiardB \&\& max(hh_menos) -

$h \_a \_m e n o s(a)<\operatorname{menos} \& \& \quad \max \left(h h \_m a i s\right)$-h_a_mais $(a)<$ mais

\% Diferente do proposto no PDP Normal que trata somente uma linha perfil

$$
\begin{aligned}
& \operatorname{maxim}(b)=h \_a(a) ; \\
& \text { index_max }(b)=a ; \\
& b=b+1 ;
\end{aligned}
$$

else

end

break;

end

end 
Rotina Principal para o Cálculo com a técnica CLEAN

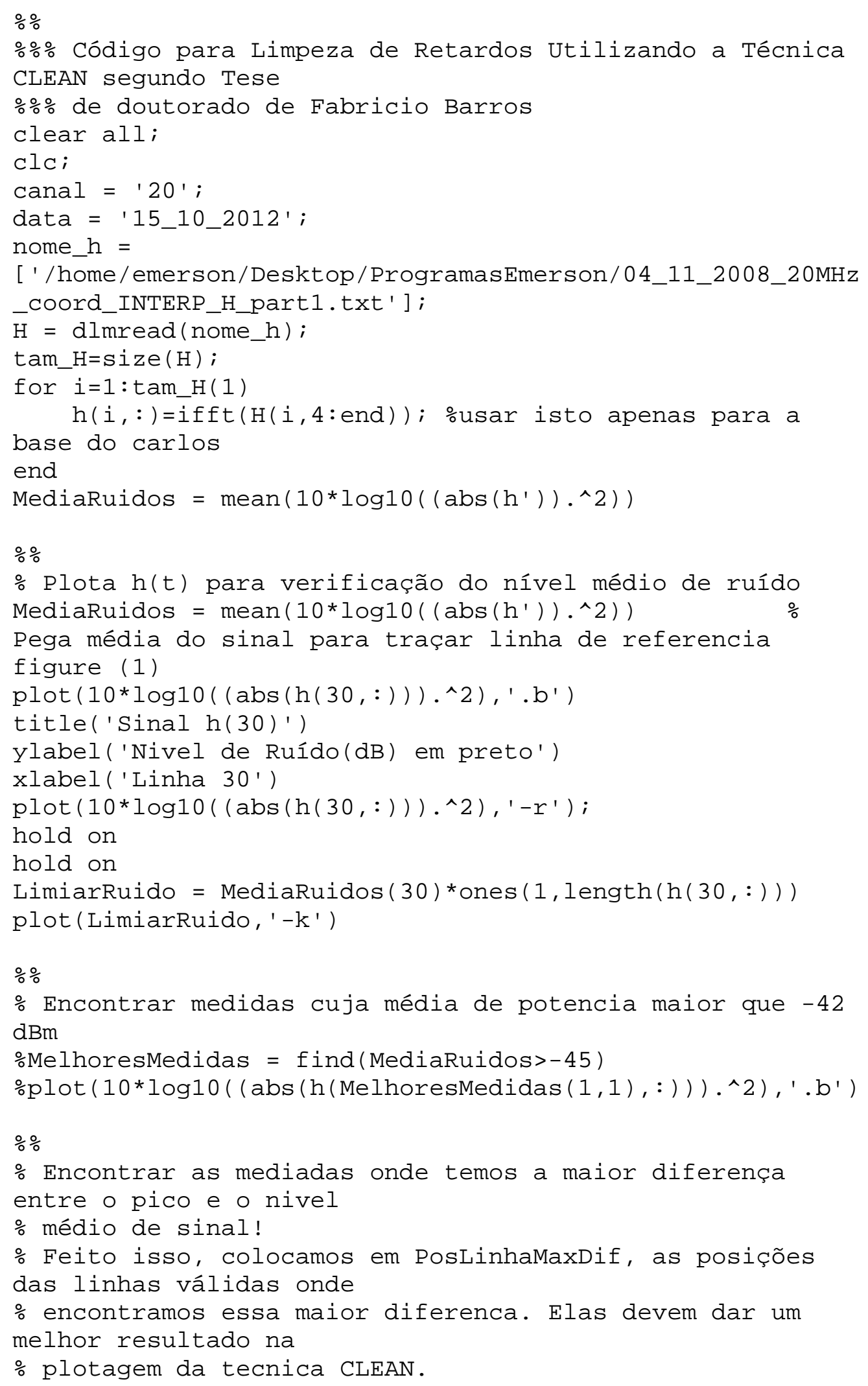




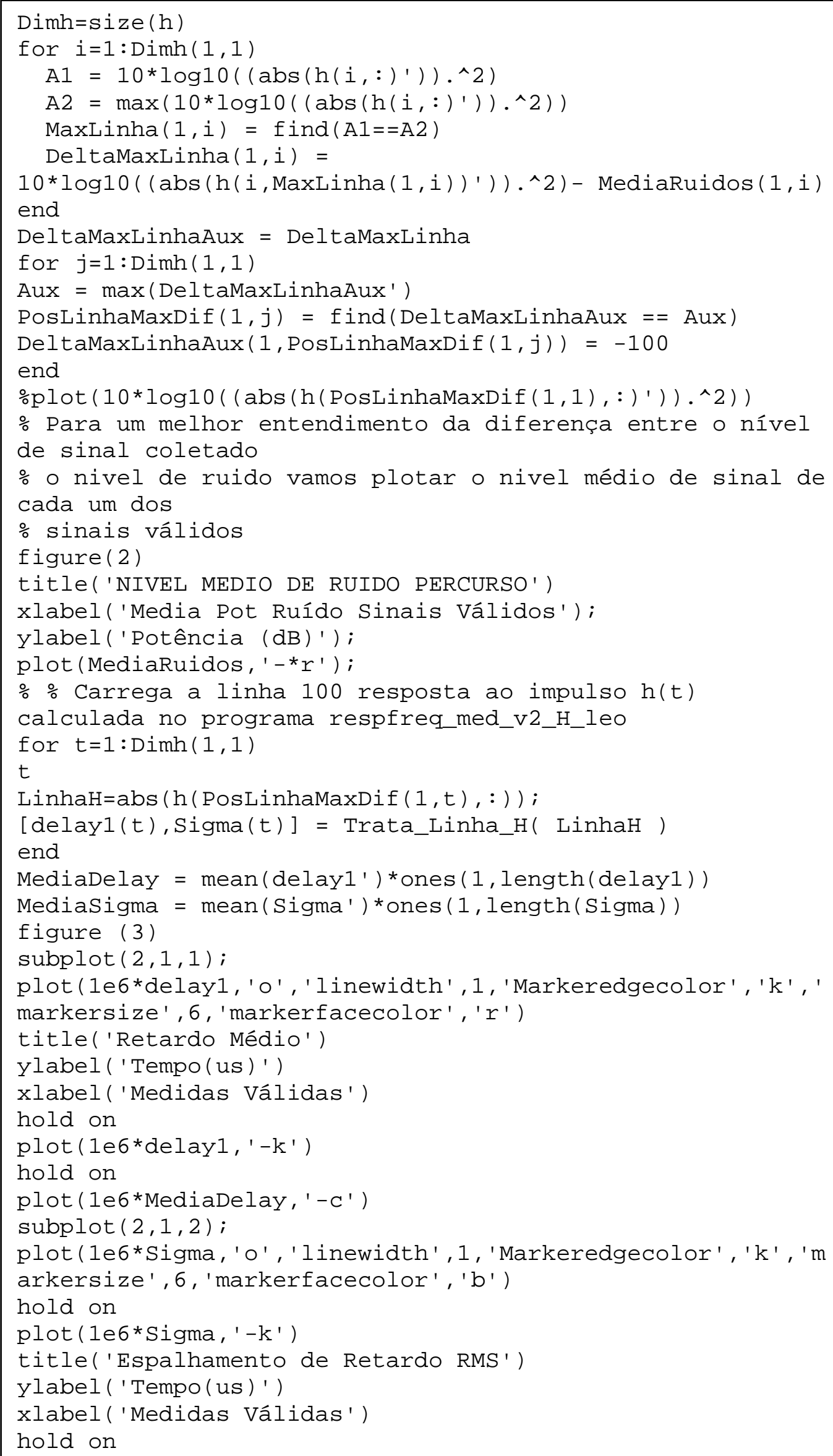




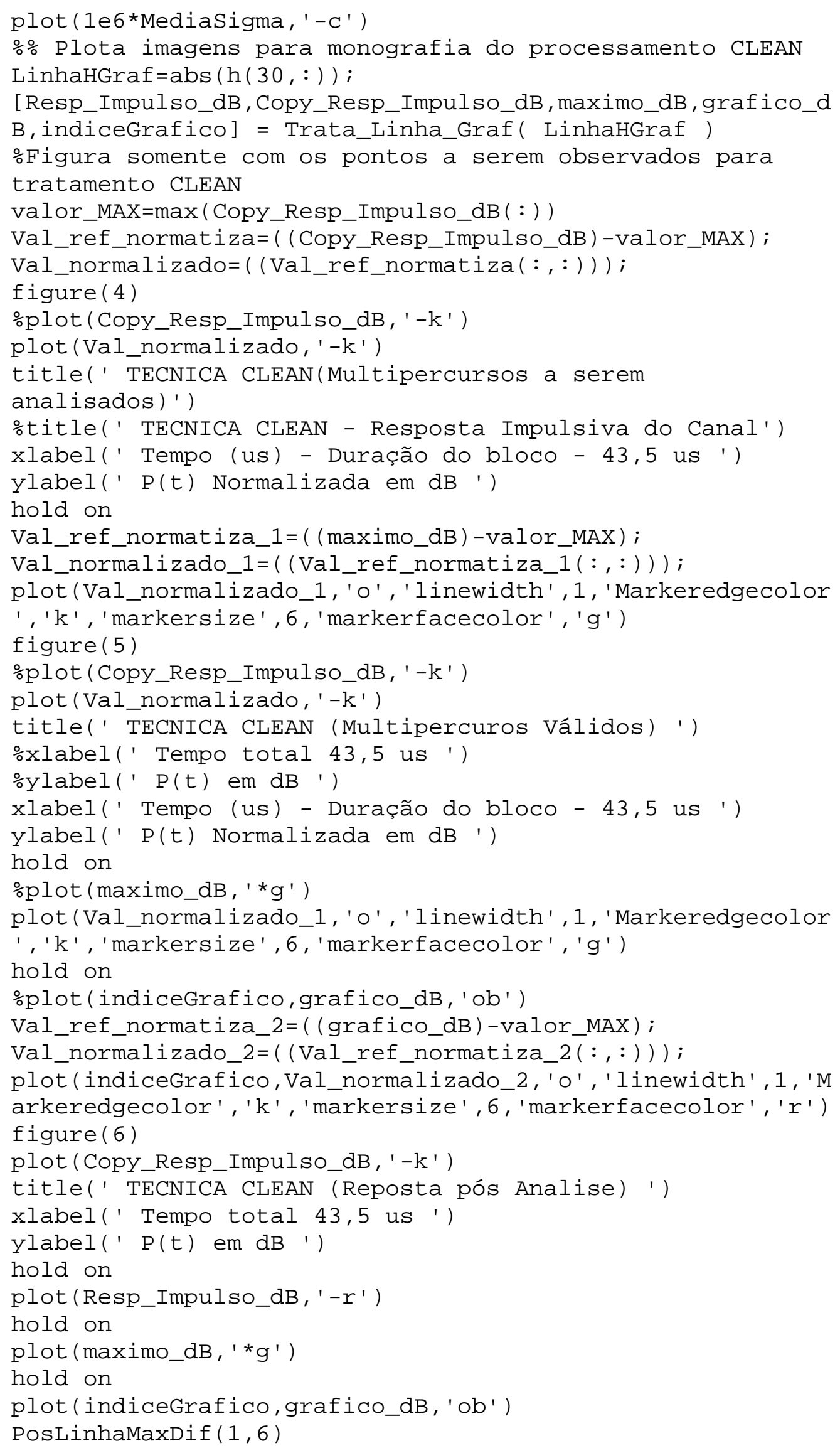


Rotina para a técnica CLEAN

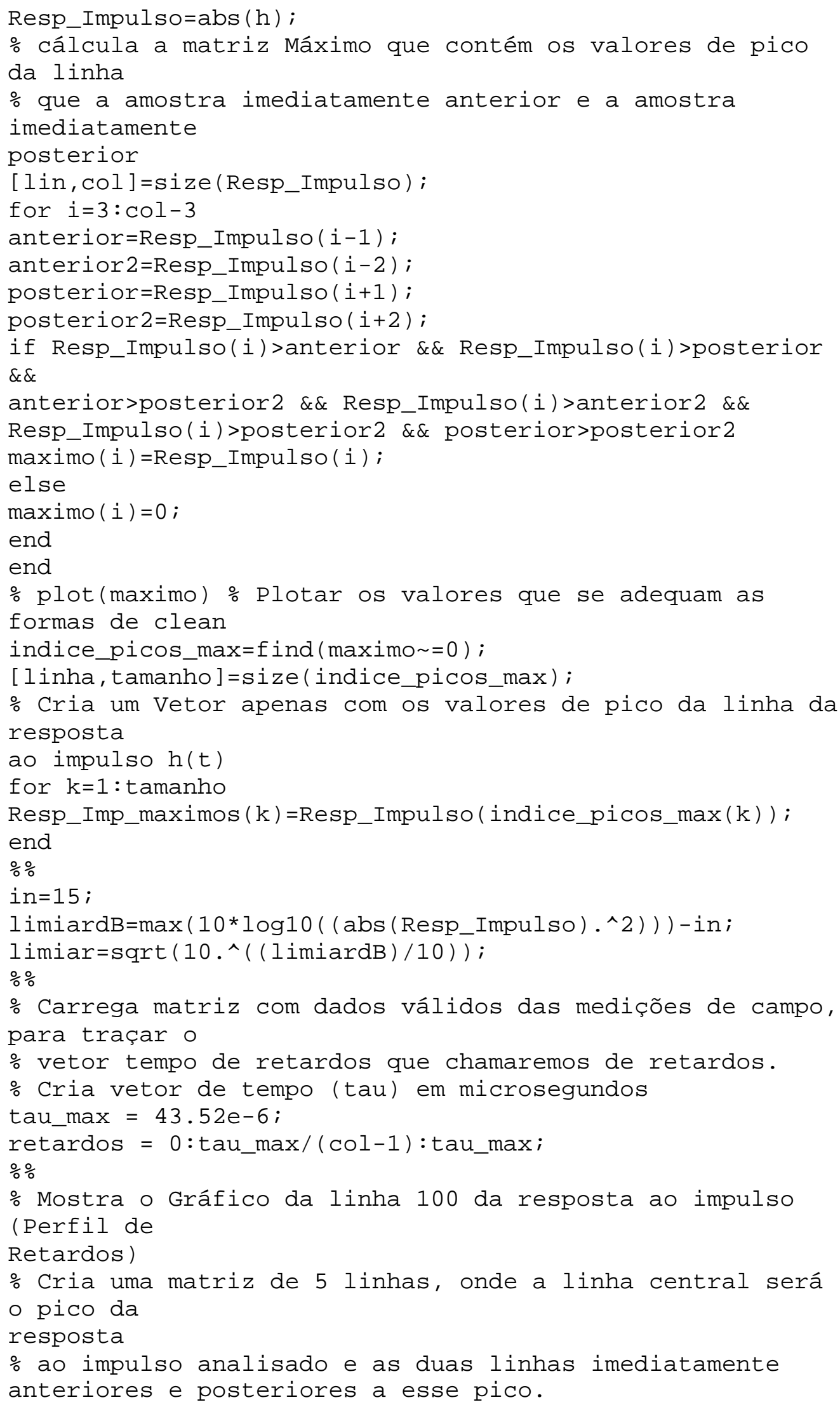




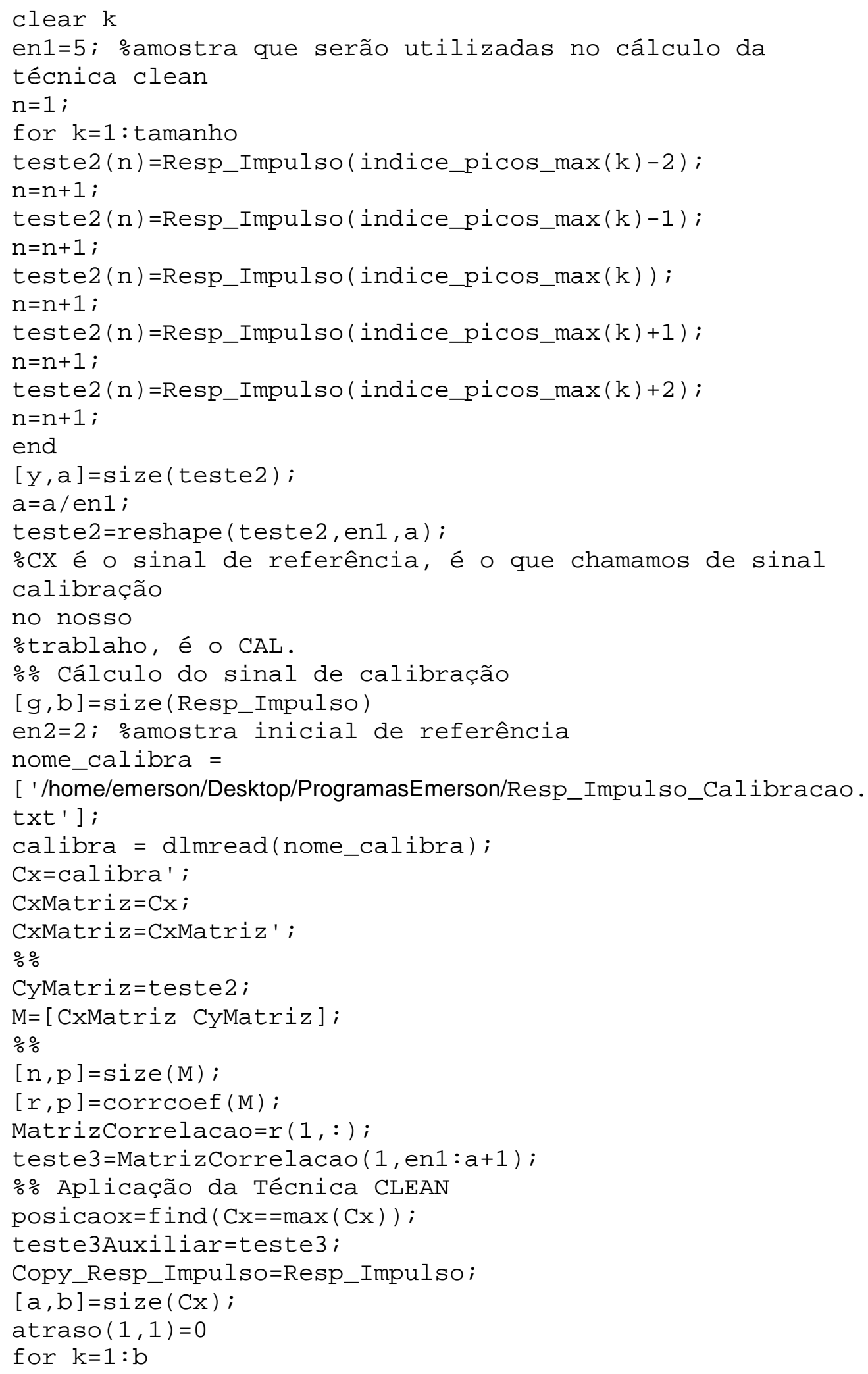




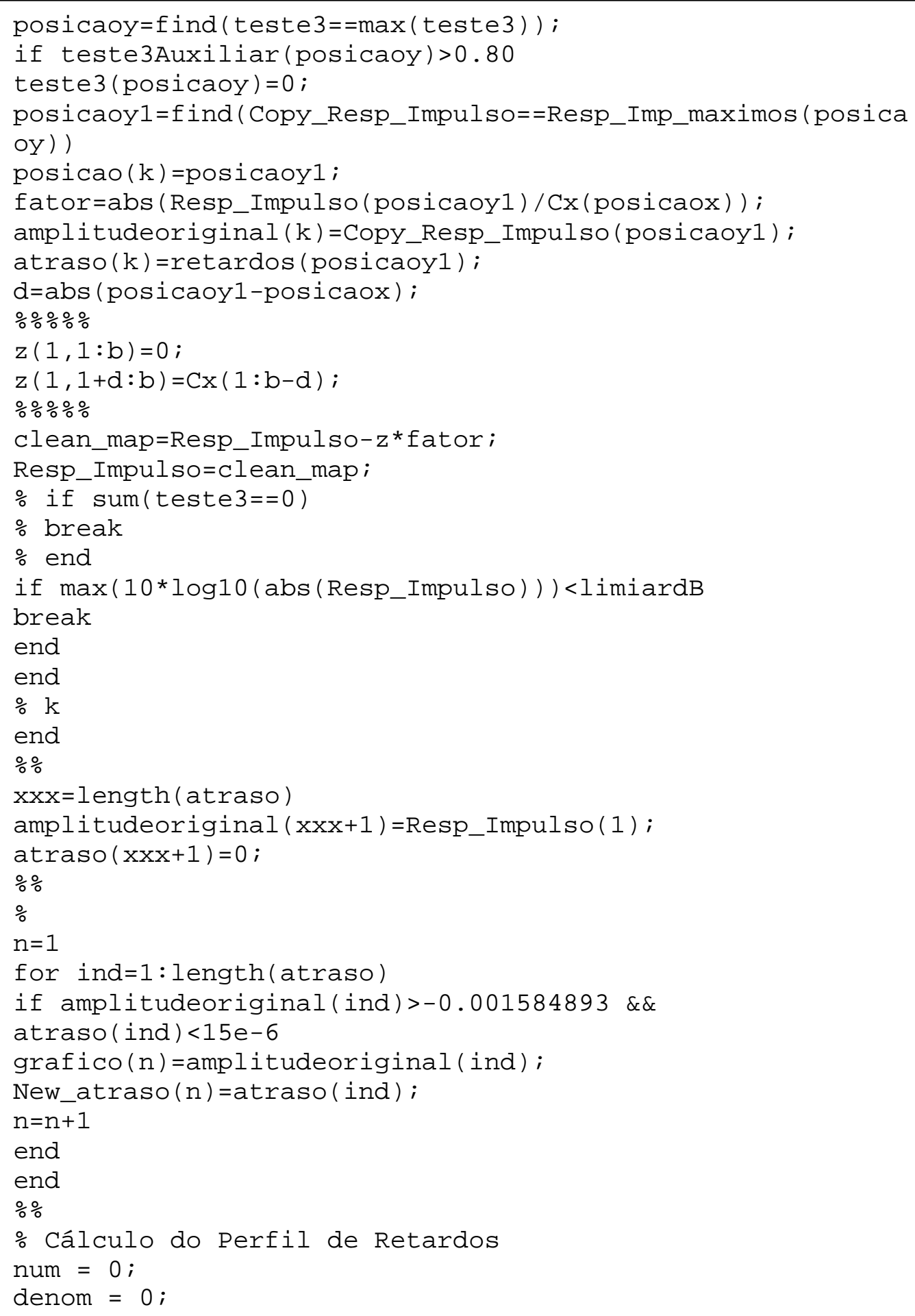


Rotina de cálculo do Retardo Médio e Desvio Padrão

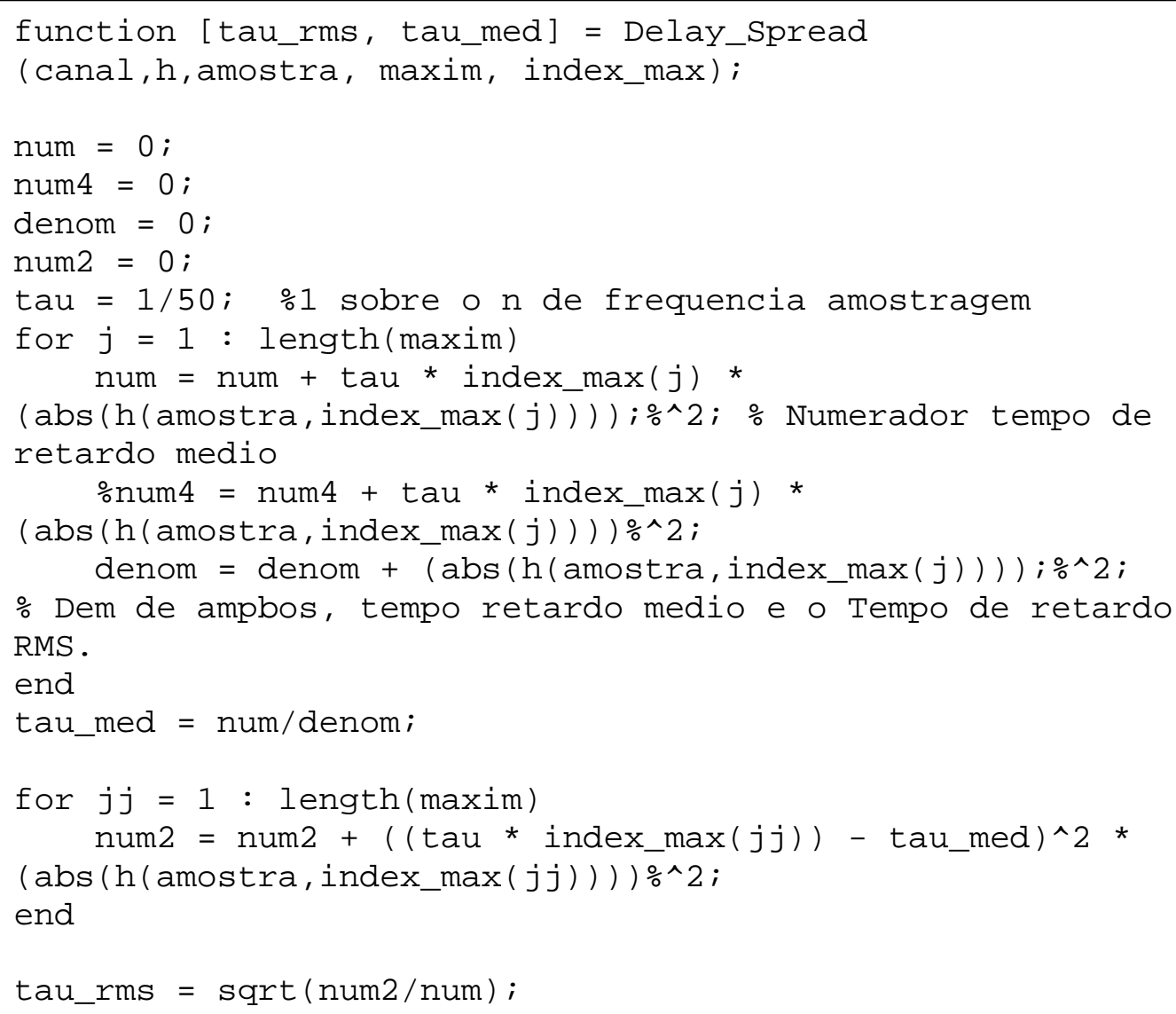


10

Anexo B: Especificação de Equipamentos

DataSheet Antena Receptora para faixa de $2.5 \mathrm{GHz}$

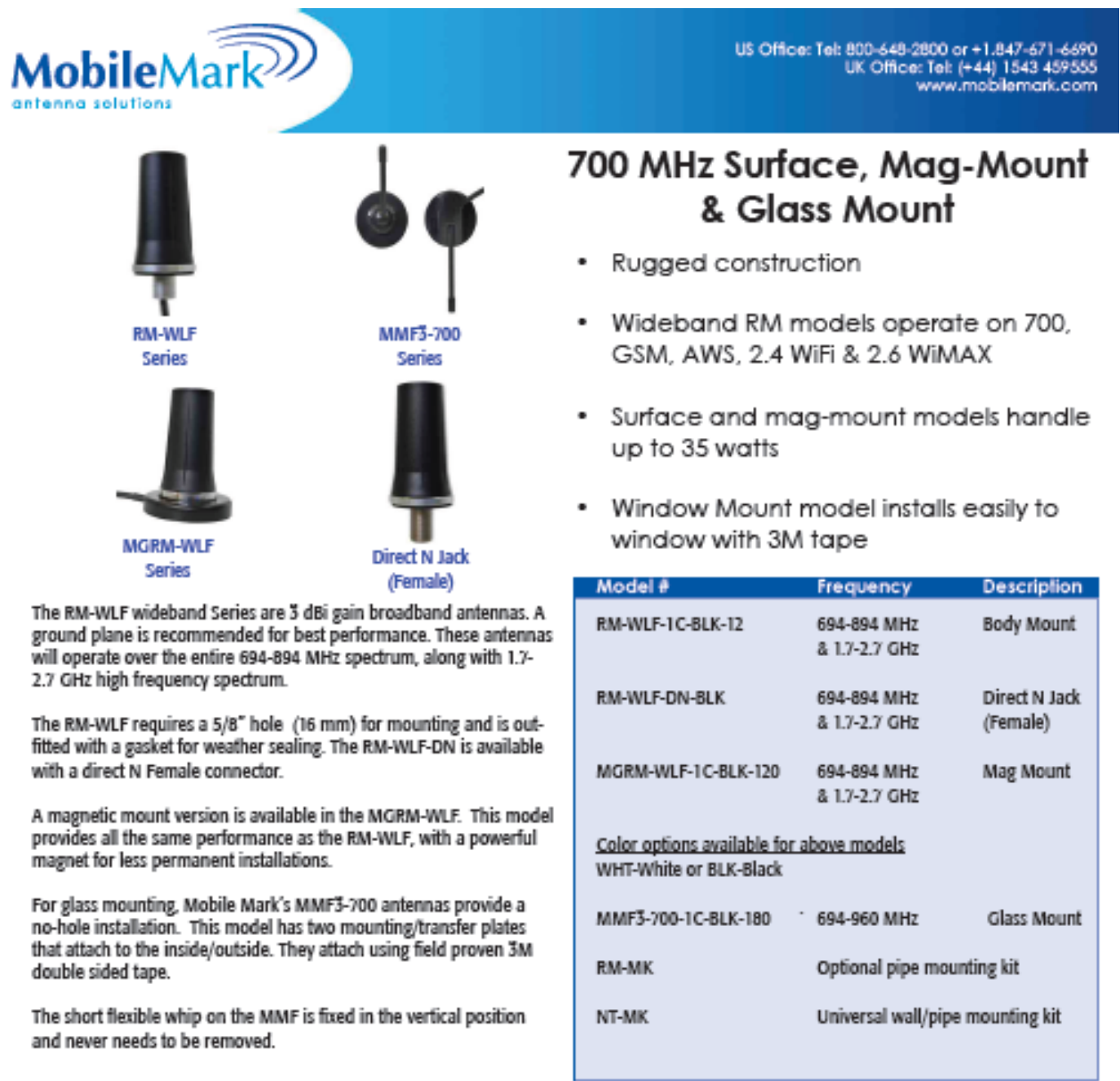

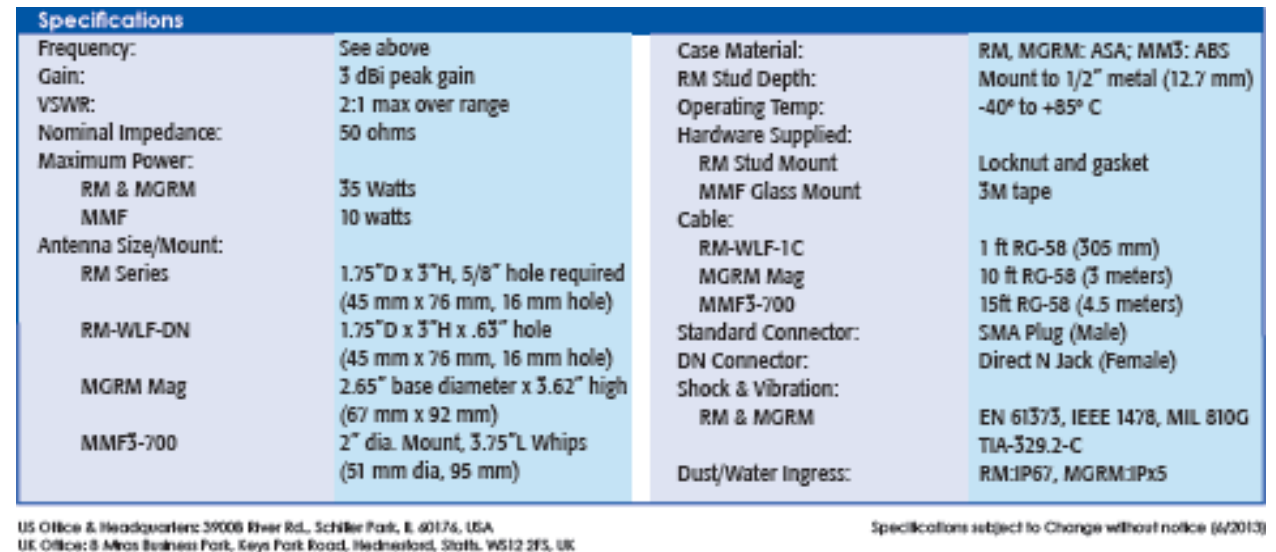




\section{DataSheet LNA de recepção para faixa de $2.5 \mathrm{GHz}$}

Features:

> Broad band, low noise, and high gain

Low VSWR, unconditional stable

- Small size, low cost

> SMA female connector IO

Operating temperature $-40 \sim+75^{\circ} \mathrm{C}$, storage temperature $-45 \sim+125^{\circ} \mathrm{C}$

Electrical Specifications

\begin{tabular}{|c|c|}
\hline Frequency Range & $1.0 \mathrm{GHz}$ to $8.0 \mathrm{MHz}$ \\
\hline Noise Figure & $1.5 \mathrm{~dB}$ typical, 20 Maximum $@ 25^{\circ} \mathrm{C}$ \\
\hline P-ldB Compression Point & $+13 \mathrm{dBm}$ \\
\hline Nominal Gain & $33 \mathrm{~dB} @ 25^{\circ} \mathrm{C}$ \\
\hline Gain flames5 & $+-1.5 \mathrm{~dB}$ Typical \\
\hline Gain Variation & +-1.5 dB Typical \\
\hline Input VSWR. & 2.0:1 typical \\
\hline Output VSWR & 2.0:1 typical \\
\hline Spurious & $-60 \mathrm{dBC} \max$ \\
\hline Operating Temperature & -40 to $+75^{\circ} \mathrm{C}$ \\
\hline Survival Temperature & -45 to $+125^{\circ} \mathrm{C}$ \\
\hline DC Power Sumply & $120 \mathrm{~mA} @+8 \sim 12 \mathrm{~V}$ \\
\hline In/Out comnectors & SMA female \\
\hline Size & $1.5 \mathrm{~s} 0.85^{\prime \prime} \times 0.375^{\prime \prime}$ \\
\hline
\end{tabular}

Mechanical Structure:

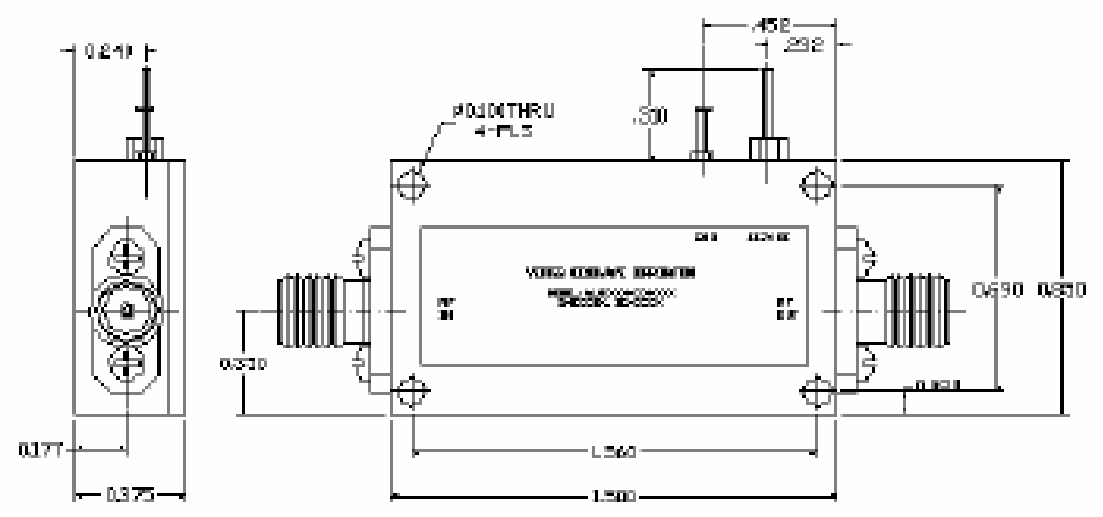

Note: All units in inches.

735 West Duarte Road, Suite 401, Arcadia, CA 91007

Phone: (626) 821-9118, Fax: (626) 602-3101, sales awenteq.com, www.wenteq.com 


\section{Antena de Transmissão para a faixa de $3.5 \mathrm{GHz}$}

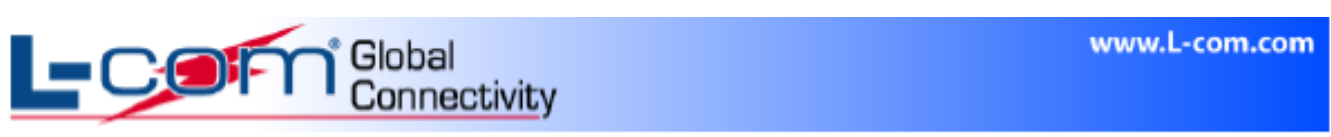

HyperLink Wireless 3.5 GHz $15 \mathrm{dBi} 120$ Degree Vertical Polarized Sector Panel Antenna - Model: HG3515P-120

\section{Applications and Features}
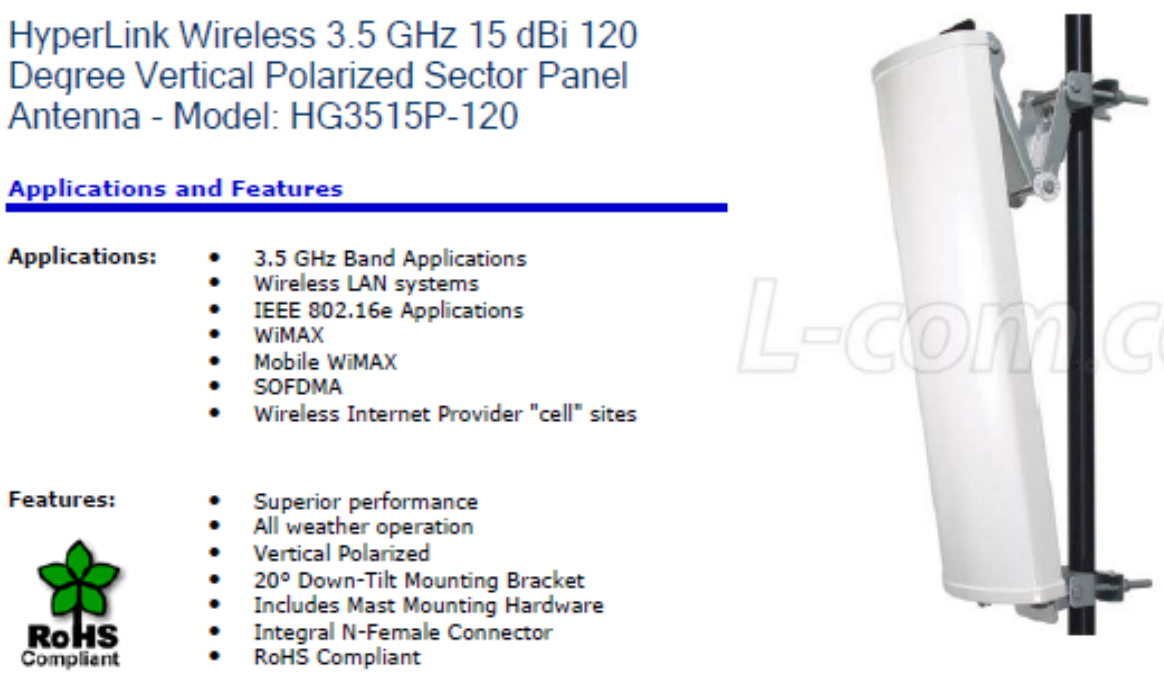

\section{Description}

The HyperGain@ HG3515P-120 Sector Panel Antenna combines high gain with a wide $120^{\circ}$ beam-width. It is a professional quality "cell site" antenna designed primarily for service providers in the $3.5 \mathrm{GHz}$ band. Typical applications include IEEE 802.16e, WiMAX and Mobile WiMAX applications.

This $3.5 \mathrm{GHz}$ sector antenna features a heavy-duty plastic radome for all-weather operation. The heavy-duty mounting system allows installation adjusts from 0 to 20 degrees down tilt.

This is an ideal choice for Wireless Internet Provider "cell" sites since the cell size can be easily determined by adjusting the down-tilt angle. Horizontal coverage is a full 120 degrees.

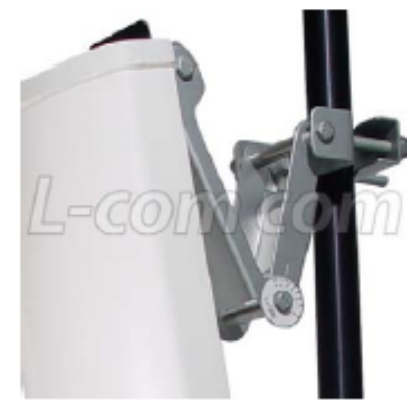




\section{LCO们

Specifications

\begin{tabular}{|l|l|}
\hline Frequency & $3400-3700 \mathrm{MHz}$ \\
\hline Gain & $15 \mathrm{dBi}$ \\
\hline Polarization & Vertical \\
\hline Horizontal Beam Width & $120^{\circ}$ \\
\hline Vertical Beam Width & $8^{\circ}$ \\
\hline Impedance & $50 \mathrm{Ohm}$ \\
\hline VSWR & $\leq 1.5: 1$ avg. \\
\hline Front to Back Ratio & $\leq 21 \mathrm{~dB}$ \\
\hline Max. Input Power & 50 Watts \\
\hline Lightning Protection & DC Ground \\
\hline Connector & Integral N-Female \\
\hline Weight & $5.0 \mathrm{lbs} .(2.3 \mathrm{~kg})$ \\
\hline Dimensions & $24.8 \times 6.3 \times 2.3 \mathrm{in}(630 \times 160 \times 60 \mathrm{~mm})$ \\
\hline Radome Material & UV-inhibited PVC \\
\hline Mounting & $1.5^{\circ}(40 \mathrm{~mm})$ to $2^{\circ}(53 \mathrm{~mm})$ dia. mast max. \\
\hline Operating Temperature & $-40^{\circ} \mathrm{C}$ to $60^{\circ} \mathrm{C}\left(-40^{\circ} \mathrm{F}\right.$ to $\left.140^{\circ} \mathrm{F}\right)$ \\
\hline Rated Wind & $>130 \mathrm{MPH}(210 \mathrm{Km} / \mathrm{h})$ \\
\hline RoHS Compliant & Yes \\
\hline
\end{tabular}

Wind Loading Data

\begin{tabular}{|c|c|}
\hline Wind Speed (MPH) & Loading \\
\hline 100 & $34 \mathrm{lb}$. \\
\hline 125 & $54 \mathrm{lb}$. \\
\hline
\end{tabular}

RF Antenna Gain Patterns
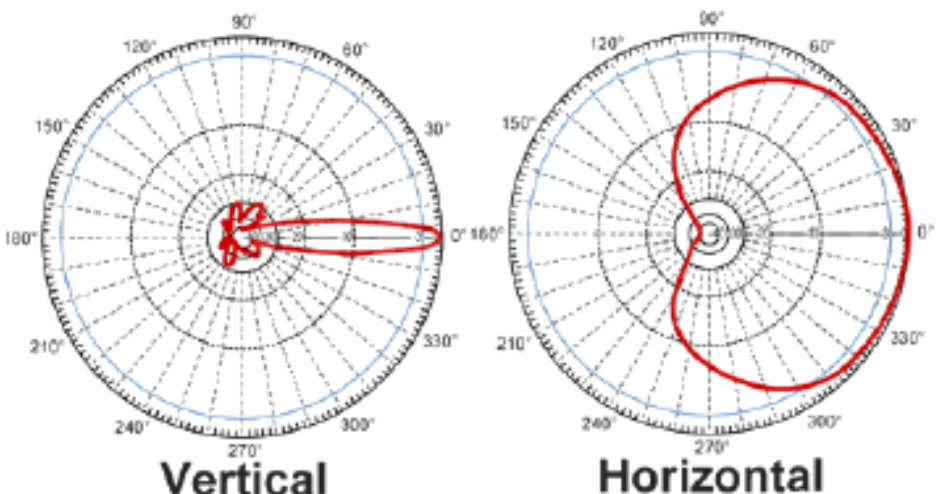

Horizontal

\section{Guaranteed Quality}

This product is backed by L-Com's Limited Warranty. 


\section{DataSheet Antena Receptora para faixa de $3.5 \mathrm{GHz}$}

Con Global Www.L-com.com

HyperLink Wireless 3.5 MHz 5 dBi RP-SMA Plug High Model: HG3505RD-RSP Performance "Rubber Duck" Antenna

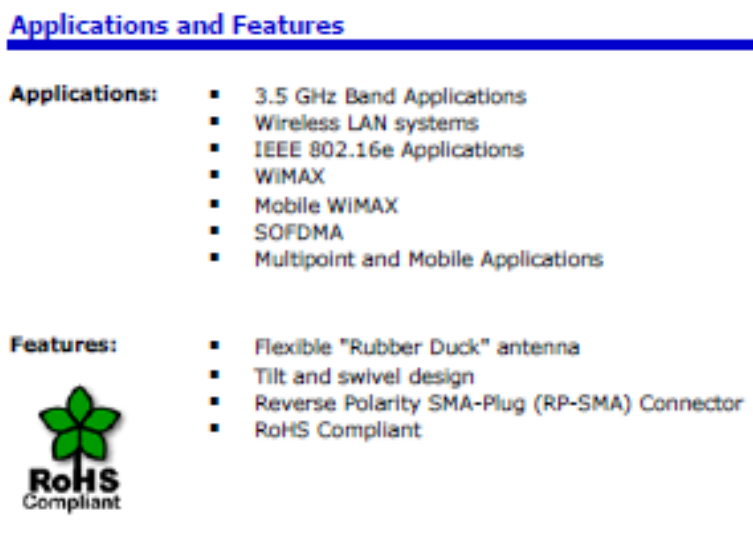

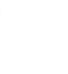




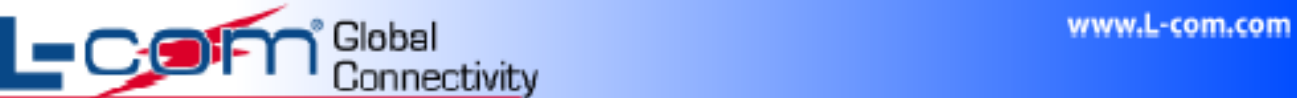

Mechanical Specifications

\begin{tabular}{|l|l|}
\hline Weight & $0.7 \mathrm{az} .(20 \mathrm{~g})$ \\
\hline Length & $8.2 \mathrm{in} .(210 \mathrm{~mm})$ \\
\hline Max. Diameter & $0.52^{\circ}(13 \mathrm{~mm})$ \\
\hline Finish & Matte Black \\
\hline Connector & RP-SMA Plug \\
\hline Operating Temperature & $-30^{\circ} \mathrm{C}$ to $60^{\circ} \mathrm{C}\left(-22^{\circ} \mathrm{F}\right.$ to $\left.140^{\circ} \mathrm{F}\right)$ \\
\hline Polarization & Vertical \\
\hline Flame Rating & UL $94 \mathrm{HB}$ \\
\hline RoHS Compliant & Yes \\
\hline
\end{tabular}

Dimensions

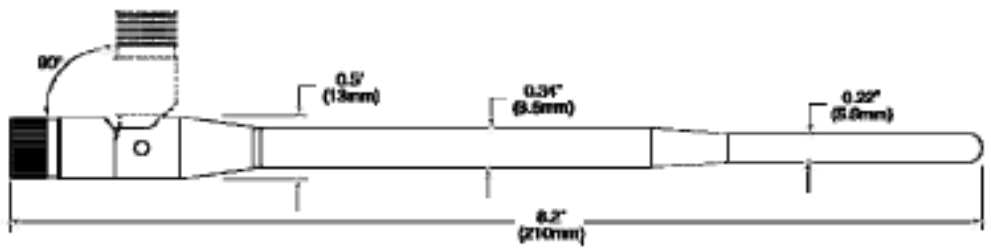

RF Antenna Patterns
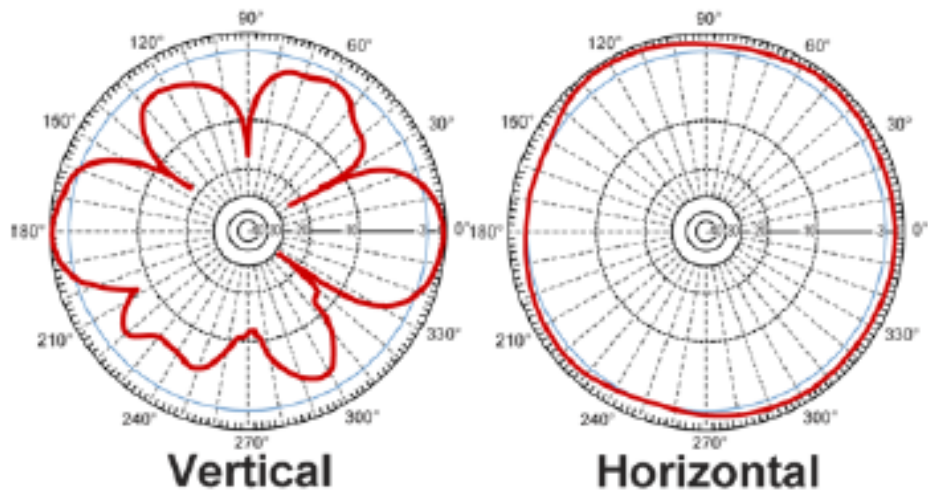

\section{Guaranteed Quality}

This product is backed by L-Com's Limited Warranty

Optional Magnetic Mount

\begin{tabular}{|c|l|l|}
\hline 10 & HMA6 & $\begin{array}{l}\text { Reverse-Polarity SMA-Jack (RP-SMA lack) magnetic mount with } 5 \mathrm{ft} \text {. high performance low-loss } \\
100 \text { series cable terminated with a Reverse-Polarity SMA Plug (RP-SMA Plug) or Reverse-Polarity } \\
\text { TNC Plug (RP-TNC Plug) connector. Custom connectors and cable lengths also avallable. }\end{array}$ \\
\hline
\end{tabular}

LCOM, INC. 45 EEECHNOCO DRIVE NORTH ANDOVER, MA 01845

WWWL-COM COM E-MAN-SALESGL-COM COM PHONE: 1-800-343-1455 FAX: 1-979-689-9484 o L-com, InC. Al Righta Resenved. L-com Global Comectivty and the L-com logo are regletered marka. 